The

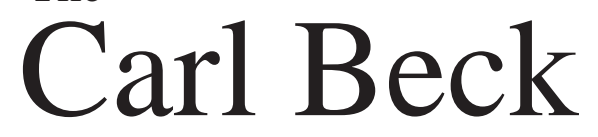

Papers

in Russian \&

East European Studies

Number 1804

John Löwenhardt and Stephen White

\title{
The Russian Regions: A Bibliography
}

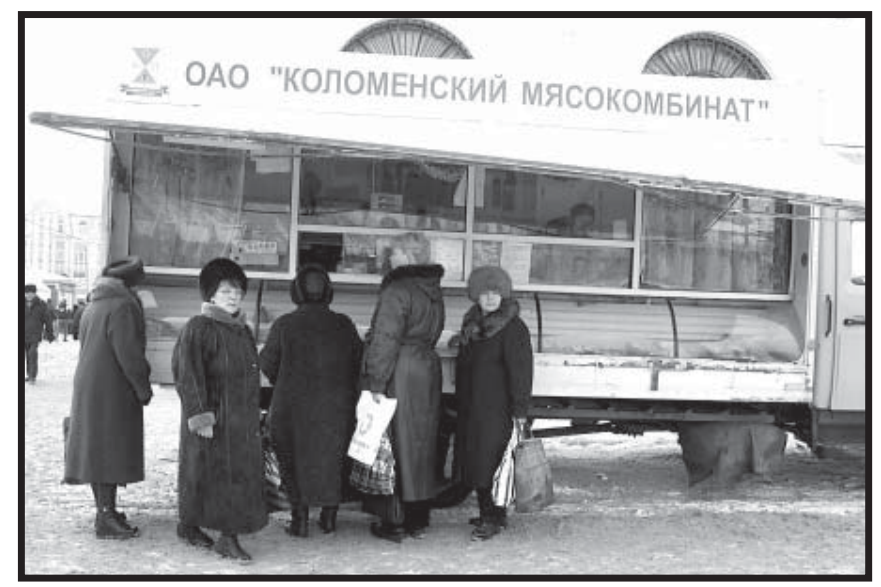

Kolomensky Myasokombinat 
The

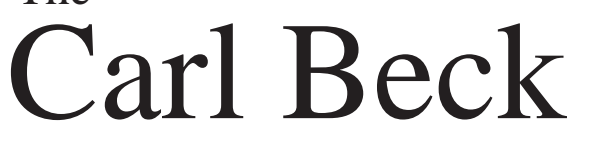

Papers

in Russian \&

East European Studies

Number 1804

John Löwenhardt and Stephen White

\section{The Russian Regions: A Bibliography}


John Löwenhardt has worked at the Universities of Amsterdam and Leiden in the Netherlands, and was then the first Alexander Nove Professor at the University of Glasgow and the Director of its Centre for Russian and East European Studies. His recent publications include Stuck in the Middle: The Shared Neighbourhood of the EU and Russia, 2000-2005 (The Hague: Clingendael, 2005).

Stephen White is Professor of International Politics and a Senior Associate Member of the School of Slavonic and East European Studies at the University of Glasgow, in Scotland. His recent publications include Putin's Russia and the Enlarged Europe (with Roy Allison and Margot Light, Blackwell, 2006), and Politics in Europe (with others, CQ Press, 2007).

No. 1804, February 2007

(c) 2007 by The Center for Russian and East European Studies, a program of the University Center for International Studies, University of Pittsburgh

ISSN 0889-275X

The Carl Beck Papers

Editors: William Chase, Bob Donnorummo, Ronald H. Linden

Managing Editor: Eileen O’Malley

Editorial Assistant: Vera Dorosh

Photograph from cover taken by John Löwenhardt.

Submissions to The Carl Beck Papers are welcome. Manuscripts must be in English, double-spaced throughout, and between 40 and 90 pages in length. Acceptance is based on anonymous review. Mail submissions to: Editor, The Carl Beck Papers, Center for Russian and East European Studies, 4400 Posvar Hall, University of Pittsburgh, Pittsburgh, PA 15260. 
Not long ago scholars had little access to information about the Russian regions. In Soviet times, a handful of studies had dealt with regional and local government within the Soviet state, but the lack of accessibility of the oblasti, kraia, and avtonomnye respubliki made the empirical base for such studies rather flimsy. Local newspapers, as former Sovietologists remember well, could not be exported, and a trip to Saratov or Vladivostok to interview the party bosses on the details of decision-making in the provincial party bureau was not likely to yield dividends. Our view of politics and society in the USSR, as a result, was pretty much limited to what went on within the "Garden Ring" of Moscow. Up to the end of Soviet rule, Merle Fainsod's seminal study of provincial life in the 1930s, based on the Smolensk Party Archives captured by German troops in 1941, stood more or less alone. ${ }^{1}$

By the early 1990s, it had become clear to many that Russia's regions and republics were going to play an important role in the country's future. By that time, several scholars had already penetrated deep into the Russian countryside and were observing, gathering, and interviewing. The first general study of the politics of the regions appeared in 1994, just after the new constitution had been adopted (Friedgut and Hahn, cited below). An impressive number of studies - both comparative between regions and case studies of individual regions - has since appeared in print, and quite a number of single author, book length studies. Another new and potentially more important development has been that our colleagues in Russia are now able to produce excellent work on center-periphery relations in their own country, and in many cases on the politics of their own region.

As a result, we now have a much better picture of the diversity of regimes and economies in the Russian regions than ever before, and the moment seems appropriate for a first select bibliography. Considering that the authors of the works cited in this bibliography are dealing with a topic that has witnessed rapid political, social, and economic change over the past fifteen years or so, we believe the bibliography to be a testimony to the exemplary way in which the field of Russian studies has adapted to the demise of the Soviet Union. We also believe that the period with which we deal-from 1990 up to 2005, in a few cases 2006 - is likely, in retrospect, to have a certain unity and to mark a certain stage in the development of the Russian federal state. At the outset, the USSR was in rapid decline and the republics and regions were being urged (in Boris Yeltsin's celebrated phrase) to "seize as much sovereignty as they could swallow." By the end, President Vladimir Putin was reasserting central authority, regional governors were no longer to be directly elected but nominated by the president himself, and the first steps had been taken toward the consolidation of the eighty-nine republics and regions into a much smaller number (the first merger, 
between Perm' oblast and the Komi-Permiak autonomous district, came into effect in December 2005).

This bibliography, while not inclusive, seeks to include a very high proportion of the published scholarship on the Russian regions that appeared in English, French, German, and Russian during these momentous years. We have concentrated on items that are likely to have lasting scholarly value and have omitted most journalistic commentaries; even so, it is a lengthy list. For the convenience of users we have divided it into the following sections:

(1) General, page 4;

(2) Federalism and Center-Periphery Relations, page 8;

(3) Legal Aspects, page 15;

(4) Regimes and Elites, page 16;

(5) Parties, Politicians, and Elections, page 21;

(6) Economic and Social Aspects, page 25;

(7) Individual Regions, ordered by individual "subjects of the federation" and in some cases by larger geographical areas, 32;

(8) Periodicals, 93;

(9) Reference, 93; and

(10) Internet sites, page 95.

In addition, we have added a brief annotation when in our judgement this would be helpful to readers, particularly when the contents of a volume are not readily apparent from its title. We hope that the result will be a useful guide to the state of play in Russian regionovedenie as it enters a new stage of its development.

We wish to thank those who have helped us prepare this bibliography by providing advice or sharing titles: Valentin Bazhanov in Ul'ianovsk; Michael Bradshaw in Leicester; Rene Does in Amsterdam; Tania Konn-Roberts of Glasgow University Library; Neil Melvin in Leeds; Valentin Mikhailov in Moscow; John Slocum in Chicago; Dmitry Gorenburg in Washington DC; Vladimir Gel'man in St Petersburg; and two anonymous reviewers. We owe much also to the excellent bibliographical resources of the State Historical Library in Moscow, and to the assistance, in Glasgow, of Julia Korosteleva.

${ }^{1}$ Although some valiant attempts were made, including Philip Stewart's Political Power in the Soviet Union: A Study of Decision-Making in Stalingrad (Indianapolis \& New York: BobbsMerrill, 1968), Jerry Hough's The Soviet Prefects: The Local Party Organs in Industrial decision-Making (Cambridge MA: Harvard University Press, 1969), and Ronald J. Hill's Soviet Political Elites: The Case of Tiraspol (London: Martin Robertson, 1977), while work on local government had been carried out by Michael Frolic, William Taubman and Theodore Friedgut. 


\section{Journal Abbreviations}

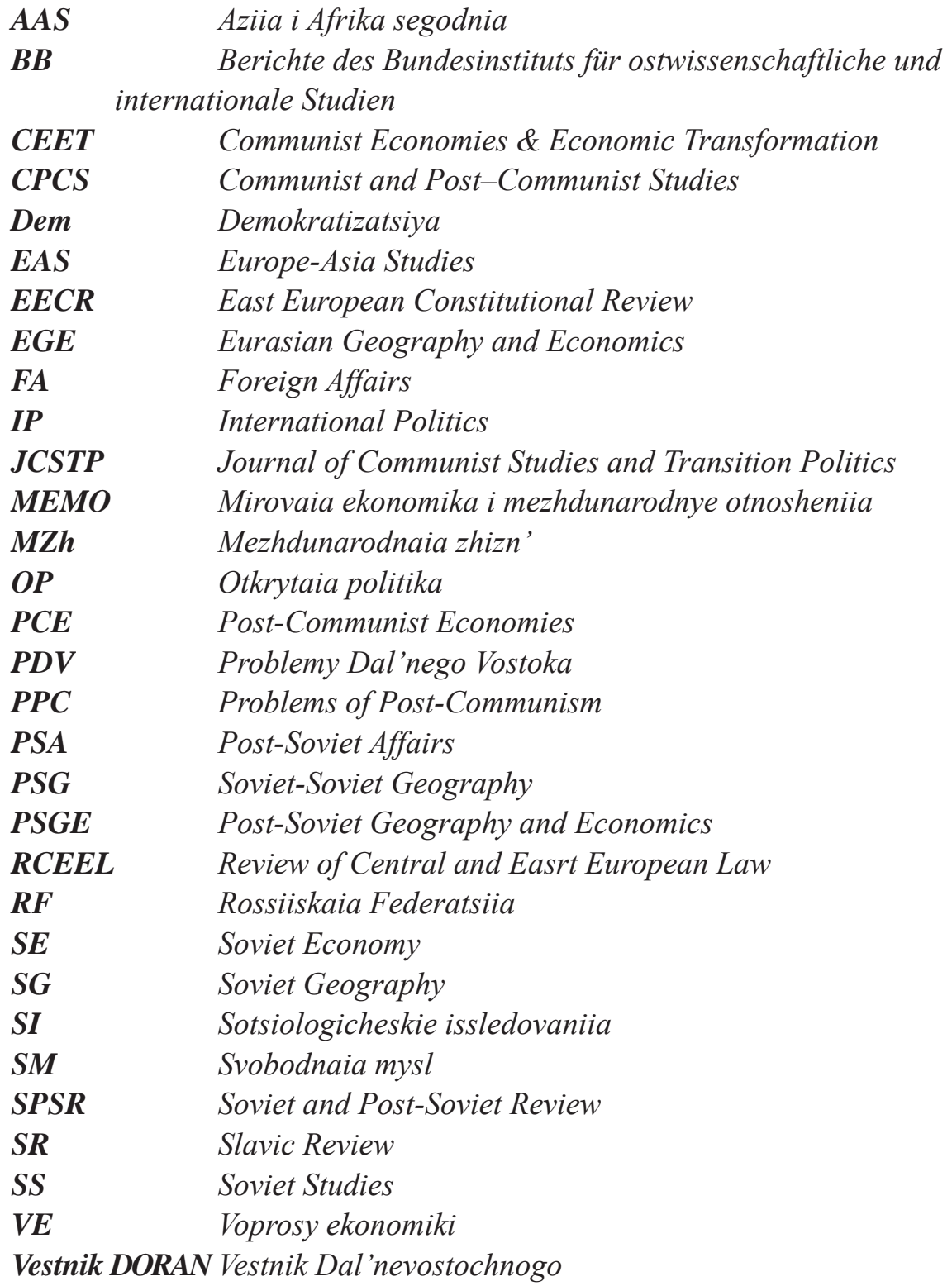




\section{General}

Ahlberg, Rurik. "Economic Development, Civil Society and Democratic Orientation: A Study of Russia's Regions.” JCSTP 16, no. 3 (September 2000): 21-38.

Andrews, Josephine, and Kathryn Stoner-Weiss. "Regionalism and Reform: Evidence from the Russian Provinces." PSA Vol. 11, no. 4 (October-December 1995): 384-406.

Bassin, M., and K. E. Aksenov, eds. Identichnost' $i$ geografiia v postsovetskoi Rossii. St. Petersburg: Helicon Plus, 2003.

Bordeaux, Michael. "Religion Revives in All Its Variety: Russia’s Regions Today." Religion, State \& Society 28, no. 1 (March 2000): 9-22.

Büscher, Klemens. "Regionalismus und Nationalismus in der Rußländischen Föderation: Ein Tagungsbericht." Osteuropa 45, no. 12 (December 1995): 1161-63.

Busygina, Irina M. "Die Regionen Rußlands in den internationalen und außenwirtschaftlichen Beziehungen," Osteuropa 48, no. 11-12 (NovemberDecember 1998): 1101-09.

—. "Russia's Regions in Search of Identity." Acta Slavonica Iaponica 19 (2002): 296-312.

Chernyshov, A. G. “Tsentr-provintsiia v regional'nom samosoznanii." Polis no. 3, 1999, 100-04.

Chugrov, S. "O regional'noi fragmentatsii rossiiskogo politicheskogo soznaniia." $M E M O$, no. 1, 1998, 29-41.

Dakhin, A. V. and N. P. Raspopov. "Problema regional'noi stratifikatsii v sovremennoi Rossii." Polis no. 4, 1998, 132-44.

Drobizheva, L. M., A. R. Aklaev, V. V. Koroteeva, and G. U. Soldatova. Demokratizatsiia i obrazy natsionalizma v Rossiiskoi Federatsii 90-kh godov. Moscow: Mysl', 1996.

Friedgut, Theodore H., and Jeffrey W. Hahn, eds. Local Power and Post-Soviet Politics. Armonk, N.Y.: M. E. Sharpe, 1994.

Gel'man, Vladimir, and Olga Senatova. "Sub-National Politics in Russia in the

Post- Communist Transition Period: A View from Moscow." Regional and Federal Studies 5, no. 2 (Summer 1995): 211-33.

Gel'man, Vladimir, Sergei Ryzhenkov, and Michael Brie. Making and Breaking Democratic Transitions: The Comparative Politics of Russia's Regions.

Lanham, Md.: Rowman \& Littlefield, 2003.

Gel'man, Vladimir, and Ted Khopf, eds. Tsentr i regional'nye identichnosti v Rossii. 
St. Petersburg: Izdatel'stvo Evropeiskogo universiteta v Sankt-Peterburge, 2003.

Glezer, O., and P. Polyan, eds., Rossii $i$ ee regiony $v$ XX veke: territoriiarasselenie-migratsiia. Moscow: OGI, 2005.

Covers territory, population, and migration and includes a detailed account of the 2002 census.

Glinskaia, E. B., and S. N. Smirnov, eds. Territorial'nye problemy sotsial'noi politiki. Moscow: State University Higher School of Economics, 2000.

Granberg, A. G., ed. Strategiia makroregionov Rossii: metodologicheskie podkhody, prioritety i puti realizatsii. Moscow: Nauka, 2004.

Gorenburg, Dmitry. "Nationalism for the Masses: Popular Support for Nationalism in Russia's Ethnic Republics." EAS 53, no. 1 (January 2001): 73-104.

. Minority Ethnic Mobilization in the Russian Federation. Cambridge: Cambridge University Press, 2003.

Götz, Roland, and Uwe Halbach. Politisches Lexikon Rußland: Die nationalen Republiken und Gebietseinheiten der Rußländischen Föderation. Munich: Beck, 1994.

Guboglo, E. M., ed. V labirintakh samoopredeleniia $i$ samoutverzhdeniia: etnicheskaia mobilizatsiia natsional'nykh men'shinstv. Vol. 1. Moscow: TsIMO, 2003.

Harris, James R. The Great Urals: Regionalism and the Evolution of the Soviet System. Ithaca, N.Y.: Cornell University Press, 1999.

Herd, Graeme P., and Anne Aldis, eds. Russian Regions and Regionalism. London: RoutledgeCurzon, 2003.

Particular attention is devoted to Nizhnii Novgorod, Sakha, St Petersburg, Kaliningrad, Moscow, and Primorskii krai.

Hough, Jerry F. "The Political Geography of European Russia: Republics and Oblasts." PSGE 39, no. 2 (February 1998): 63-95.

Jarygina, T., and G. Martschenko. "Regionale Prozesse in der ehemaligen UdSSR und im neuen Rußland." Osteuropa 43, no. 3 (March 1993): 211-28.

Kirkow, Peter. "Local Self-government in Russia: Awakening from Slumber?" EAS 49, no. 1 (January 1997): 43-58.

_. Russia's Provinces: Authoritarian Transformation versus Local Autonomy? New York: St. Martin's, 1997.

The primary emphasis is upon Altaiskii and Primorskii kraia.

Kivenen, Markku, and Katri Pynnöiemi, eds. Beyond the Garden Ring: Dimensions of Russian Regionalism. Helsinki: Kikimora Publications, 2002. 
A varied collection with contributions from American, British, and Scandinavian as well as Russian authors, with some emphasis on the northwestern regions.

Kolstø, Pål, and Helge Blakkisrud, eds. Nation-Building and Common Values in Russia. Lanham, Md.: Rowman \& Littlefield, 2004.

As well as general chapters, particular attention is devoted to Komi, Bashkortostan, Dagestan, Novosibirsk region, St Petersburg, and Moscow.

Komarov, I. K., and E. N. Eremenko, eds. Srednerusskii region: problemy $i$ perspektivy. Moscow: RAU Universitet, 1995.

A special issue of the journal Obozrevatel'; the focus is upon the Kostroma, Moscow, Novgorod, Pskov, Riazan', Tver', and Iaroslavl' regions.

Krindatsch, Aleksej D., and Rostislaw F. Turowskij. "Die wiederspenstigen Regionen: Besteht in Rußland die Möglichkeit einer kommunistischen 'Restauration' oder einer regionalen 'Reconquista'?' Osteuropa 43, no. 12 (December 1993): 1124-46.

Krylov, M. P. 'Regional'naia identichnost' $v$ istoricheskom iadre evropeiskoi Rossii." SI, no. 3, 2005, 13-23.

Lapina, N. Iu., ed. Regional'nye protsessy v sovremennoi Rossii: ekonomika, politika, vlast’. Sbornik statei. Moscow: INION, 2003.

Leksin, V. N., and A. N. Shvetsov. Gosudarstvo i regiony: teoriia i praktika gosudarstvennogo regulirovaniia territorial'nogo razvitiia. 3d ed. Moscow: Editorial URSS, 2000.

A first edition appeared in 1997 and a second in 1999.

Makarychev, A. S., ed. Sravnitel'nyi regionalizm: Rossiia, SNG, Zapad. Materialy mezhdunarodnogo issledovatel skogo proekta. Nizhnii Novgorod: Nizhnegorodskii gosudarstvennyi universitet, 1997.

. Region v sostave federatsii: politika, ekonomika, pravo. Nizhnii Novgorod: Nizhegorodskii gosudarstvennyi universitet, 1999.

Marsh, Christopher, and Paul Froese. "The State of Freedom in Russia: A Regional Analysis of Freedom of Religion, Media, and Markets." Religion, State \& Society 32, no. 2 (June 2004): 137-50.

Matsuzato, Kimitaka, ed. Regions: A Prism to View the Slavic-Eurasian World: Towards a Discipline of "Regionology.” Sapporo: Slavic Research Center, Hokkaido University, 2000.

Individual chapters deal with Sakha and the regional elite as well as with other regional issues in Russia and the former Soviet republics.

. Fenomen Vladimira Putina i rossiiskie regiony: pobeda neozhidannaia ili zakonomernaia? Sbornik statei. (Slaviano-evraziiskie issledovaniia, vyp. 1.) 
Moscow: Materik, 2004.

Individual chapters are cited by the appropriate region below.

McAuley, Mary. Russia 's Politics of Uncertainty. Cambridge: Cambridge University Press, 1997.

Particular attention is given to Krasnodar krai, Perm' and Tomsk oblasti, the republics of Sakha and Tatarstan, and St. Petersburg.

Nicholson, Martin. Towards a Russia of the Regions. Oxford: Oxford University Press, 1999.

Pain, Emil. "'Back to the USSR?' New Trends in Russian Regional Policy.” Dem 9, no. 2 (Spring 2001): 182-92.

Prava cheloveka v regionakh Rossiiskoi Federatsii: sbornik dokladov o sobytiiakh

2001 goda. Moscow: Moskovskaia Khel'sinskaia gruppa, 2002.

A serial publication; the volume for 1999 was published in 2000; the volume for 2003, edited by S. Lukashevskii, was published in 2004.

Prokozhev, A. A., and I. A. Karmanova. Regiony Rossii: sotsial'noe razvitie $i$ bezopasnost'. Moscow: Novosti, 2004.

Raleigh, Donald J., ed. Provincial Landscapes: Local Dimensions of Soviet Power, 1917-1953. Pittsburgh, Pa.: University of Pittsburgh Press, 2001.

Ruble, Blair A., Jodi Koehn, and Nancy E. Popson, eds. Fragmented Space in the Russian Federation. Baltimore, Md.: Johns Hopkins University Press, 2001.

Sergunin, Alexander A. "Regionalizatsiia Rossii: rol' mezhdunarodnykh faktorov."

Polis no. 3, 1999, 76-88.

Shlapentokh, Vladimir, Roman Levita, and Mikhail Loiberg. From Submission

to Rebellion: The Provinces versus the Center in Russia. Boulder, Colo.: Westview Press, 1997.

Shtul'berg, B. M., and V. G. Vvedenskii. Regional'naia politika Rossii: teoreticheskie osnovy, zadachi i metody realizatsii. Moscow: Gelius, 2000.

Stavrakis, Peter J., Joan DeBardeleben, and Larry Black, eds. Beyond the Monolith:

The Emergence of Regionalism in Post-Soviet Russia. Washington, D.C.: Woodrow Wilson Center Press, 1997.

Stoner-Weiss, Kathryn. "Regionalism and Reform in Provincial Russia." PSA 11, no. 4 (October-December 1995): 384-406.

- Local Heroes: The Political Economy of Russian Regional Governance. Princeton, N.J.: Princeton University Press, 1997.

Particular emphasis is given to Nizhnii Novgorod, Tiumen', Iaroslavl', and Saratov oblasti.

Taagepera, Rein. The Finno-Ugric Republics and the Russian State. London: Hurst, 
1999.

Ethnographic in orientation; particular emphasis is placed upon the threat represented by the deterioration of the natural environment.

Titkov, A. S. "Obrazy regionov v rossiiskom massovom soznanii." Polis no. 3, 1999, 61-75.

Treisman, Daniel S. After the Deluge: Regional Crises and Political Consolidation in Russia. Ann Arbor: University of Michigan Press, 1999.

Deals with fiscal transfers and "fiscal appeasement" across regions, with regional voting and with the political strategies of regional governors.

Treivish, A. I., and S. S. Artobolevskii, eds. Regionalizatsiia v razvitii Rossii: geograficheskie protsessy i problemy. Moscow: Editorial URSS, 2001.

Deals mostly with economic issues but includes a chapter on the "political landscape"; it aims to consider the implications of regionalism for Russian development.

Turovskii, R. F., ed. Politicheskie protsessy v regionakh Rossii. Moscow: Tsentr politicheskikh tekhnologii, 1998.

\section{Federalism and Center-Periphery Relations}

Abdulatipov, R. G. Paradoksy suvereniteta: perspektivy cheloveka, natsii, gosudarstva. Moscow: Slavianskii dialog, 1995.

Abdulatipov, R. G., L. F. Boltenkova, and Iu. F. Iarov. Federalizm v istorii Rossii. Moscow: Respublika, 1993.

Aleksandrov, V. M., and A. V. Semenov. "Sostoianie i perspektivy razvitiia federal'nykh okrugov Rossiskoi Federatsii." Pravovedenie No. 3, 2002, 8595.

Alexseev, Mikhail A., ed. Center-Periphery Conflict in Post-Soviet Russia: A Federation Imperiled. New York: St. Martin's Press, 1999.

Andreev, A. V., and A. T. Karasev. "Predstavitel'naia vlast' v sub"ektakh Rossiiskoi Federatsii: obshchee i osobennoe." Pravovedenie, no. 1, 2003, 56-61.

Bahry, Donna. "The New Federalism and the Paradoxes of Regional Sovereignty in Russia." Comparative Politics 37, no. 2 (January 2005): 127-46.

Belousov, Viktor, and Mikhail Belousov. "Reforma federativnykh otnoshenii: indikator uspekha." Vlast', no. 2, 2002, 32-35.

Busygina, Irina M. "Das Institut der Vertreter des Präsidenten in Rußland: Probleme des Werdegangs und Entwicklungsperspektiven.” Osteuropa 46, no. 7 (July 1996): 664-75.

. "Die Gouverneure im föderativen System Rußlands." Osteuropa 47, no. 6 
(June 1997): 544-56.

. "Der asymmetrische Föderalismus: Zur besonderen Rolle der Republiken in der Russischen Föderation." Osteuropa 48, no. 3 (March 1998): 239-52.

Cherepanov, V. A. Konstitutsionno-pravovye osnovy razdeleniia gosudarstvennoi vlasti mezhdu Rossiiskoi Federatsiei i ee sub'ektami. Moscow: MZ-Press, 2003.

Teoriia rossiiskogo federalizma. Moscow: MZ-Press, 2005.

Clark, William. "Presidential Prefects in the Russian Provinces: Yeltsin's Regional Cadres Policy." In Graeme Gill, ed., Elites and Leadership in Russian Politics. Basingstoke: Macmillan, 1998, 24-51.

Crosston, Matthew.Shadow Separatism:ImplicationsforDemocratic Consolidation. Aldershot: Ashgate, 2004.

Examines how the regional use of bilateral autonomy treaties has influenced the long-term stability, legitimacy, and efficacy of the state.

Dobrynin, N. M. Federalizm: istoriko-metodologicheskie aspekty. Novosibirsk: Nauka, 2005.

Dowley, Kathleen M. "Striking the Federal Bargain in Russia: Comparative Regional Government Strategies." CPCS 31, no. 4 (December 1998): 35980 .

Drobizheva, L. M., ed. Asimmetrichnaia federatsiia: vzgliad iz tsentra, republik $i$ oblastei. Moscow: Institut sotsiologii RAN, 1998.

Farukshin, Midkhat. "Federalizm i demokratiia: slozhnyi balans." Polis, no. 6, 1997, 164-73.

Particular attention is paid to the position of Tatarstan.

—. Sovremennyi federalizm: rossiiskii i zarubezhnyi opyt. Kazan': Izdatel'stvo Kazanskogo universiteta, 1998.

- Federalizm: teoreticheskie i prikladnye aspekty. Moscow: Iurist', 2004.

Federalizm: teoriia, praktika, istoriia. Moscow: Brat, 1996-.

Issued quarterly by the Institute of Economics of the Russian Academy of Sciences.

Fedosov, P. A., et al. "Perspektivy rossiiskogo federalizma: federal'nye okruga; regional'nye politicheskie rezhimy; munitsipalitety." Polis, no. 4, 2002, 15983.

Filippov, Mikhail, and Olga Shevtsova. "Asymmetric Bilateral Bargaining in the New Russian Federation: A Path-Dependence Explanation.” CPCS 32, no. 1 (March 1999): 61-76.

Forsberg, Tuomas, ed. Contested Territory: Border Disputes at the Edge of the Former Soviet Empire. Aldershot: Edward Elgar, 1995. 
Galkin, A. A., et al. "Federalizm i publichnaia sfera v Rossii." Polis, no. 4, 2001, 132-61.

First of a series of papers emanating from the project "Federalism and the Public Sphere in Russia and Canada"; continued in Galkin et al. (2002) and Fedosov et al. (2002). Three further articles on comparative issues of Russian and Canadian federalism appear in Politiia 4, no. 27 (Winter 2002-03). . "Evoliutsiia rossiiskogo federalizma." Polis, no. 3, 2002, 96-128.

Garkusha, P. I. Pravovoi status gubernatorstva v Rossii. Rostov on Don: Rostizdat, 2004.

Gel'man, Vladimir. "Subnational Institutions in Contemporary Russia." In Neil Robinson, ed., Institutions and Political Change in Russia. Basingstoke: Macmillan, 2000, 85-105.

Goode, J. Paul. "The Push for Regional Enlargement in Putin's Russia.” PSA 20, no. 3 (July-September 2004): 219-57.

Particular attention is paid to Perm' and Tiumen'.

Gorenburg, Dmitry. "Regional Separatism in Russia: Ethnic Mobilisation or Power Grab?” EAS 51, no. 2 (March 1999): 245-74.

Hahn, Gordon M. "Putin's Federal Reforms: Reintegrating Russia's Legal Space or Upsetting the Metastability of Russia's Asymmetrical Federalism." Dem 9, no. 4 (Fall 2001): 498-530.

. "The Impact of Putin's Federative Reforms on Democratization in Russia." PSA 19, no. 2 (April-June 2003), 114-53.

_. "The Past, Present, and Future of the Russian Federal State." Dem 11, no. 3 (Summer 2003): 343-62.

Hale, Henry E., and Rein Tagerpera. "Russia: Consolidation or Collapse?” EAS 54, no. 7 (November 2002): 1101-25.

Hughes, James R. "Managing Secession Potential in the Russian Federation." Regional and Federal Studies 11, no. 3 (Autumn 2001), 36-68.

Hyde, Matthew. "Putin's Federal Reforms and Their Implications for Federal Power in Russia." EAS 53, no. 5 (July 2001): 719-43.

Ivanov, V. N. Rossiia federativnaia: krizis i puti ego preodoleniia. Moscow: ISPI RAN, 1999.

- Sotsiologiia federalizma. Moscow: ISPI, 2004.

2001.

ed. Rossiia federativnaia: problemy i perspektivy. Moscow: ISPI RAN,

Considers interethnic as well as center-periphery aspects and the comparative experience of Belarus and Yugoslavia; an appendix includes survey data. 
Ivanov, V. N., and O. A. Iarovoi. Rossiiskii federalizm: stanovlenie i razvitie. Moscow: RITs ISPI RA, 2000.

Incorporates survey data and a dictionary of concepts. A second edition appeared in 2001.

Ivanov, V. V. "Novye podkhody k teorii territorial'nogo ustroistva i federativnaia sistema Rossii." Pravovedenie, no. 3, 2002, 63-84

.Avtonomnyeokrugavsostavekraia, oblastei-fenomen "slozhnosostavnykh sub"ektov Rossiiskoi Federatsii": konstitutsionno-pravovoe issledovanie. Moscow: Izdatel'stvo Moskovskogo universiteta, 2002.

Jackson, L. J., and N. J. Lynn. "Constructing 'Federal Democracy' in Russia: Debates over Structures of Power in the Regions." Regional and Federal Studies 12, no. 1 (Spring 2002): 91-125.

Kahn, Jeffrey. "The Parade of Sovereignties: Establishing the Vocabulary of the New Russian Federation.” PSA 16, no. 1 (January-March 2000): 58-89.

. Federalism, Democratization, and the Rule of Law in Russia. Oxford: Oxford University Press, 2002.

Deals with developments from the late Soviet period to Putin's federal reforms.

Kempton, Daniel R. "Russian Federalism: Continuing Myth or Political Salvation?" Dem 9, no. 2 (Spring 2001): 201-42.

Kempton, Daniel R., and Terry D. Clark. Unity or Separation: Center-Periphery Relations in the Former Soviet Union. Westport, Conn.: Praeger, 2002.

Khairullina, I. R. "Reforma federativnogo ustroistva i interesy regiona." SI, no. 11, 1998, 58-60.

Kirkow, Peter. "Roulette zwischen Zentrum und Regionen." 1. "Rußlands asymmetrischer Föderalismus." Osteuropa 45, no. 11 (November 1995): 1004-20.

—. "Im Labyrinth russischer Regionalpolitik: Ausgehandelter Föderalismus und institutionelle Veränderungen." Osteuropa 47, no. 1 (January 1997), 3851.

Kistanov, V. V. Federal'nye okruga Rossii: vazhnyi shag v ukreplenie gosudarstva. Moscow: Ekonomika, 2000.

Kolobov, A. O., and I. P. Skliarov. Sovremennyi rossiiskii federalizm. Nizhnii Novgorod: ISI NNGU, 2001.

Konstitutsionno-pravovoe regulirovanie otnoshenii mezhdu RF i ee sub"ektami. St. Petersburg: Iuridicheskii Tsentr Press, 2004.

Kurashvili, K. T. Federativnaia organizatsiia rossiiskogo gosudarstva. Moscow: Sputnik, 2000. 
Lapidus, Gail W. "Asymmetrical Federalism and State Breakdown in Russia." PSA 15, no. 1 (January-March 1999): 74-82.

Lapina, N. Iu., and A. E. Chirikova. "Regional'naia vlast' i reforma rossiiskogo federalizma: stsenarii politicheskogo budushchego." SI, no. 4, 2001, 16-26.

Leksin, V. N., and A. N. Shvetsov. Gosudarstvo i regiony: teoriia i praktika gosudarstvennogo regulirovaniia territorial'nogo razvitiia. 3d ed. Moscow: Editorial URSS, 2000.

Leksin and Shvetsov are the editors of Munitsipal'naia Rossiia: sotsial'no-ekonomicheskaia situatsiia, pravo, statistika, 5 vols. in 12 parts (Moscow: Editorial URSS, 2001), an encyclopedic and largely statistical study of approximately six hundred towns and nineteen hundred districts. Eleven of the twelve parts focus on particular macroregions.

Lynn, Nicholas, and Aleksei V. Novikov. "Refederalizing Russia: Debates on the Idea of Federalism in Russia." Publius: The Journal of Federalism 27, no. 2 (Spring 1997): 187-203.

Lysenko, Vladimir. Ot Tatarstana do Chechni (stanovlenie novogo rossiiskogo federalizma). Moscow: Institut sovremennoi politiki, 1995.

- Razvitie federativnykh otnoshenii v sovremennoi Rossii. Moscow: Institut sovremennoi politiki, 1995.

Matsuzato, K., ed. Tret'e zveno gosudarstvennogo stroitel'stva Rossii: podgotovka $i$ realizatsiia Federal'nogo Zakona ob obshchikh printsipakh organizatsii mestnogo samoupravleniia v Rossiiskoi Federatsii. Occasional Papers on Changes in the Slavic-Eurasian World 73. Sapporo: Slavic Research Center, Hokkaido University, 1998.

Mick, Christoph. "Probleme des Föderalismus in Rußland." Osteuropa 44, no. 7 (July 1994): 611-29.

Nelson, Lynn D., and Irina Y. Kuzes. "Regional Variations in the Implementation of Russia's Federal District Reform." Dem 10, no. 1 (Winter 2002): 5-18.

. "Political and Economic Coordination in Russia's Federal District Reform: A Study of Four Regions." EAS 55, no. 4 (June 2003): 507-20.

Particular attention is paid to Sverdlovsk, Voronezh, and Smolensk oblasti and Tatarstan.

Ordeshook, Peter C. "Russia's Party System: Is Russian Federalism Viable?" PSA 12, no. 3 (July-September 1996): 195-217.

Ordeshook, Peter C., and Olga Shvetsova. "If Madison and Hamilton Were Merely Lucky, What Hope Is There for Russian Federalism?" Constitutional Political Economy 6, no. 2 (Spring 1995): 107-26.

Osipian, S. A. Tipologiia rossiiskogo federalizma $i$ konstitsionno-pravovye 
problemy organizatsii gosudarstvennoi vlasti $i$ prokurorskogo nadzora. Moscow: Gumanitarii, 2004.

Ostrow, Joel M. "Conflict-Management in Russia's Federal Institutions." PSA 18, no. 1 (January-March 2002): 49-70.

Pascal, Elizabeth. Defining Russian Federalism. Westport Conn.: Praeger, 2003.

Perović, Jeronim. Die Regionen Russlands als neue politische Kraft: Chancen und Gefahren des Regionalismus für Russland. Bern: Peter Lang, 2001.

-. "Regionalisierung unter Putin: Alte Muster und neue Trends." Osteuropa 52, no. 4 (April 2002): 427-42.

Petersson, Bö. National Self-Images and Regional Identities in Russia. Aldershot: Ashgate, 2001.

Draws on interviews with deputies in Khabarovsk, Perm', St. Petersburg, and Volgograd as well as the State Duma.

Petrov, Nikolai. "Seven Faces of Putin's Russia: Federal Districts as the New Level of State-Territorial Composition." Security Dialogue 33, no. 1 (March 2002): 73-91.

Radvanyi, Jean. "And What If Russia Breaks Up? Towards New Regional Divisions." PSG 33, no. 2 (February 1992): 69-77.

Reddaway, Peter, and Robert W. Orttung, eds. Dynamics of Russian Politics: Putin's Reform of Federal-Regional Relations. 2 vols. Lanham, Md.: Rowman \& Littlefield, 2004-05.

Volume 1 provides an overview of the reforms and examines the progress of reform in the seven federal districts; volume 2 considers the impact of the reforms on institutions and policies. The first volume of a fuller Russian version has also appeared: Nikolai Petrov, ed., Federal'naia reforma, 2000-2003. vol. 1, Federal'nye okruga (Moscow: Moskovskii obshchestvennyi nauchnyi fond, 2003).

Roeder, Philip G. "Soviet Federalism and Ethnic Mobilization." World Politics 43, no. 1 (January 1991): 196-232.

Ross, Cameron. "Federalism and Democratisation in Russia." Communist and Post-Communist Studies 30, no. 4 (December 2000): 403-20.

- "Putin's Federal Reforms and the Consolidation of Federalism in Russia: One Step Forward, Two Steps Back?" CPCS 36, no.1 (March 2003): 29-47.

Rossiia: tsentr i regiony. Moscow: Institut sotsial'no-politicheskikh issledovanii RAN, 1997-. A serial publication; issue 11 appeared in 2003.

Sharlet, Robert. "Resisting Putin's Federal Reforms on the Legal Front." Dem 11, no. 3 (Summer 2003): 335-42.

Slider, Darrell. "Russia’s Market-Distorting Federalism.” PSGE 38, no. 8 (October 
1997): 445-60.

Söderlund, Peter J. "The Significance of Structural Power Resources in the Russian Bilateral Treaty Process, 1994-1998." CPCS 36, no. 3 (September 2003): 311-24.

Solnick, Steven L. "Federal Bargaining in Russia." EECR 4, no. 4 (Fall 1995): $52-58$.

. "The Political Economy of Russian Federalism: A Framework for Analysis." PPC 43, no. 6 (November-December 1996): 13-25.

-. "Is the Center Too Weak or Too Strong in the Russian Federation?" In Valerie Sperling, ed., Building the Russian State. Boulder, Colo.: Westview Press, 2000, 137-56.

Stepan, Alfred. "Russian Federalism in Comparative Perspective." PSA 16, no. 2 (April-June 2000): 133-76.

Stoliarov, Mikhail. Federalism and the Dictatorship of Power in Russia. London: Routledge, 2003.

A translation of Federalizm i derzhavnost': rossiiskii variant (Moscow: Slavianskii dialog, 2001).

Stoner-Weiss, Kathryn. "Central Weakness and Provincial Autonomy: Observations on the Devolution Process in Russia." PSA 15, no. 1 (January-March 1999): 87-106.

Thumann, Michael. "Between Appeasement and Coercion: Russia's CenterPeriphery Relations from Yeltsin to Putin.” Dem 9, no. 2 (Spring 2001): 193200.

Tolz, Vera, and Irina Busygina. "Regional Governors and the Kremlin: The Ongoing Battle for Power." CPCS 30, no. 4 (December 1997): 401-26.

Treisman, Daniel S. "Russia's 'Ethnic Revival': The Separatist Activism of Regional Leaders in a Postcommunist Order." World Politics 49, no. 2 (January 1997): 212-49.

Umnova, I. Sovremennaia rossiiskaia model' razdeleniia vlasti mezhdu federatsiei i ee sub"ektami. Moscow: INION RAN, 1996.

Valentei, S. D. Federalizm: rossiiskaia istoriia i rossiiskaia real'nost'. Moscow: Institut ekonomiki RAN, 1998.

Vvedenskii, V. G., and A. Iu. Gorokhov. Rossiia: ispytanie federalizmom. Moscow: Serebriannye niti, 2002.

A discussion of contemporary models of federalism and (in the last chapter) of their implications for Russia.

Zhuchenko, A. A. Sootnoshenie konstitutsii respublikv sostave Rossiiskoi Federatsii 
s Konstitutsiei Rossii: problemy teorii i praktiki. Moscow: Aviaizdat, 2001.

\section{Legal Aspects}

Alexander, James. "Federal Reforms in Russia: Putin's Challenge to the Republics." Dem 12, no. 2 (Spring 2004): 233-63.

Bezrukov, A. V. Sovershenstvovanie vzaimodeistviia Rossiiskoi Federatsii i ee sub"ektov (konstitutsionno-pravovoi aspekt). Krasnoiarsk: SIuI MVD RF, 2002.

Bukhval'd, E. "Regulirovanie otnoshenii sobstvennosti mezhdu Rossiiskoi Federatsiei i ee sub"ektami." VE, no. 7, 1997, 97-111.

Chinarikhina, G. "Dogovor kak sposob razgranicheniia polnomochii i predmetov vedeniia mezhdu sub"ektami federativnykh otnoshenii v Rossii." Vlast', no. 9, 1996, 20-25.

Chirkin, V. E. "O sushchnosti sub"ekta federatsii: traditsii i realii." Gosudarstvo $i$ pravo,_no. 7, July 2003, 5-9.

Dudko, I. G. Zakonodatel'stvo sub"ektov Rossiiskoi Federatsii. Problemy teorii $i$ praktiki. Saransk: MorGU, 2004.

Hahn, Gordon M. 'Putin's Federal Reforms: Reintegrating Russia's Legal Space or Upsetting the Metastability of Russia's Asymmetrical Federalism." Dem 9, no. 4 (Fall 2001): 498-530.

Heinemann-Grüder, Andreas. "Integration durch Asymmetrie? Regionale Verfassungen und Statuten in Rußland." Osteuropa 48, no. 7 (July 1998): 672-88.

Kjeldsen, Stig. "The Treaty Process Evolves: Russian Bilateral Power-Sharing Treaties." RCEEL 24, no. 5/6 (1998): 363-85.

Konenko, P. B. "Politicheskie faktory konstitutionnogo stroitel'stva v respublikakh Rossiiskoi Federatsii." Polis, no. 6, 2003, 135-43.

Luchterhand, Otto. "Staatsangehörigkeitsrecht im Wandel von der UdSSR zur Russländischen Föderation." Osteuropa 52, no. 6 (June 2002): 697-718.

Malikov, M. F., ed. Pravovye osnovy rossiiskogo federalizma. Ufa: RIO BashGU, 2004.

Metshin, I. R. Pravovaia sistema respubliki v sostave Rossiiskoi Federatsii. Moscow: Norma, 2002.

Particular attention is paid to the position of Tatarstan.

Schneider, Eberhard. "Die russischen Machtabgrenzungsverträge." Osteuropa 47, no. 6 (June 1997): 569-79. 
Shishkin, Sergei. Gosudarstvenno-pravovye problemy regionalizatsii v Rossiiskoi Federatsii. Irkutsk: Izdatel'stvo Irkutskogo gosudarstvennogo universiteta, 1996.

Smith, Graham. "Russia, Multiculturalism and Federal Justice." EAS 50, no. 8 (December 1998): 1393-411.

Snugrov, A. Iu. "Iz opyta razvitiia instituta ombudsmena v regionakh Rossii." Polis, no. 2, 2002, 147-54.

Sungurov, A. Iu., ed. Komissii i upolnomochennye po pravam cheloveka: opyt rossiiskikh regionov. St. Petersburg: Norma, 2002.

\section{Regimes and Elites}

Afanas'ev, M. N. “Izmeneniia v mekhanizme funktsionirovaniia praviashchikh regional'nykh elit." Polis, no. 6, 1994, 59-66.

_. "Formirovanie predstavitel'nykh sobranii praviashchikh regional'nykh grupp." Polis, no. 4, 1998, 116-19.

Antipov, A., and A. Golovkov. "Regional'naia elita Rossii v izbiratel'nykh kampaniiakh 1995 i 1996 godov." Vlast', no. 9, 1996, 68-70.

Babaeva, L. V., and A. E. Chirikova. "Politicheskie orientatsii regional'nykh elit." Biznes i politika, no. 3, 1996, 11-16.

Badovskii, D. V., and A. Iu. Shutov. "Regional'nye elity v postsovetskoi Rossii: osobennosti politicheskogo uchastiia." Kentavr, no. 6, 1995, 3-23.

Chirikova, A. E. "Rossiiskie direktora i regional'naia vlast: poisk optimal'nykh modelei vzaimodeistviia." SI, no. 11, 2001, 35-46.

_. "Regional'nye elity i regional'nye protsessy: vlast' i politika." In L. Drobizheva, ed., Rossiia reformiruiushchaiasia. Moscow: Academia, 2002, 8-33.

—_. "Informatsionnye aktory v regionakh" SI, no. 11, 2003, 13-22.

."Ispolnitel'naia vlast'v regionakh: pravila igry formal'nye i neformal'nye." Obshchestvennye nauki i sovremennost', no. 3, 2004, 71-79.

Chirikova, A. E., and N. Iu. Lapina. "Reforma rossiiskogo federalizma: regional'nye elity v poiskakh strategii.” In V. A. Iadov, ed., Rossiia: transformiruiushcheesia obshchestvo. Moscow: Kanon-Press-Ts, 2001, 359-72.

DeBardeleben, Dzh. "Otnoshenie k vlasti v regionakh Rossii.” SI, no. 6, 2000, 88-98.

Dines, V., A. Durnov, and A. Nikolaev. "Dinamika osvoeniia regional'noi elitoi sovremennykh izbiratel'nykh tekhnologii." Vlast', no. 8, 1999, 76-80. 
Drobizheva, L. M. "A Comparison of Elite Groups in Tatarstan, Sakha, Magadan, and Orenburg." PSA 15, no. 4 (October-December 1999): 387-406.

- Govorit elita respublik Rossiiskoi Federatsii. Moscow: Institut etnologii i antropologii RAN, 1996.

Based on over a hundred interviews with politicians, businessmen, scholars, and others.

Druziaka, E. V. "Vliianie regional'nykh praviashchikh elitna massovoe politicheskoe soznanie (osnovnye podkhody k izucheniiu)." Vestnik Moskovskogo Universiteta, series 12, Politicheskie nauki, no. 4, 2001, 41-59.

Duka, A. V., ed. Regional'nye elity Severo-Zapada Rossii: politicheskie $i$ ekonomicheskie orientatsii. St. Petersburg: Aleteiia, 2001.

Galliamov, R. R. "Politicheskie elity rossiiskikh respublik: osobennosti transformatsii v postsovetskii period." Polis, no. 2, 1998, 108-15.

Gaman, O. "Regional'nye elity v postsovetskoi Rossii." $R F$, no. 10, 1995, 53-55. . "Regional'nye elity sovremennoi Rossii." Dialog, no. 8, 1996, 8-11.

Gaman-Golutina, O. V. "Regional'nye elity: personal'nyi sostav i tendentsii evoliutsiia." Polis, no. 2, 2004, 6-19, and no. 3, 2004, 22-32.

_. "Regional'nye elity Rossii v zerkale ekspertnogo oprosa." Vlast', no. 5, 2004, 3-10.

Gel'man, Vladimir. "Regional'nye rezhimy: zavershenie transformatsii?" $S M$, no. 9, 1996, 13-22.

_. "Regional'naia vlast' v sovremennoi Rossii: instituty, rezhimy i praktiki." Polis, no. 1, 1998, 87-105. . "Regime Transition, Uncertainty and Prospects for Democratisation: The Politics of Russia's Regions in a Comparative Perspective." EAS 51, no. 6 (September 1999): 939-56.

Gel'man, Vladimir, et al., eds. Organy gosudarstvennoi vlasti sub"ektov Rossiiskoi Federatsii. Moscow: Mezhdunarodnyi institut gumanitarno-politicheskikh issledovanii, 1998.

Gel'man, Vladimir, Sergei Ryzhenkov, and Mikhail Bri, eds. Rossiia regionov: transformatsiia politicheskikh rezhimov. Moscow: Ves' mir, 2000.

Glubutskii, A. Iu., and A. V. Kynev. "Partiinaia sostavliaiushchaia zakonodatel'nkh sobranii rossiiskikh regionov." Polis, no. 3, 2003, 71-87.

Hahn, Jeffrey. "Attitudes towards Reform Among Provincial Russian Politicians." PSA 9, no. 1 (January-March 1993): 66-85.

Hale, Henry E. "Explaining Machine Politics in Russia's Regions: Economics, Ethnicity, and Legacy.” PSA 19, no. 3 (July-September 2003): 228-63.

Ignatov, V., and A. Ponedelkov. "Regional'nye elity i rossiiskii federalism." Vlast', 
no. 1, 2002, 51-56.

Kim, Seongjin. "Regional Cleavages in Russian Legislative Politics, 1990-93." Regional and Federal Studies 15, no. 1 (March 2005): 93-121.

Kirkow, Peter, Philip Hanson, and Andrei Treivish. "Networks, Linkages and Legacies: Evidence from an Elite Survey in Six Russian Provinces in 19961997." CEET 10, no. 3 (September 1998): 405-13.

Komarovskii, V. S., et al. Regional'nye elity i naselenie o politike i politikakh. Moscow: Izdatel'stvo RAGS, 1996.

Kryshtanovskaia, O. V. "Formirovanie regional'noi elity: printsipy i mekhanizmy." SI, no. 11, 2003, 3-13.

Kukolev, I. V. "Regional'nye elity: bor'ba za vedushchie roli prodolzhaetsia." Vlast', no. 1, 1996, 46-52.

Kuz'min, A. S., N. Dzh. Melvin, and V. D. Nechaev. "Regional'nye politicheskie rezhimy v postsovetskoi Rossii: opyt tipologizatsii." Polis, no. 3, 2002, 14255.

Lapina, Natal'ia Iu. Regional'nye elity Rossii: modeli povedeniia i politicheskoi orientatsii. Moscow: INION RAN, 1997.

__. "Regional'nye elity Rossii: kto pravit na mestakh?" Rossiia i sovremennyi mir, no. 1, 1998, 98-120.

Lapina, N. Iu., and A. E. Chirikova. "Regional'naia vlast' v Rossii: paradoksy stanovleniia." Obshchestvo i ekonomika, no. 5, 1999, 127-59.

- "Regional'naia ekonomicheskie elity: Mentalitet, povedenie, vzaimodeistvie s vlast'iu." Obshchestvo i ekonomika, no. 6, 1999, 230-78.

_. "Politicheskie orientatsii regional'nykh elit." Politiia, no. 3, 1999, 2030.

- Regional'nye elity v RF: modeli povedeniia i politicheskie orientatsii. Moscow: INION RAN, 1999.

_. "Politicheskoe samoopredelenie regional'nykh elit." SI, no. 6, 2000, 98107.

- Strategii regional'nykh elit: ekonomika, modeli vlasti, politicheskii vybor. Moscow: INION RAN, 2000.

—. "Regional'naia vlast': paradoksy perekhodnogo obshchestva." Politiia, no. 4, 2000, 84-98.

_. "Regional'naia vlast' i ekonomicheskie elity: sotsiologicheskaia khronika nachala XXI veka." Obshchestvo i ekonomika, no. 6, 2002, 93-119 (part 1), and no. 7, 2002, 88-122 (part 2).

—. "Transformatsiia rossiiskoi regional'noi elity: vpered v nomenklaturnoe 
budushchee?" MEMO, no. 6, 2005, 33-44.

Lowberg, Mikhail. "Social Structure and Political Tenets of the New Branch of the

Russian Regional Elite.” In Vladimir Shlapentokh et al., eds., The New Elite in Post-Communist Eastern Europe. College Station: Texas A\&M University Press, 1999, 241-50.

Magomedov, A. "Politicheskie elity rossiiskoi provintsii." MEMO, no. 4, 1994, $72-79$.

— . "Politicheskaia ideologiia lokal'nykh praviashchikh elit v Rossii." Rossiia i sovremennyi mir, no. 4, 1994, 152-76.

. Lokal'nye elity $i$ ideologii regionalizma v noveishei Rossii: sravnitel'nyi analiz. Ul'ianovsk: Ul'ianovskii gosudarstvennyi tekhnicheskii universitet, 1998.

. Misteriia regionalizma. Regional'nye praviashchie elity $i$ regional'nye ideologii: Modeli politicheskogo vossozdaniia 'snizu'. Moscow: MONF, 2000.

Based on a study of the middle Volga (Tatarstan, Kalmykiia, Saratov region, and Nizhnii Novgorod region).

Makarkin, A. V. "Regional'nye politicheskie elity: smena pokolenii." Politiia, no. 1, 1998, 33-49.

Marsh, Christopher. "Social Capital and Democracy in Russia." CPCS 33, no. 2 (June 2000): 183-99.

_. "Social Capital and Grassroots Democracy in Russia's Regions: Evidence from the 1999-2001 Gubernatorial Elections." Dem, 10, no. 1 (Winter 2002): 19-36.

Matsuzato, K. "Local Elites in Transition: County and City Politics in Russia, 1985-1996." EAS 51, no. 8 (December 1999): 1367-1400.

McMann, Kelly M., and Nikolai V. Petrov. "A Survey of Democracy in Russia's Regions." PSGE 41, no. 3 (April-May 2000): 155-82.

Mel'vil', A., ed. Transformatsiia rossiiskikh regional'nykh elit $v$ sravnitel'noi perspektive. Moscow: MONF, 1999.

A set of conference proceedings; the third part contains a series of studies of specific regions.

Mendras, Marie. "How Regional Élites Preserve Their Power." PSA 15, no. 4 (October-December 1999): 295-311.

Mokhov, V. P. Evoliutsiia regional'noi politicheskoi elity Rossii (1950-1990 gg.).

Perm': Permskii gosudarstvennyi tekhnologicheskii universitet, 1998.

. Regional'naia politicheskaia elita Rossii (1945-1991 gg.) Perm': Permskoe 
knizhnoe izdatel'stvo, 2003.

Moses, Joel. "Soviet Provincial Politics in an Era of Transition and Revolution, 1989-91." SS 44, no. 3 (1992): 479-509.

Novikova, O. S., I. O. Babkin, and A. Iu. Khots. "Mnenie regional'noi elity." SI, no. 9, 2001, 37-43

Petrov, N. "Politicheskaia elita v tsentre i na mestakh." Rossiiskii monitor, no. 5, 1995, 41-63.

Raspopov, N. P. “Sotsial'no-politicheskaia stabil'nost' regiona-sub”ekta RF.” Polis, no. 3, 1999, 89-99.

Ross, Cameron, ed. Regional Politics in Russia. Manchester: Manchester University Press, 2002.

Includes comparative as well as region-specific contributions; the latter are noted in appropriate sections below.

Schutow, Andrej, and Dmitrij Badowskij. "Politik in den Regionen Rußlands und die Rolle der Eliten.” Osteuropa 45, no. 12 (December 1995): 1127-43.

Sharafutdinova, Gulnaz. "When Do Elites Compete? The Determinants of Political Competition in Russian Regions." Comparative Politics 38, no. 3 (April 2006): 273-93.

Sistema vlastnykh otnoshenii v RF: Regional'nyi aspekt. Ed. N. V. Merklikin. Moscow: RAN, 1996.

Steen, Anton, and Vladimir Gel'man, eds. Elites and Democratic Development in Russia. London: Routledge, 2003.

Tsygankov, Andrei. "Manifestations of Delegative Democracy in Russian Local Politics: What Does It Mean for the Future of Russia?" CPCS 31, no. 4 (December 1998): 329-44.

Weigle, Marcia A. "The Construction of an Independent Public Sphere in Russia's Regions.” Dem 5, no. 2 (Spring 1997): 239-62.

Zeletdinova, El'vira. "Mekhanizmy demokratizatsii regional'noi administrativnoi elity." Vlast', no. 7, 2002, 22-29.

Zhuravlev, A. "Politicheskie predpochteniia regional'noi elity nakanune izbiratel'nykh kampanii." Vlast', no. 5, 1999, 14-19.

Zlotnik, Marc. "Russia's Governors: All the President's Men?" $P P C$ 43, no. 6 (November-December 1996): 26-34.

_. "Russia's Elected Governors: A Force to Be Reckoned With." Dem 5, no. 2 (Spring 1997): 184-96. 


\section{Parties, Politicians and Elections}

Akhromenko, A. S. 'Strukturirovanie elektoral'nogo prostranstva v rossiiskikh regionakh: faktornyi analiz parlamentskikh vyborov, 1995-2003 gg." Polis, no. $2,2005,26-40$.

"Elektoral'noe uchastie i absenteizm v rossiiskikh regionakh: zakonomernosti i tendentsii." Vestnik Moskovskogo Universiteta, series 12, Politicheskie nauki, no. 3, 2005, 95-113.

Berezkin, Andrei V., Mikhail Myagkov, and Peter Ordeshook. "Location and Political Influence: A Further Elaboration of their Effects on Voting in Recent Russian Elections." EGE 44, no. 3 (April-May 2003): 169-83.

Brown, Ruth. "Party Development in the Regions: When Did Parties Start to Play a

Part in Politics?" In John Löwenhardt, ed., Party Politics in Post-Communist

Russia. London: Frank Cass, 1998, 9-30.

Chugrov, S. "Elektoral'noe povedenie rossiiskikh regionov (statisticheskii analiz vyborov dekabrya 1995 g.)." MEMO, no. 6, 1996, 27-39.

Clem, Ralph S., and Peter R. Craumer. "The Politics of Russia's Regions: A Geographical Analysis of the Russian Election and Constitutional Plebiscite of December 1993." PSG 36, no. 2 (February 1995): 67-86.

. "A Rayon-Level Analysis of the Russian Election and Constitutional Plebiscite of December 1993." PSG 36, no. 8 (October 1995): 459-75. . "The Geography of the Russian 1995 Parliamentary Election: Continuity, Change, and Correlates." PSG 36, no. 10 (December 1995): 587-616.

. "Roadmap to Victory: Boris Yel'tsin and the Russian Presidential Elections of 1996." PSGE 37, no. 6 (June 1996): 335-54.

. "Urban-Rural Voting Differences in Russian Elections, 1995-1996: A Rayon-Level Analysis." PSGE 38, no. 7 (September 1997): 379-95.

"The Regional Dimension." In Laura Belin and Robert W. Orttung, eds., The Russian Parliamentary Elections of 1995. Armonk, N.Y.: M. E. Sharpe, 1997, 137-59.

- "Regional Patterns of Voter Turnout in Russian Elections, 1993-96." In Matthew Wyman, Stephen White, and Sarah Oates, eds., Elections and Voters in Post-communist Russia. Cheltenham: Edward Elgar, 1998, 40-67.

. "Regional Patterns of Political Preference in Russia: The December 1999

Duma Elections." PSGE 41, no. 1 (January 2000): 1-29.

. "Spatial Patterns of Political Choice in the Post-Yeltsin Era: The Electoral Geography of Russia's 2000 Presidential Election.” PSGE 41, no. 7 (October- 
November 2000): 465-82.

. "Redrawing the Political Map of Russia: The Duma Election of December 2003." EGE 45, no. 4 (June 2004): 241-61.

DeBardeleben, Joan. "Fiscal Federalism and How Russians Vote." EAS 55, no. 3 (May 2003): 339-63.

DeBardeleben, Joan, and Aleksander A. Galkin. "Electoral Behaviour and Attitudes in Russia: Do Regions Make a Difference or Do Regions Just Differ?” In Peter J. Stavrakis et al., eds., Beyond the Monolith: The Emergence of Regionalism in Post-Soviet Russia. Washington, D.C.: Woodrow Wilson Center Press, 1997, 57-80.

Gehlbach, Scott. "Shifting Electoral Geography in Russia’s 1991 and 1996 Presidential Elections." PSGE 41, no. 5 (July-August 2000): 379-88.

Gel'man, Vladimir, and Ol'ga Senatova. "Politicheskie partii v regionakh Rossii." In Vladimir Gel'man, ed., Ocherki rossiiskoi politiki: issledovaniia $i$ nabliudeniia 1993-1994gg. Moscow: Institute of Humanitarian and Political Research, 1994, 16-30.

Gimpelson, Vladimir, Darrell Slider, and Sergei Chrugov. "Political Tendencies in Russia's Regions: Evidence from the 1993 Parliamentary Elections." SR 53, no. 3 (Fall 1994): 711-32.

Glubotskii, A. Iu., and A. V. Kynev. "Opyt smeshannykh vyborov v rossiiskikh regionakh.” Polis, no. 2, 2003, 124-42.

Golosov, Grigorii V. "Povedenie izbiratelei v Rossii: teoreticheskie perspektivy i rezul'taty regional'nykh vyborov." Polis, no. 4, 1997, 44-56.

- "From Adygeya to Yaroslavl: Factors of Party Development in the Regions of Russia, 1995-1998." EAS 51, no. 8 (December 1999): 1333-65.

."Elity, obshcherossiiskie partii, mestnye izbiratel'nye sistemy (o prichinakh razvitiia politicheskikh partii v regionakh Rossii)." Obshchestvennye nauki $i$ sovremennost', no. 3, 2000, 51-75.

. "Izmerenie rossiiskikh regional'nykh izbiratel'nykh sistem." Polis, no. 4, 2001, 71-85.

. "Political Parties, Electoral Systems, and Women's Representation in the Regional Legislative Assemblies of Russia, 1995-1998." Party Politics 7, no. 1 (January 2001): 45-68.

- Political Parties in the Regions of Russia: Democracy Unclaimed. Boulder, Colo.: Lynne Rienner, 2003.

Ishiyama, John T. "Regionalism and the Nationalization of the Legislative Vote in Post-Communist Russian Politics.” CPCS 35, no. 2 (June 2002): 155-68. 
Hahn, Jeffrey W. "Reforming Post-Soviet Russia: The Attitudes of Local Politicians." In Theodore H. Friedgut and Jeffrey W. Hahn, eds., Local Power and Post-Soviet Politics. Armonk, N.Y.: M. E. Sharpe, 1994, 208-38.

- "Democratization and Political Participation in Russia's Regions." In Karen Dawisha and Bruce Parrott, eds., Democratic Changes and Authoritarian Reactions in Russia, Ukraine, Belarus, and Moldova. Cambridge: Cambridge University Press, 1997, 130-74.

—. "Regional Elections and Political Stability in Russia." PSGE 38, no. 5 (May 1997): 251-63.

Heinemann-Grüder, Andreas. "Transformation durch Elitenwechsel? Indikatoren des Systemwechsels am Beispiel russischer Regionaleliten." Osteuropa 47, no. 1 (January 1997): 26-37.

Helf, Gavin, and Jeffrey W. Hahn. "Old Dogs and New Tricks: Party Elites in the Russian Regional Elections of 1990." SR 51, no. 3 (Fall 1992): 511-30.

Hutcheson, Derek S. Political Parties in the Russian Regions. London: RoutledgeCurzon, 2003.

Particular attention is paid to the Volga region.

Ishiyama, John T. "The Russian Proto-parties and the National Republics." CPCS 29, no. 4 (December 1996): 395-411.

Kolosov, V. A. "The Geography of Elections of USSR People's Deputies by National-Territorial Districts and the Nationalities Issue." $S G$ 31, no. 10 (December 1990): 753-66.

_. "Politicheskie orientatsii rossiiskikh regionov: proizoshel li v dekabre 1995 'obval'?" Polis, no. 1, 1996, 91-102.

Kolosov, V. A., and R. F. Turovskii. "Itogi gubernatorskikh vyborov." Vlast', no. 3, 1997, 50-56.

_. "Osenne-zimnie vybory glav ispolnitel'noi vlasti v regionakh: stsenarii peremen.” Polis, no. 1, 1997, 97-108.

Konitzer, Andrew. Voting for Russia's Governors: Regional Elections and Accountability under Yeltsin and Putin. Baltimore, Md.: Johns Hopkins University Press, 2006.

Konitzer-Smirnov, Andrew. "Jurisdictional Voting in Russia's Regions: Initial Results from Individual-Level Analyses." EAS 55, no. 1 (January 2003): 133-53.

- "Incumbent Electoral Fortunes and Regional Economic Performance during Russia's 2000-2001 Regional Executive Election Cycle." PSA 19, no. 1 (January-March 2003): 46-79. 
Kudinov, O. P. Osnovy organizatsii $i$ provedeniia izbiratel'nykh kampanii $v$ regionakh Rossii. Kaliningrad: Iantarnyi Skaz, 2000.

Kynev, A. V. "V ozhidanii novogo elektoral'nogo predlozheniia (vybory regional'nykh zakonodatel'nykh sobranii kontsa 2004-nachala 2005 g.).” Polis, no. 3, 2005, 116-30.

Liukhterhandt-Mikhaleva, G., and S. Ryzhenkov. Vybory i partii v regionakh Rossii. Moscow: Letnii sad, 2000.

A "sbornik uchebnykh materialov" to accompany a course on political geography.

Makarenko, B. I., ed. Politika v regionakh: gubernatory i gruppy vliianiia. Moscow: Tsentr politicheskikh tekhnologii, 2002.

Marsh, Christopher. "Social Capital and Grassroots Democracy in Russia's Regions: Evidence from the 1999-2001 Gubernatorial Elections." Dem 10, no. 1 (Winter 2002): 19-36.

Matsuzato, Kimitaka, ed. Vzryvnoi poias-96: rossiiskie regiony i elektoral'noe povedenie. Occasional Papers on Regional/Subregional Politics in PostCommunist Countries 3. Sapporo: Slavic Research Center, Hokkaido University, 1999.

McFaul, Michael, and Nikolai Petrov. "Russian Electoral Politics after Transition: Regional and National Assessments." PSGE 38, no. 9 (November 1997): 507-49.

McFaul, Maikl, Nikolai Petrov, and Andrei Riabov, eds. Rossiia v izbiratel'nom tsikle 1999-2000 godov. Moscow: Gel'fand, 2000.

Several chapters give detailed consideration to the regional dimension.

Moraski, Bryon J. "Electoral System Design in Russian Oblasti and Republics: A Four Case Comparison." EAS 55, no. 3 (May 2003): 437-68.

Particular attention is paid to Saratov region, Udmurtiia, Novosibirsk region, and Buriatiia.

. Elections by Design: Parties and Patronage in Russia's Regions. DeKalb: Northern Illinois University Press, 2006.

Moraski, Bryon J., and William M. Reisinger. "Explaining Electoral Competition across Russia's Regions." Slavic Review 62, no. 2 (Summer 2003): 278-301

Moses, Joel C. "Voting, Regional Legislatures and Electoral Reform in Russia." EAS 55, no. 7 (November 2003): 1049-75.

Emphasises the cases of Perm' and Novosibirsk.

O'Loughlin, John, Michael Shin, and Paul Talbot. "Political Geographies and Cleavages in the Russian Parliamentary Elections." PSGE 37, no. 6 (June 1996): 355-85. 
Panov, P. V. “Izmenenie elektoral'nykh institutov v Rossii (krossregional'nyi sravnitel'nyi analiz)." Polis, no. 6, 2004, 16-28.

- "Reforma regional'nykh izbiratel'nykh system i razvitie politicheskikh partii v regionakh Rossii (krossregional'nyi sravnitel'nyi analiz).” Polis, no. 5, 2005, 102-17.

Sleptsov, N. S., I. V. Kukolev, and T. M. Ryskova. "Lidery rossiiskikh regionov: ispytanie plebistsitom." SI, no. 7, 1998, 118-28.

Slider, Darrell. "Elections to Russia's Regional Assemblies." PSA 12, no. 3 (JulySeptember 1996): 243-64.

Smirnova, M. "Gubernatorskie vybory: izbiratel'nyi marafon 1996-1997 gg." Vlast', no. 4, 1998, 28-36.

Söderlund, Peter. "Electoral Success and Federal-Level Influence of Russian Regional Executives." EAS 57, no. 4 (June 2005): 521-41.

Solnick, Steven L. "Gubernatorial Elections in Russia, 1996-97." PSA 14, no. 1 (January-March 1998): 48-80.

Stadelbauer, Jörg. "Zur regionalen Differenzierung der Duma-Wahlergebnisse." Osteuropa 46, no. 5 (May 1996): 449-57.

_. "Russische Präsidentschaftswahlen 1996: Dokumentation regionaler Wahlergebnisse." Osteuropa 46, no. 11 (November 1996): 1096-107.

Tucker, Joshua A. Regional Economic Voting: Russia, Poland, Hungary, Slovakia, and the Czech Republic, 1990-1999. Cambridge: Cambridge University Press, 2006.

\section{Economic and Social Aspects}

Akinin, P. V., and S. V. Stepanova, eds. Regional'nyi rynok truda v usloviiakh transformatsii rossiiskoi ekonomiki (na materialakh Iuzhnogo federal'nogo okruga). Stravropol': Stavropol'skaia servisshkola, 2002.

Alekseev, Michael, and Galina Kurlyandskaya. "Fiscal Federalism and Incentives in a Russian Region." Journal of Comparative Economics 31, no. 1 (March 2003): 20-33.

Alekseev, V. V., et al., eds. Problemnye regiony resursnogo tipa: ekonomicheskaia integratsiia Severo-vostoka, Urala, i Sibiri. Novosibirsk: IEOPP SO RAN, 2002.

Aliev, V. G., ed. Regional'nye problemy perekhodnoi ekonomiki: voprosy teorii $i$ praktiki. Moscow: Ekonomika, 2002.

Badmakhalgaev, A. Ts., and A. L. Badmakhalgaev. Ekonomicheskoe raionirovanie 
i regional'naia ekonomika v Rossii. Elista: KISEPI, 2005.

Bahry, Donna. "Ethnicity and Equality in Post-Communist Economic Transition:

Evidence from Russia's Republics." EAS 54, no. 5 (July 2002): 673-99.

Baranov, S., and T. Skuf'ina. "Analiz mezhregional'noi differentatsii i postroenie reitingov sub"ektov Rossiiskoi Federatsii." VE, no. 8, 2005, 54-75.

Berkowitz, Daniel, and David DeJong. "Russia's Internal Border." Regional

Science and Urban Economics 29, no. 5 (1999): 633-49.

Bradshaw, Michael J. Regional Patterns of Foreign Investment in Russia. London:

Royal Institute of International Affairs, 1995.

Bradshaw, Michael J., and Philip Hanson. "Understanding Regional Patterns of Economic Change in Russia: An Introduction.” CEET 10, no. 3 (September 1998): 285-304.

Bradshaw, Michael J., and D. J. B. Shaw, eds. Regional Problems During Economic Transition in Russia: Case Studies. Russian Regional Research Group Working

Paper Series, no. 1. Birmingham: University of Birmingham, 1996.

Bradshaw, Michael J., and Karen Vartapetov. "A New Perspective on Regional Inequalities in Russia." EGE 44, no. 6 (September 2003): 403-29.

Brock, Gregory J. "Foreign Direct Investment in Russia's Regions, 1993-95: Why So Little and Where Has It Gone?" Economics of Transition 6, no. 2 (April 1998): 349-61.

Bylov, Gleb, and Douglas Sutherland. "Statistical Overview." CEET 10, no. 3 (September 1998): 305-18.

Chepurnykh, N. V., A. L. Novoselov, and A. V. Merzlova. Regional'noe razvitie: sel'skaia mestnost'. Moscow: Nauka, 2005.

Chirikova, A. E., and Lapina, N. Iu. "Osnovnye napravleniia evoliutsii ekonomicheskoi regional'noi elity." Rossiiskii sotsial'no-politicheskii vestnik, no.1, 2000, 6-12.

Clark, Carol L. "The Transformation of Labor Relations in Russian Industry: The Influence of Regional Factors in the Iron and Steel Industry." PSGE 37, no. 2 (February 1996): 88-112.

Dininio, Phyllis, and Robert W. Orttung. "Explaining Patterns of Corruption in the Russian Regions." World Politics 57, no. 4 (July 2006): 500-29.

Dmitrieva, Oksana. Regional Development: The USSR and After. London: UCL Press, 1996.

The author deals primarily with the USSR and CIS. Only a small section of the book (pages 165-188) is devoted to regional development in Russia, 1989-1992.

Ekonomicheskie reformy v regionakh Rossiiskoi Federatsii: Opyt i perspektivy. 
Moscow: Institut sovremennoi politiki, 1998.

Ermolaev, M. B., and A. N. Il'chenko. Trudovaia migratsiia v regione: modeli analiza i prognozirovaniia. Moscow: Finansy i statistika, 2004.

Fedorov, L. "Regional Inequality and Regional Polarization in Russia, 1990-99." World Development 30, no. 3 (March 2002): 443-56.

Filippova, Elena, Dominik Arel', and Katrin Gusef. Etnografiia perepisi-2002. Moscow: Aviaizdat, 2003.

Filippova, N.A.Formirovanie rynka truda imekhanizm realizatsii politikizaniatosti: federal'nyi $i$ regional'nyi aspekty. Saransk: Izdatel'stvo Mordovskogo universiteta, 2001.

Gavrilenkov, Evgeny. "On Some Issues of Regional Economics in Russia." In Shugo Minagawa and Osamu Ieda, eds., Socio-Economic Dimensions of the Changes in the Slavic-Eurasian World. Sapporo: Slavic Research Center, Hokkaido University, 1996: 311-27.

Gavriliuk, V. V. Provintsial'naia molodezh'epokhi peremen. Tiumen': Izdatel'stvo TiumGU, 2005.

Glezer, O., and P. Polian, eds. Rossiia $i$ ee regiony $v$ XX veke: territoriiarasselenie-migratsiia. Moscow: OGI, 2005.

Gnevko, V. A. Regional'nye problemy innovatsionnogo razvitiia ekonomiki. St. Petersburg: IUE, 2004.

Gokhberg, M. Federal'nye okruga Rossii: analiz i perspektivy ekonomicheskogo razvitiia. Moscow: Finansy i statistika, 2002.

Golubitskaia, M. V., and I. I. Sanin. Sotsial'no-ekonomicheskaia politika regionov Rossii: otsenka sovremennogo sostoianiia, problemy, perspektivy. Moscow: Saturn, 2001.

Granberg, A., ed. Regional'noe razvitie: opyt Rossii $i$ Evropeiskogo Soiuza. Moscow: Ekonomika, 2000.

Granberg A., and Iu. S. Zaitseva. "Mezhregional'nye sopostavleniia valovogo regional'nogo produkta $\mathrm{v}$ Rossiiskoi Federatsii: podkhody i ekspertnye raschety." Voprosy statistiki, no. 2, 2003, 3-17.

Gudyrin, S. N. Gosudarstvennoe regulirovanie regional 'nogo razvitiia. Astrakhan': AGU, 2003.

Gurtov, V. A., et al. Prioritety ekonomicheskogo razvitiia sub"ektov Rossiiskoi Federatsii. Moscow: Kuchkovo pole, 2005.

Hanson, Philip. "Problemy vzaimootnoshenii tsentra i regionov v rossiiskoi ekonomicheskoi politike.” VE, no. 9, September 1994, 30-37. . "How Many Russias? Russia’s Regions and Their Adjustment to Economic 
Change." International Spectator 32, no. 1 (January-March 1997): 39-52.

- "Regional Economic Differences." In Brigitte Granville and Peter Oppenheimer, eds., Russia's Post-Communist Economy. Oxford: Oxford University Press, 2001, 419-44.

Hanson, Philip, and Michael Bradshaw, eds. Regional Economic Change in Russia.

Cheltenham: Edward Elgar, 2000.

Herrera, Yoshiko M. Imagined Economies: The Sources of Russian Regionalism.

Cambridge: Cambridge University Press, 2005.

Iandiev, M. I. Finansy regionov. Moscow: Finansy i statistika, 2002.

Institut Vostok-Zapad. Federal'nyi biudzhet i regiony: struktura finansovykh potokov. Moscow: MAKS Press, 2001.

An English version is also available: Alexei M. Lavrov and Alexei G. Makushkin, eds., The Fiscal Structure of the Russian Federation: Financial Flows between the Center and the Regions (Armonk, N.Y.: M. E. Sharpe, 2001).

Karelina, M. V. “Regional'nye profsoiuzy v sotsial'nom dialoge.” SI, no. 3, 2005, 62-70.

Katrovskii, A. P. Territorial'naia organizatsiia vysshei shkoly. Smolensk: Oikumena, 2003.

Khorev, B. S. "Economic Decentralisation and Regionalism." $S G$ 31, no. 7 (September 1990): 509-16.

Kirkow, Peter. "Ekonomicheskoe samorazvitie regionov Rossii: predvaritel'nyi sravnitel'nyi analiz Altaiskogo i Primorskogo kraev." Vestnik DORAN, no. 1, 1994, 3-11.

."Roulette zwischen Zentrum und Regionen.” 2. "Rußlands wirtschaftlicher Umbruch.” Osteuropa 46, no. 1 (January 1996): 13-29. ."Russia's Regional Puzzle: Institutional Change and Economic Adaptation." CEET 9, no. 3 (1997): 261-87.

. "Rußlands Regionen im Vergleich: Zwischen institutionellem Wandel, Finanzknappheit und wirtschaftlicher Anpassung." Osteuropa 47, no. 10/11 (October-November 1997): 1109-21.

—. "Foreign Trade Arrangements in Russia and Its Regions: Relying on Foreign Capital to Generate Growth?" PCE 11, no. 1 (March 1999): 79-98.

Kirkow, Peter, Philip Hanson, and A. Treivish. "Networks, Linkages, and Legacies:

Evidence from an Elite Survey in Six Russian Provinces in 1996-1997." CEET 10, no. 3 (September 1998): 405-13.

Kistanov, V., and N. Kopylov. Regional'naia ekonomika Rossii. Moscow: Finansy i statistika, 2002. 
Klimanov, V. V. Regional'nye sistemy i regional'noe razvitie v Rossii. Moscow: Editorial URSS, 2003.

Kozlov, L. A., et al. Regional'naia ekonomika: novye podkhody. Moscow: Nauka, 1993.

Kulapin, A. P. Sotsial'no-konfliktogennoe prostranstvo regiona. Kazan': Izdatel'stvo KGFEI, 2005.

Kuznetsova, O. V. "Regional'naia politika v Rossii v postsovetskoe vremya." Obshchestvennye nauki i sovremennost', no. 2, 2005, 67-77.

Langhammer, Rolf J., Matthew J. Sagers, and Matthias Lücke. "Regional Distribution of the Russian Federation's Export Earnings Outside the Former Soviet Union and Its Implications for Regional Economic Autonomy." PSG 33, no. 10 (December 1992): 617-34.

Lapina, N., and A. Chirikova. "Vlast' i biznes v rossiiskikh regionakh." Obshchestvo i ekonomika, no. 1, 2000, 146-57.

Lavrov, A. "Asimmetriia biudzhetnogo ustroistva Rossii: problemy i resheniia." Konstitutsionnoe pravo: vostochnoevropeiskoe obozrenie, no. 1, 1997, 4049.

- Mify i rify rossiiskogo biudzhetnogo federalizma. Moscow: Magistr, 1997.

Lavrovskii, B., and Ye. Postnikova. "Transfertnyi mekhanizm: preodolen li krizis?" $V E$, no. 8, 2005, 84-96.

Le Houerou, Philippe, and Michael Rutkowski. "Federal Transfers in Russia: Their Impact on Regional Revenues and Incomes." Comparative Economic Studies 38, no. 2-3 (Summer-Fall 1996): 21-44.

Litwack, John M. "Central Control of Regional Budgets: Theory with Applications to Russia." Journal of Comparative Economics 30, no. 1 (March 2002): 5175.

Liventsev, N., and Ia. Lisovolik. "Regional'nye aspekty prisoedineniia Rossii k VTO." MEMO, no. 5, 2002, 49-58.

Lysenko, V. N., and V. N. Podoprigorii, eds. Ekonomicheskie reformy v regionakh Rossiiskoi Federatsii: opyt $i$ perspektivy. Moscow: Institut sovremennoi politiki, 1998.

Makhmutov, Anas. "Ekonomicheskaia reforma v Rossii: regional'nye problemy."

In Shugo Minagawa and Osamu Ieda, eds., Socio-Economic Dimensions of the Changes in the Slavic-Eurasian World. Sapporo: Slavic Research Center, Hokkaido University, 1996, 328-45.

Mau, Vladimir, and Konstantin Yanovskiy. "Political and Legal Factors of Economic 
Growth in Russian Regions." PCE 14, no. 3 (September 2002): 321-39.

McAuley, Alastair. "The Determinants of Russian Federal-Regional Fiscal Relations: Equity or Political Influence?” EAS 49, no. 3 (May 1997): 43144.

McIntyre, Robert. "Regional Stabilisation Policy under Transitional Period Conditions in Russia: Price Controls, Regional Trade Barriers and Other Local-level Measures.” EAS 50, no. 5 (July 1998): 859-73.

Mnatsakanian, A. G. Transformatsiia biudzhetnykh otnoshenii na regional'nom urovne. Kaliningrad: Izdatel'stvo Baltiiskogo instituta ekonomiki i finansov, 2003.

Murakami, Takashi, and Shinichiro Tabata, eds. Russian Regions: Economic Growth and Environment. Sapporo: Slavic Research Center, Hokkaido University, 2000.

Murakhovskii, N. V. Transformatsiia kak forma preobrazovaniia ekonomiki Rossii $v$ perekhodnyi period. Omsk: Izdatel'stvo Omskogo gosudarstvennogo universiteta, 2004.

Pchelintsev, O. S. Regional'naia ekonomika $v$ systeme ustoichego razvitiia. Moscow: Nauka, 2004.

Perov, G. O. Depressivnyi rossiiskii region: tendentsii razvitiia i upravlenie sotsial'no-ekonomicheskimi izmeneniiami. Rostov-on-Don: RGU, 2002.

Peterson, D. J. "The Regionalization of Russia's Economy and Its Impact on the Environment and Natural Resources." In Peter J. Stavrakis et al., eds., Beyond the Monolith: The Emergence of Regionalism in Post-Soviet Russia. Washington, D.C: The Woodrow Wilson Center Press, 1997, 145-64.

Piliasov, A. "Politicheskie i ekonomicheskie faktory razvitiia rossiiskikh regionov." $V E$, no. 5, 2003, 67-82.

Plotitsyna, A. A. Regional'nye rynki truda v sovremennoi Rossii: teoriia i praktika. Moscow: Finansovaia akademiia, 2004.

Polenev, A. O. Mezhregional'naia differentsiatsiia $i$ metodologiia analiza $i$ gosudarstvennogo regulirovaniia. Moscow: Editorial URSS, 2003.

Popov, Vladimir. "Fiscal Federalism in Russia: Rules versus Electoral Politics." Comparative Economic Studies 46, no. 4 (December 2004): 515-41.

Prokhozhev, A. A., and I. A. Karmanova. Regiony Rossii: sotsial'noe razvitie $i$ bezopasnost'. Moscow: Novosti, 2004.

Places particular emphasis on the Central Federal District.

Romanova, L. A. Ekonomika regiona: Samostoiatel'nost' $i$ gosudarstvennoe regulirovanie. Perm': Izdatel'stvo Permskogo universiteta, 1994. 
Rozanova, T. G. Ekonomika regiona: teoriia i praktika. Moscow: Izdatel'stvo MGTU im. Baumana, 2004.

Rynochnaia transformatsiia $v$ Rossii: politicheskii $i$ ekonomicheskii potentsial regionov. Issledovatel'skii proekt. Moscow: IMEIPI RAN, 1997.

Schwanitz, Simone. Rußlands Regionen als neue Machtzentren: föderale und regionale Entscheidungsstrukturen am Beispiel der Privatisierung des Rüstungssektors. Baden-Baden: Nomos Verlagsgesellschaft, 1998.

Segbers, Klaus, ed. Explaining Post-Soviet Patchworks. Vol. 3. The Political Economy of Regions, Regimes, and Republics. Aldershot: Ashgate, 2001.

Among the chapters particular attention is given to St. Petersburg, Kalingrad, Komi, West Siberia, and Moscow, as well as to comparative themes.

Selm, Bert van. "Economic Performance in Russia's Regions." EAS 50, no. 4 (June 1998): 603-18.

Shevtsov, Iu. "Evoliutsiia rossiiskogo biudzhetnogo federalizma." VE, no. 8, 2005, $76-83$.

Sidorova, N. P. Fenomen bednosti v regional'nom izmerenii. Khabarovsk: Izdatel'stvo DVAGS, 2005.

Slider, Darrell. "Privatization in Russia's Regions." PSA 10, no. 4 (OctoberDecember 1994): 367-96.

Stepanov, A. G. Gosudarstvennoe regulirovanie ekonomiki regiona. Moscow: Finansy i statistika, 2004.

Sutherland, D., and P. Hanson. "Structural Change in the Economies of Russia's Regions." EAS 48, no. 3 (May 1996): 367-92.

Tabata, Shinichiro. "Transfers from Federal to Regional Budgets in Russia: A Statistical Analysis." PSGE 39, no. 8 (October 1998): 447-61.

Treisman, Daniel. "The Politics of Intergovernmental Transfers in Post-Soviet Russia." British Journal of Political Science 26, no. 3 (July 1996): 299-335. -. "Deciphering Russia's Federal Finance: Fiscal Appeasement in 1995 and 1996." EAS 50, no. 5 (July 1998): 893-906.

Twigg, Judyth. "Russian Health Care Reform at the Regional Level: Status and Impact." PSGE 42, no. 3 (April-May 2001): 202-19.

"Social Capital in Russia's Regions." In Judyth L. Twigg and Kate Schecter, eds., Social Capital and Social Cohesion in Post-Soviet Russia. Armonk, N.Y.: M. E. Sharpe, 2003, 168-88.

Wallich, Christine I., ed. Russia and the Challenge of Fiscal Federalism. Washington, D. C.: The World Bank, 1994.

Westland, Hans, Alexander Granberg and Folke Snickars, eds. Regional 
Development in Russia: Past Policies and Future Prospects. Cheltenham: Edward Elgar, 2000.

Vardomskii, L. Otkrytie rossiiskoi ekonomiki: regional'noe izmerenie. Moscow: IMEEiPI RAN, 1997.

Zhuravskaya, Yekaterina. "Incentives to Provide Local Public Goods: Fiscal Federalism Russian Style." Journal of Public Economics 76, no. 3 (2000): 337-68.

Zinurova, R. I. "Osobennosti reproduktivnogo povedeniia v rossiiskikh regionakh." SI, no. 3, 2005, 82-87.

Zubarevich, N. V. Sotsial'noe razvitie regionov Rossii: problemy $i$ tendentsii perekhodnogo perioda. Moscow: Editorial URSS, 2003.

Gives particular attention to rural/urban, income, gender and educational differences. A second edition was published in 2005.

Zubarevich, Natal'ia. "Krupnyi biznes i regiony.” SM, no. 1, 2005, 64-79.

\section{Individual Regions}

Titles are ordered by subject of the Russian Federation; headings for areas not coinciding with individual subjects, such as Siberia or the Far East, are in square brackets. Works that contain substantial sections on more than one subject are listed under each of the respective subject headings. $(\boldsymbol{R} .=$ Respublika $)$

\section{R. Adygeia}

Khadzhebeikov, R. G. Respublika Adygeia: problemy reformirovaniia obshchestva v 80-90 gg. Maikop: Adygeiskoe respublikanskoe knizhnoe izdatel'stvo, 1997.

See also: Northern Caucasus.

\section{R. Altai}

Goncharova, O. A., ed. Etnosotsial'nye problemy Gornogo Altaia v XX veke: materialy nauchno-prakticheskoi konferentsii, posviashchennoi 50-letiiu Gorno-Altaiskogo gosudarstvennogo universiteta 28 aprelia $1999 \mathrm{~g}$. GornoAltaisk: Gorno-Altaiskii gosudarstvennyi universitet, 2000.

\section{Altaiskii krai}

Kirkow, Peter. "Das Altaj-Gebiet zwischen Autonomiebestrebung und wirtschaftlicher Ausdifferenzierung: Eine Fallstudie.” Osteuropa 44, no. 4 
(April 1994): 367-84.

. "Regional Politics and Market Reform in Russia: The Case of the Altai." EAS 46, no. 7 (1994): 1163-87.

Kupershtokh, V. L., et al. "Problemy problemnogo regiona (rezul'taty issledovaniia territorii Altaiskogo kraia)." EKO, no. 4, 1997, 96-112.

Rastov, Iu. E. "Protestnoe povedenie v regione." SI, no. 6, 1996, 40-49.

Shubkin, V. N. "Vlastvuiushchie elity Sibiri (na materialakh Altaiskogo kraia)." Sotsiologicheskii zhurnal, no. 1, 1995, 147-55.

-. "The Dominant Elites of Siberia: The Altai Region." In Vladimir Shlapentokh et al., eds., The New Elite in Post-Communist Eastern Europe. College Station: Texas A\&M University Press, 1999, 251-64.

\section{Arkhangel'skaia oblast'}

Pliusnin, Iu. M. Pomory: naselenie poberezhii Belogo moria v gody krizisa (19952001). Novosibirsk: RITS NGU, 2003.

\section{Astrakhanskaia oblast’}

"Vorota v Kaspii: Astrakhanskaia oblast'." Rossiia, no. 7, 1997, 53-66.

Zeletdinova, E. A. "Politicheskie orientatsii Astrakhanskoi oblasti." Vlast', no. 8, 1999, 20-24.

. 'Astrakhanskaia oblast': analiz rezul'tatov parlamentskikh i prezidentskikh vyborov." Polis, no. 4, 2000, 123-29.

\section{R. Bashkortostan}

Akat'ev, Iu. V., et al. "Tendentsii razvitiia sotsial'noi struktury bashkirskogo sela." SI, no. 7, 1998, 54-59.

Akchurin, B. G. "Dukhovnoe zdorov'e sel'skogo naseleniia Bashkortostana." SI, no. $12,2001,103-7$.

Alexander, James, and Jörn Grävingholt. "Evaluating Democratic Progress inside Russia: The Komi Republic and the Republic of Bashkortostan." Dem 9, no. 4 (Winter 2002): 77-105.

Burkhanova, F. B. Sovremennyi brak v Bashkortostane. Ufa: RIO BashGU, 2004. Fattakhov, R. V. "Deviat' let strategicheskikh problem ekonomiki Bashkortostana." Federalizm: teoriia, praktika, istoriia, no. 2, 2000, 139-58.

Frank, A. Islamic Historiography and 'Bulghar' Identity among the Tatars and Bashkirs of Russia. Leiden: Brill, 1998. 
Golubko, M. N. "Opyt i uroki soverenizatsii (na materialakh Bashkortostana i

Tatarstana)." Otechestvennaia istoriia, no. 2, 1995, 17-52.

Gorenburg, Dmitry. "Identity Change in Bashkortostan: Tatars into Bashkirs and Back." Ethnic and Racial Studies 22, no. 3 (May 1999): 554-80.

Graney, Katherine E., "Education Reforn in Tatarstan and Bashkortostan: Sovereignty Projects in Post-Soviet Russia.” EAS 51, no. 4 (June 1999): 61132.

Grävingholt, Jörn. "Bashkortostan: A Case of Regional Authoritarianism." In Cameron Ross, ed., Regional Politics in Russia. Manchester: Manchester University Press, 2002, 177-92.

Hale, Henry E. "Bashkortostan: The Logic of Ethnic Machine Politics and Democratic Consolidation." In Timothy J. Colton and Jerry F. Hough, eds., Growing Pains: Russian Democracy and the Election of 1993. Washington. D.C.: Brookings Institution Press, 1998, 599-636.

- "Machine Politics and Institutionalized Electorates: A Comparative Analysis of Six Duma Elections in Bashkortostan." JCSTP 15, no. 4 (December 1999): 70-110.

Ilishev, Ildus G. "Nation-Building and Minority Rights in Post-Soviet Russia: The Case of Bashkortostan." In Yaacov Ro'i, ed., Democracy and Pluralism in Muslim Eurasia. London: Cass, 2004, 307-28.

Kazakbaev, R. Kh. “Ustanovki molodezhi Bashkorostana na zhizn' v sele.” SI, 11, 2005, 77-81.

Kulchik, Iu. G. Etnopoliticheskie protsessy v Bashkortostane: informatsionnoanaliticheskii obzor. Moscow: Kul'turnaia initsiativa, 1992.

Kuzeev, R. G. "Natsional'nye dvizheniia i federalizm v Rossii." Etnograficheskoe obozrenie, no. 6, 1993, 46-59.

—. Demokratiia, grazhdanstvennost', etnichnost'. Moscow: Tsentr po izucheniiu mezhnatsional'nykh otnoshenii IEA RAN, 1999.

Le Torrivellec, Xavier. "Le crépuscule des ethnies: Le recensement russe de 2002 en République du Bachkorstostan." Revue d'études comparatives est-ouest 34, no. 4 (December 2003): 29-58.

Matsuzato, K., ed. Regiony Rossii: khronika i rukovoditeli. Vol. 8. Respublika Marii El, Chuvashskaia Respublika, Respublika Bashkortostan. SRC Occasional Papers, special issue. Sapporo: Slavic Research Center, Hokkaido University, 2003, 212-342.

Nasibullin, R. T., and I. Khodzhaev. “Zemel'naia reforma v Bashkortostane.” SI, no. $8,1999,32-34$. 
Osobennosti ustoichego razvitiia respubliki Bashkortostana: sbornik nauchnykh trudov. Ufa: RIO BashGU, 2003.

Rabinovich, Igor', and Sergei Fufaev. “Khoziain: shtrikhi k politicheskomu portretu Murtuzy Rakhimova." Pro et Contra, no. 2, 1997, 71-84.

“Respublika Bashkortostan.” Zhizn'natsional'nostei, no. 5, 1996, 2-96.

"Respublika Bashkortostan: sotsiologiia peremen." SI, no. 8, 1997, 3-108.

A collection of related articles.

Safargaleev,D., and S.Fufaev. “Likibashkirskoigosudarstvennosti." Konstitutionnoe pravo: vostochnoevropeiskoe obozrenie, no. 2 (19), 1997, 79-85.

Safin, F. G. "Iazykovoi aspekt suverenizatsii v Bashkortostane." Otechestvennaia istoriia, no. 4-5, 1994, 159-80.

_. Iz khroniki etnicheskoi mobilizatsii: Respublika Bashkortostan. Moscow: Tsentr po izucheniiu mezhnatsional'nykh otnoshenii instituta etnologii i antropologii im. N. N. Miklukho-Maklaia, 1999.

__. "Kontury etnosotsial'noi zhizni v Bashkortostane." SI, no. 10, 2001, 9498.

Selivanov, A. I. "Bashkortostan-'neizvestnaia zemlia' na politicheskoi karte Rossii." Polis, no. 6, 1995, 138-44.

Shafikov, M. T. Nauchno-obrazovatel'nyi potentsial regiona: sushchnost', struktura, sostoianie i dinamika. Ufa: Gilem, 2002.

Valiullin, Shamil. "Bashkortostan and the Search for a National Identity: The History and Politics of Bashkir Separatism.” Slovo 10, no. 1-2 (1998): 14977.

Vorobev, D. V., and D. V. Grushkin. Ideia natsional'noi gosudarstvennosti $i$ problemy etnicheskoi diskriminatsii v Respublike Bashkortostan. Moscow: Zvenya/Memorial, 1999.

Zakirova, V. M. “Bashkirskaia 'svakha'—opyt, rezul'taty, problemy.” SI, no. 9, 2004, 91-94.

\section{Belogorodskaia oblast'}

Borodulina, N. A. "Belgorodskaya oblast': ekonomika, partii, lidery." Vlast', no. 12, 1995, 36-42.

Revtov, E. V. “Regional'noe zakonodatel'noe sobranie: osobennosti formirovaniia i funktsionirovaniia." SI, no. 9, 2003, 79-84. 


\section{Brianskaia oblast'}

Lallemand, Jean-Charles. "Politics for the Few: Elites in Bryansk and Smolensk." PSA 15, no. 4 (October-December 1999): 312-35.

\section{R. Buriatiia}

Amogolonova, D. D., and T. D. Skrynnikova. "Prostranstvo ideologicheskogo diskursa postsovetskoi Buriatii." Polis, no. 2, 2005, 53-63.

Balkhanov, I. G. "Sotsialializatsiia i etnichnost' buriat v gorodskikh usloviiakh." SI, no. 2, 2003, 55-59.

Biltrikova, A. V. Buriatskaia natsional'naia intelligentsiia na sovremennom etape. Ulan-Ude: Izdatel'stvo Buriatskogo nauchnogo tsentra SO RAN, 2001.

"Buriatiia." $R F$, no. 21, 1995, 25-45.

Dagbaev, E. D. Pressa $i$ natsional'no-politicheskii protsess regiona: opyt politicheskogo i sotsiologicheskogo analiza. Ulan-Ude: Rossiiskaia akademiia nauk, Sibirskoe otdelenie, Buriatskii nauchnyi tsentr, 1995.

Dobrynina, M. I. Russkaia intelligentsiia v Buriatii. Ulan-Ude: Izdatel'stvo Buriatskogo gosuniversiteta, 2004.

Elaev, A. Buriatiia: put' $k$ avtonomii $i$ gosudarstvennosti. Moscow: IVF Antal, 1994.

- Buriatskii narod: stanovlenie, razvitie, samoopredelenie. Moscow and Ulan-Ude: Vestkom, 2000.

Elaeva, I.E. "Buriatskaiaintelligentsia: dominanty etnicheskogo samoopredeleniia." Ekonomicheskoe obozrenie, no. 2, 1998, 126-39.

Iril'deeva, L. G. "Natsional'no-kul'turnye ob"edineniia etnicheskikh men'shinstv Respubliki Buriatiia." Etnograficheskoe obozrenie, no. 5, 2000, 129-43.

Karnyshev, A. D. Mezhetnicheskoe vzaimodeistvie v Buriatii: sotsial'naia psikhologiia, istoriia, politika. Ulan-Ude: Izdatel'stvo Buriatskogo gosudarstvennogo universiteta, 1997.

Khamutaev, V. A. Buriat-mongol'skii vopros: istoriia, pravo, politika. Ulan-Ude: Garmaev, 2000.

Osinsky, I. I. "Traditsional'nye tsennosti v dukhovnoi kul'ture buriatskoi natsional'noi intelligentsii.” SI, no. 3, 2001, 80-83.

Osinsky, I. I., and E. V. Gylykova. Buriatskaia gorodskaia sem 'ia na rubezhe XXXXI vekov: sotsiologicheskii analiz. Ulan-Ude: BGU, 2003.

Potapov, L. V., and S. Liubanovskaia. "Buriatiia: problemy i perspektivy." 
Ekonomist, no. 9, 1997, 36-42.

Randalov, Iu. B., et al., eds. Natsional 'naia intelligentsiia, dukhovenstvo, i problemy sotsial'nogo, natsional'nogo vozrozhdeniia narodov Respubliki Buriatiia. Ulan-Ude: Buriatskii nauchnyi tsentr SO RAN, 1995.

—. Problemy novogo etapa kul'turnogo vozrozhdeniia narodov Buriatii: po materialam sotsiologicheskikh issledovanii. Ulan-Ude: Buriatskii nauchnyi tsentr SO RAN, 2001.

"Respublika Buriatiia: Vorota na Vostok." MZh, no. 5-6, 1993, 5-160.

Stroganova, E. A. "Natsional'no-kul'turnoe vozrozhdenie v Buriatii: vzgliad izvnutri sela." Etnograficheskoe obozrenie, no. 1, 1997, 86-99.

- Buriatskoe natsional'no-kul'turnoe vozrozhdenie: konets 80kh-seredina 90kh godov XX veka. Moscow: Natalis, 2001.

Tivanenko, A. Zabaikal'skii tupik: kto vinovat v obnishchanii Buriatii i kak nam zhit'dal'she? Moscow: RITs MDK, 2005.

Zateev, V. I., and N. S. Babushkina. "Dvuiazychie v sovremennoi Buriatii." SI, no. 10, 2000, 58-64.

Zhalsanova, V. G. Politicheskaia elita Buriatii na sovremennom etape. Ulan-Ude: BNTs SP RAN, 2003.

\section{Caucasus}

Cornell, Svante E. "Ethnic Relations and Democratic Transition in the NorthWestern Caucasus." In Yaacov Ro'i, ed., Democracy and Pluralism in Muslim Eurasia. London: Cass, 2004, 343-58.

Dzidzoev, V. D. Natsional'nye otnosheniia na Kavkaze. Vladikavkaz: Ir, 1995.

Gadzhiev, K. S. Geopolitika Kavkaza. Moscow: Mezhdunarodnye otnosheniia, 2003.

Kan Sam Gu. “Genezis konfliktov v Zakazkaz'e i rol' Rossii.” MEMO, no. 10, 2002, 93-102.

\section{R. Chechnia}

Baskhanova, L. S.-E. Chechnia: obshchestvennoe mnenie $v$ usloviiakh etnopoliticheskogo konflikta. Rostov-on-Don: Izdatel'stvo Tsentra sistemnykh regional'nykh isslevodaniia i prognozirovaniia, 2004.

Basnukaev, M. "Problemy politiko-ekonomicheskogo razvitiia Chechni v postsovetskii period." MEMO. no. 12, 2001, 85-93.

Basnukaev, Musa, and Magomed Iriskhanov. "Obshchestvennoe mnenie o situatsii v Chechenkoi Respublike." Vestnik obshchestvennogo mneniia, no. 4 (78), 
July-August 2005, 19-29.

Bennett, Vanona Crying Wolf: The Return of War to Chechnya. London: Picador, 1998.

A journalist's account, strongly pro-Chechen. An updated edition appeared in 2001.

Chechentsy: istoriia i sovremennost'. Ed. Iu. A. Aidaeva. Moscow: Mir domu tvoemu, 1996.

Chechnia i Rossiia: obshchestva i gosudarstva. Ed. D. E. Furman. Moscow: Fond Andreia Sakharova, 1998.

Cornell, Svante E. "International Reactions in Massive Human Rights Violations:

The Case of Chechnya." EAS 51, no. 1 (January 1999): 85-100.

- Small Nations and Great Powers: A Study of Ethnopolitical Conflict in the Caucasus. London: RoutledgeCurzon, 2000.

Degoev, Vladimir. "Chechenskaia voina prezhde i teper'." Druzhba narodov, no. 1, 2000, 163-75.

Derluguian, Georgi M. "Ethnofederalism and Ethnonationalism in the Separatist

Politics of Chechnya and Tatarstan: Sources or Resources?" International Journal of Public Administration 22, no. 9-10 (September-October 1999): $1387-1428$.

Dudaeva, Anna. Million pervyi. Moscow: Ul'tra. Kul'tura, 2003.

A memoir of General Dudaev, by his widow.

Dunlop, John B. Russia Confronts Chechnya: Roots of a Separatist Conflict.

Cambridge: Cambridge University Press, 1998.

First of an intended two volumes.

"Eksperty spetssluzhb o polozhenii v Chechne." Dialog, no. 7, 2000, 77-87.

Evangelista, Matthew. The Chechen Wars: Will Russia Go the Way of the Soviet Union? Washington, D.C.: Brookings Institution, 2002.

Feigin, M. "Vtoraia chechenskaia voina." Novyi mir, no. 12, 1995, 159-71.

Gall, Carlotta, and Thomas de Waal. Chechnya: A Small Victorious War. London: Pan, 1997.

Gammer, Moshe. The Lone Wolf and the Bear: Three Centuries of Chechen Defiance of Russian Rule. London: Hurst, 2005.

German, Tracy C. Russia's Chechen War. London: RoutledgeCurzon, 2003.

Giuliano, Elise. "Islamic Identity and Political Mobilization in Russia: Chechnya and Dagestan Compared." Nationalism and Ethnic Studies 11, no. 2 (Summer 2005): 195-220.

Goltz, Thomas. Chechnya Diary: A War Correspondent's Story of Surviving the War in Chechnya. New York: Thomas Dunne Books, 2003. 
Hughes, James. "Chechnya: Understanding the Causes of a Protracted Post-Soviet Conflict." Civil Wars 4, no. 4 (Winter 2001): 11-48.

Kagarlitsky, Boris. "Chto s nami proiskhodit, ili uroki Basaeva." SM, no. 8, 1995, $18-25$.

- "Chechnia: predvaritel'nye itogi." SM, no.1, 1997, 33-44.

Khaikin, S. R., and N. A. Cherenkova. "Izuchenie obshchestvennogo mneniia Chechenskoi Respubliki.” Mir Rossii, no. 3, 2003, 3-34.

Khasbulatov, Ruslan. Razmyshleniia o voine i mire. Moscow: Graal', 2002.

- Vlast': mech i kovarstvo. Moscow: Graal', 2002.

. Vzorvannaia zhizn'. Moscow: Graal', 2002.

. Bol'shaia strategicheskaia voina. Moscow: Graal', 2003.

- Chuzhie: istoriko-politicheskii ocherk o chechentsakh $i$ ikh gosudarstvennosti. Moscow: Graal', 2003.

All these volumes are subtitled Kreml' $i$ rossiiskaia-chechenskaia voina; the author, an economist and former parliamentary speaker, is himself a Chechen.

Kosikov, I. G. "Chechenskaia Respublika segodnia." Vlast', no. 5, 2001, 53-60.

Kosikov, I. G., and L. S. Kosikova. "Chechenskaia Respublika: itogi i problemy postsovetskoisotsial'no-ekonomicheskoievoliutsii."Rossiiskiiekonomicheskii zhurnal, no. 8, 2000, 36-51 and no. 10, 2000, 22-36.

Kratkaia annotirovannaia bibliografiia chechenskogo konflikta. Moscow: RAN, 2002.

Kravchenko, I. N. Chechenskii krizis: prichiny, kharakter, posledstviia (90-e gody $X X$ v.). Vladikavkaz: SOGU, 2004.

Krech, Hans. Der russische Krieg in Tschetschenien (1994-1996): Ein Handbuch. Berlin: Köster, 1997.

—. Der zweite Tschetschenien-Krieg (1999-2002): Ein Handbuch. Berlin: Köster, 2002.

Kriminal'nyi rezhim. Chechnia, 1991-95 g.g.: fakty, dokumenty, svidetel'stva. Moscow: Kodeks, 1995.

Prepared under the auspices of the Ministry of Internal Affairs.

Kudriavtsev, Alexei. "Democratic Values and Political Reality in Chechnya, 19911999." In Yaacov Ro'i, ed., Democracy and Pluralism in Muslim Eurasia. London: Cass, 2004, 359-74.

Lapidus, Gail. "Contested Sovereignty: The Tragedy of Chechnya." International Security 23, no. 1 (Summer 1998): 5-49.

. "The Dynamics of Secession in the Russian Federation: Why Chechnya?" In Mikhail A. Alexseev, ed., Center-Periphery Conflict in Post-Soviet Russia: 
A Federation Imperiled. New York: St. Martin's, 1999, 47-94.

. "Putin's War on Terrorism: Lessons from Chechnya." PSA 18, no. 1 (January-March 2002): 41-48.

Lieven, Anatol. Chechnya: Tombstone of Russian Power. New Haven, Conn.: Yale University Press, 1998.

Luchin, V. "Chechenskii vopros: konstitutionnyi aspekt." Dialog, no. 10, 1995, $19-23$.

Mäkinen, Sirke. "Russia's Integrity: Russian Parties of Power and the Yabloko Association on Russo-Chechen Relations, 1999-2001." EAS 56, no. 8 (December 2004): 1157-89.

Malashenko, Aleksei, and Dmitrii Trenin. Vremia Iuga: Rossiia v Chechne, Chechnia v Rossii. Moscow: Gel'fand, 2002.

An English translation is also available: Dmitri V. Trenin and Aleksei V. Malashenko, Russia's Restless Frontier: The Chechnya Factor in Post-Soviet Russia (Washington, D.C.: Carnegie Endowment, 2004).

Medvedev, R. A. "“Vashno, chtoby Chechnia nikogda i nikem ne ispol'zovalas' kak platsdarm dlia napadeniia na Rossiiu. ..." Voenno-istoricheskii zhurnal, no. 2, 2001, 11-17 and no. 3, 2001, 3-8.

Mizulina, E. "Chechenskii krizis i konstitutsionnoe pravosudie." SM, no. 9, 1995, 20-30.

Nivat, Anne. Chienne de guerre: A Woman Reporter Behind the Lines of the War in Chechnya. New York: Public Affairs, 2001.

Nukhaev, Kh.-A. "Chechnya i Rossiya: odno tesnnostnoe prostranstvo-dve obshchestvennye sistemy." Zvezda, no. 4, 2003, 168-89.

Pain, E. "Chechnia i drugie konflikty v Rossii." MZh, no. 9, 1998, 91-101.

Pain, E., and A. Popov. "Chechenskaia politika Rossii s 1991 po 1994 gg." MEMO, no. $5,1995,19-32$.

Politkovskaia, Anna. Dirty War: A Russian Reporter in Chechnya. Trans. John Crowfoot. London: Harvill, 2001.

- Chuzhaia voina, ili zhizn'za shlagbaumom. Moscow: Memorial, 2002.

A collection of Politkovskaya's articles published during 2001-02.

. Vtoraya Chechenskaya. Moscow: Zakharov, 2002.

A second edition appeared in 2003. Translated as Small Corner of Hell: Dispatches from Chechnya, by Alexander Burry and Tatiana Tulchinsky (Chicago: University of Chicago Press, 2003).

Perepelkin,L. S. “Chechenskaia Respublika: sovremennaia sotsial'no-politicheskaia situatsiia.” Ekonomicheskoe obozrenie, no. 1, 1994, 3-15. 
Popov, A. A. “"Mify dumaiut liud'mi', ili sem' voprosov o chechenskoi voine." Druzhba narodov, no. 8, 2000, 117-33.

Popov, V. "K voprosu konstitutsionnogo statusa Chechni." Dialog, no. 7, 2000, $88-90$.

Proskurjakov, Aleksandr. "Tschetenchenien: Krieg ohne Ende? Strategie des asymmetrischen Kampfs." Osteuropa 53, no. 4 (April 2003): 452-63.

. "Mediatisierung im Tschenenien-Krieg: Eskalation im asymmetrischen Krieg." Osteuropa 54, no. 8 (August 2004): 50-61.

Razumov, A. "Maloi krov'iu, moguchim udarom!" SM, no. 11, 1999, 17-22.

Rossiia-Chechnia: tsep' oshibok i prestuplenii. Ed. O. P. Orlov and A. V. Cherkasov.

Moscow: Zven'ia, 1998.

Prepared by Memorial; a documentation of human rights abuses.

"Rossiia cherez prizmu Chechenskoi voiny." Znanie-sila, no. 2, 2000, 20-38.

Rossiia i Chechnia, 1990-1997 gody: dokumenty svidetel'stvuiut. Ed. I. N.

Eremenko and Iu. D. Novikov. Moscow: RAU-Universitet, 1997.

Rossiia i Chechnia: 200-letnaia voina. Ed. A. Blinskii. St. Petersburg: Satis', 2000.

A historical overview, largely documentary in character.

Rossiia i Chechnia: poiski vykhoda. St. Petersburg: Zvezda, 2003.

A collection of articles originally published in the journal Zvezda.

"Rossiia na Kavkaze." Rodina: spetsial'nyi vypusk, no. 1-2, 2000, 3-223.

Samartin, E. S. "Chechenskii gosudarstvennyi eksperiment: illiuzii i real'nost'." Nauchnaia mysl'Kazkaza, no. 1, 1995, 64-72.

Savateev, A. D. "Islam i politika v Chechenskoi Respublike." Obshchestvennye nauki i sovremennost', no. 2, 2000, 84-95.

Seely, Robert. The Russian-Chechen Conflict, 1800-2000: A Deadly Embrace. London: Cass, 2001.

Serebriannikov, V. V. "Voina v Chechne: prichiny i kharakter." Sotsial'nopoliticheskii zhurnal, no. 3, 1995, 11-23.

_. "Kosovskaia i Chechenskaia voiny v massovom soznanii Rossii i Zapada." Vlast', no. 3, 2000, 55-63; also in SI, no. 10, 2000, 66-71.

Silinsky, Vladimir. "Chechenskaia Respublika: trudnyi put' k miru i stabil'nosti." Vlast', no. 5, 2002, 3-8.

Smith, Sebastian. Allah's Mountains: The Battle for Chechnya. London: Tauris, 1998.

A revised edition appeared in 2005.

Soldner, Markus. Russlands Čečnja-Politik seit 1993. Münster: LIT-Verlag, 1999. 
Sycheva, L. A. "Neizvestnyi narod." Moskva, no. 8, 2000, 25-29.

Tishkov, V. "Ambitsii liderov i nadmennost' sily: zametki o chechenskom krizise." $S M$, no. 1, 1995, 19-28.

The author is director of the Institute of Ethnography of the Russian Academy of Sciences and for a short period held ministerial office.

. "Sem' variantov: zametki o vykhode iz chechenskogo krizisa." $S M$, no. 5 , 1996, 43-55.

. "Chechenskii krizis (sotsial'no-politicheskii analiz)." In Tishkov, Ocherki teorii i politiki etnichnosti v Rossii. Moscow: Russkii mir, 1997, 405-77.

—_. "Geopolitika Chechenskoi voiny." SM, no. 4, 1997, 65-74.

. Obshchestvo v vooruzhennom konflikte (etnografiia chechenskoi voiny). Moscow: Nauka, 2001.

- Chechnya: Life in a War-Torn Society. Berkeley and Los Angeles: University of California Press, 2004.

Troshev, Gennadii N. Moia voina: chechenskii dnevnik okopnogo generala. Moscow: Vagrius, 2001.

- Chechenskii retsidiv: zapiski komanduiushchego. Moscow: Vagrius, 2003.

A sequel, elicited by what General Troshev regarded as the surprising success of his first volume.

Tupikin, Gennadii.“Kakoi rukovoditel' nuzhen Chechne?” Vlast', no. 12, 2002, 55-58.

Wilhelmsen, Julie. "Berween a Rock and a Hard Plce: The Islamisation of the Chechen Separatist Movement." EAS 57, no. 1 (January 2005): 35-59.

Zhurnalisty na Chechenskoi voine: fakty, dokumenty, svidetel'stva. Moscow: Prava cheloveka, 1995.

On violations of the rights of journalists during 1994-95.

\section{Cheliabinskaia oblast’}

Matsuzato, Kimitaka. "The Split and Reconfiguration of Ex-Communist Party Factions in the Russian Oblasts: Chelyabinsk, Samara, Ulyanovsk, Tambov, and Tver (1991-95)." Dem 5, no. 1 (Winter 1997), 53-88.

Tsukerman, V. S. "Sotsial'no-kul'turnye prodpochteniia v Cheliabinskoi oblasti." SI, no. 10, 1997, 104-08.

\section{Chukot outonomous okrug}

Thompson, Niobe. "Migration and Resettlement in Chukotka: A Research Note." 
EGE 45, no. 1 (January-February 2004): 73-81.

\section{R. Chuvashia}

"Chuvashskaia respublika." $R F$, no. 2, 1997, 25-40.

Matsuzato, K., ed. Regiony Rossii: khronika i rukovoditeli. Vol. 8. Respublika Marii El, Chuvashskaia Respublika, Respublika Bashkortostan. SRC Occasional Papers, special issue. Sapporo: Slavic Research Center, Hokkaido University, 2003, 119-211.

Sharkov F. I. Sotsial'naia politika v sub"ektakh Rossiiskoi Federatsii: voprosy teorii i praktiki. Cheboksary: Chuvashskoe knizhnoe izdatel'stvo, 1998.

Draws on empirical research in the Chuvash Republic; deals with incomes, employment, educational and cultural issues.

Silliaste, G. G. 'Russkaia sem'ia v novoi mezhnatsional'noi situatsii." SI, no. 3, 1995, 101-09.

Trifonova, Z. A. Gorodskoe naselenie v Chuvashii. Cheboksary: Izdatel'stvo Chuvashskogo universiteta, 2004.

Vasil'eva, O. Chuvashskaia Respublika: model' etnologicheskogo monitoringa. Moscow: Institut etnologii i antropologii RAN, 2000.

\section{R. Dagestan}

Abdulazatov, Z. M. "Sovremennaia religioznaia situatsiia v Dagestane (protsessy musulmanskogo vozrozhdeniia)." Etnicheskoe obozrenie, no. 6, 2002, 6168.

Abdullaev, M. Etnopoliticheskie protsessy v respublike Dagestan: istoriko-pravovye usloviia evoliutsii. Makhachkala: DGU, 2004.

Arutiunov, S. A., et al., eds. Narody Dagestana. Moscow: Nauka, 2002.

Ataev, M. M., and N. M. Gadzhiev. Etnopoliticheskie protsessy v postsovetskom Dagestane. Makhachkala: Dagestan XXI vek, 1997.

Bobrovnikov, V. O. "Dagestan: mezhdu Rossiei i musul'manskim Vostokom." Vestnik Evrazii, no. 1, 1995, 129-38.

. "Islam i sovetskoe nasledie v kolkhozakh Severo-Zapadnogo Dagestana." Etnicheskoe obozrenie, no. 5, 1997, 132-42.

Brushtein, I. "Dagestanskie etiudy." SM, no. 10, 2005, 117-29, and no. 11, 2005, $129-44$.

Byzov, L. G., and E. A. Kulagina. "Dagestan—potentsial'naia 'goriachaia tochka' na karte Rossii." Monitoring obshchestvennogo mneniia, no. 4 (76) OctoberDecember 2005, 108-14. 
Chenciner, Robert. Daghestan: Tradition and Survival. London: RoutledgeCurzon, 1997.

"Dagestan." Ekho Kavkaza, no. 1, 1997, 1-104.

"Dagestan: sotsial'nyi portret sela." AAS, no. 4, 1993, 28-45.

Gasanov, N. N. "Russkii vopros v Dagestane." Sotsial'no-politicheskii zhurnal, no. 11-12, 1994, 45-49.

Giuliano, Elise. "Islamic Identity and Political Mobilization in Russia: Chechnya and Dagestan Compared." Nationalism and Ethnic Studies 11, no. 2 (Summer 2005): 195-220.

Gusher, A. "Dagestan: novyi ochag napryazhennosti." AAS, no. 2, 1998, 56-61. ."KliuchkKavkazu:politiko-ekonomicheskaiasituatsiiaimezhnatsional'nye otnosheniia v Dagestane.” $A A S$, no. 4, 1999, 40-45, and no. 5, 1999, 52-56. . "Lezginskii faktor: Kavkaz." $A A S$, no. 7, 1999, 2-11.

Ibragimov, M.-P., and K. Matsuzato. 'Chuzhoi, no loyal'nyi: prichiny 'nestabil'noi stabil'nosti' v Dagestane.” Polis, no. 3, 2005, 102-15.

Il'iachenko, S. V. "O migratsionnykh protsessakh v Respublike Dagestan." Vestnik statistiki, no. 3, 2003, 54-61.

Kisriev, E. F. Natsional'nost' $i$ politicheskii protsess v Dagestane. Makhachkala: Dagestanskii nauchnyi tsentr Rossiiskoi akademii nauk, Institut istorii, arkheologii i etnografii, 1998.

. Islam i vlast'v Dagestane. Moscow: OGI, 2004.

Kizriev, Enver E. "The Political Process in Dagestan: Prospects for Democracy." In Yaacov Ro'i, ed., Democracy and Pluralism in Muslim Eurasia. London: Cass, 2004, 329-42.

Kisriev, Enver, and Robert Bruce Ware. "Conflict and Catharsis: A Report on Developments in Dagestan Following the Incursions of August and September 1999." Nationalities Papers 28, no. 3 (September 2000): 479-522.

. "Russian Hegemony in Dagestan." PSA 21, no. 1 (January-March 2005): $26-55$.

Luchterhandt, Otto. Dagestan: Unaufhaltsamer Zerfall einer gewachsenen Kultur interethnischer Balance? Hamburg: Institute für Friedenssforschung und Sicherheitspolitik, 1999.

Makarov, D. V. Ofitsial'nyi i neofitsial'nyi Islam v Dagestane. Moscow: Institut vostovedeniia RAN, 2000.

."RadikalizatsiiaIslamavDagestane:vozmozhnostiipredelydzhikhadizma." Obshchestvennye nauki i sovremennost', no. 6, 2004, 147-61.

Matsuzato, Kimitaka, and Magomed-Rasul Ibragimov. "Islamic Politics at the Sub- 
National Level in Dagestan: Tariqa Brotherhoods, Ethnicities, Localism, and the Spiritual Board." EAS 57, no. 5 (July 2005): 753-80.

"Moskva-Dagestan." Ekho Kavkaza, no. 1, 1996, 2-63.

Musaeva, S. I. Mezhnatsional'nye otnosheniia v Dagestane: istoricheskie traditsii i sovremennost'. Makhachkala: Iupiter, 1999.

Oversloot, Hans, and Ger P. van den Berg. "Politics and the Ethnic Divide: Is

Dagestan Changing from Complex to Simple Oligarchy?" JCSTP 21, no. 3 (September 2005): 307-31.

Palchaev, N. N. "Mesto i rol' Narodnogo Sobraniia v strukture gosudarstvennogo ustroistva Respubliki Dagestan.” Vestnik Moskovskogo Universiteta, series 18, Sotsiologiia i politika, no. 2, 2000, 60-77.

Sadyki, A. G. "Dagestan: put' k sokhraneniiu tselostnosti." Politiia, no. 2, Summer 2000, 60-70.

Sadyki, Mukhamed-Arif. "Mesto respubliki Dagestan na geopoliticheskoi karte Rossii." Vlast', no. 5, 2001, 61-65.

__. "Dagestan i ego problemy segodnia." Vlast', no. 6, 2002, 55-58.

—. "Dagestan-Rossiia, Rossiia-Dagestan," Vlast', no. 9, 2003, 10-14.

Sadykin, M. M. "Perspektivy respubliki Dagestan v sostave Rossiiskoi Federatsii." Vestnik Moskovskogo Universiteta, series 12, Politicheskie nauki, no. 3, 1996, 31-47.

."Respublika Dagestan: avtonomii mezhdu unitarizmom i avtonomizatsiei." Vestnik Moskovskogo Universiteta, series 18, Sotsiologiia i politika, no. 4, 1998, 111-29.

Tiutiunnik, Sergei. "Kadarskaia zona.” Druzhba narodov, no. 1, 2000, 152-62.

Deals with the events of September 1999.

Ware, Robert Bruce. "Recent Russian Federal Elections in Dagestan: Implications for Proposed Electoral Reform." EAS 57, no. 4 (June 2005): 583-600.

Ware, Robert Bruce, and E. F. Kisriev. "Political Stability and Ethnic Parity: Why Is There Peace in Dagestan?" In Mikhail A. Alexseev, ed., Center-Periphery Conflict in Post-Soviet Russia: A Federation Imperiled. New York: St. Martin's, 1999, 95-130.

_. "Ethnic Parity and Democratic Pluralism in Dagestan: A Consociational Approach.” EAS 53, no. 1 (January 2001): 105-31.

Ware, Robert B., et al. "Dagestani Perspectives on Russia and Chechnya." PSA 18, no. 4 (October-December 2002): 306-31.

—. "Political Islam in Dagestan." EAS 55, no. 2 (March 2003): 287-302. 


\section{Evenk Autonomous Okrug}

Kontseptsiia strategii sotsial'no-ekonomicheskogo razvitiia Evenkii v usloviiakh formirovaniia neftegazovovo kompleksa. Krasnoiarsk: Bukva, 2004.

\section{Far East (Dal'nii Vostok)}

Akaha, Tsuneo, ed. Politics and Economies in the Russian Far East: Changing Ties with Asia Pacific. London: Routledge, 1997.

Alexseev, Mikhail A. "Socioeconomic and Security Implications of Chinese Migration in the Russian Far East." PSGE 42, no. 2 (March 2001): 122-41. Andrianov, V. "Razgosudarstvlenie v Dal'nem vostoke Rossii." PDV, no. 1, 1994, $20-24$.

. "Resursnyi potentsial i struktura ekonomiki Dal'nego Vostoka Rossii." $P D V$, no. 6, 1995, 19-27.

\section{2-6.}

Bliakher, L. E. "Politicheskie mify Dal'nego Vostoka.” Polis, no. 5, 2004, 28 -39.

Bogaturov, A. "Rossiiskii Dal'nii Vostok v novykh geoprostranstvennykh izmereniiakh." MEMO, no. 10, 2004, 90-98.

Bolyatko, A. V. Dal'nii Vostok v poiskakh strategicheskoi stabil'nosti: problemy national'noi bezopasnosti Rossii na Dal'nem Vostoke i strategicheskoi stabil'nosti v Aziatsko-Tikhookeanskom regione. Moscow: IDV RAN, 2003.

Bradshaw, Michael J., ed. The Russian Far East and Pacific Asia: Unfulfilled Potential. Richmond, U.K.: Curzon, 2001.

— , and Peter Kirkow. "The Energy Crisis in the Russian Far East: Origins and Possible Solutions." EAS 50, no. 6 (September 1998): 1043-63.

Busygina, I. M. "Rossiiskii Dal'nii Vostok." MEMO, no. 7, 1995, 106-17.

Davis, Sue. The Russian Far East: The Last Frontier? London: Routledge, 2002.

"Ekonomika Dal'nego Vostoka." Vestnik DORAN, no. 5, 1995, 19-92.

Gray, Patty. Indigenous Activism in the Russian Far East: The Chukotko Case. Cambridge: Cambridge University Press, 2003.

Considers why the "indigenous rights movement" of the Chukotko people has been unsuccessful.

Hahn, Jeffrey. "The Development of Political Institutions in Three Regions of the Russian Far East." In Cameron Ross, ed., Regional Politics in Russia. Manchester: Manchester University Press, 2002, 95-119.

Ishaev, V. I. "Strategiia razvitie rossiiskogo Dal'nego Vostoka." Vestnik Rossiiskoi Akademii nauk 71, no. 11 (November 2001): 963-79. 
Ishaev, V. I., and P. Minakir. Dal'nii Vostok Rossii: real'nosti $i$ vozmozhnosti ekonomicheskogo razvitiia. Khabarovsk: Institut ekonomicheskikh issledovanii DVO RA, 1998.

Ivanov, Vladimir I. "The Russian Far East: The Political Economy of the Defense Industry Conversion." In Shugo Minagawa and Osamu Ieda, eds., SocioEconomic Dimensions of the Changes in the Slavic-Eurasian World. Sapporo: Slavic Research Center, Hokkaido University, 1996, 174-95.

Kontorovich, Vladimir. "Can Russia Resettle the Far East?" $P C E$ 12, no. 3 (September 2000): 365-84.

- "Economic Crisis in the Russian Far East: Overdevelopment or Colonial Exploitation?" PSGE 42, no. 6 (September 2001): 391-415.

Minakir, Pavel, ed. The Russian Far East: An Economic Handbook. Trans. Gregory

L. Freeze. Armonk, N.Y.: M. E. Sharpe, 1994.

A massive (495 pp.) compendium of data.

Moltz, James Clay. "Core and Periphery in the Evolving Russian Economy: Integration or Isolation of the Far East?" PSGE 37, no. 3 (March 1996): 17594.

Murray, W.E. Natural Resources in the Pacific-Asia Region: A Selected Bibliography. Russian Regional Research Group Working Paper Series, no. 9. University of Birmingham: School of Geography and Environmental Sciences and Centre for Russian and East European Studies, 1997.

Roszman, Gilbert. "The Crisis in the Russian Far East: Who is to Blame?" PPC 44, no. 5 (September-October 1997): 3-12.

Shinkovsky, M. Iu. "Transnatsional'noe sotrudnichestvo kak rychag razvitiia Rossiiskogo Dal'nego Vostoka." Polis, no. 5, 2004, 62-70.

Thornton, Judith, and Charles E. Ziegler, eds. Russia's Far East: A Region at Risk. Seattle: University of Washington Press, 2002.

Turaev, Vadim A. "Territorial'nyi podkhod k resheniiu etnicheskikh problem na rossiiskom Dal'nem Vostoke." In Koichi Inoue and Tomohiko Uyama, eds., Quest for Models of Coexistence: National and Ethnic Dimensions of Changes in the Slavic Eurasian World. Sapporo: Slavic Research Center, Hokkaido University, 1998, 289-316.

Vakhnenko, R. V. "Problems of Passenger Mobility and Road Transport in the Southern Far East Region." SG 31, no. 1 (January 1990), 61-64.

White, Stephen, Ian McAllister, and Yeongmi Yun. "Electoral Behavior in the Russian Far East, 1995-2000: Contextual and Compositional Effects.” EGE 43, no. 2 (March 2002): 143-59. 
Iakutiia (See R. Sakha)

\section{Iaroslavskaia oblast’}

Busza, Eva, and Jeffrey W. Hahn. "Women and Politics in Russia: The Yaroslavl' Study." Women and Politics 16, no. 3 (1996): 55-87.

Hahn, Jeffrey W. "Local Politics and Political Power in Russia: The Case of Yaroslavl." SE 7, no. 4 (1991): 322-41.

— D.C.: Woodrow Wilson Center Press, 2001.

Lapina, N. Iu., and A. E. Chirikova. Regiony-lidery: ekonomika i politicheskaya dinamika. Moscow: Institut sotsiologii RAN, 2002.

Focuses on Iaroslavl' and Samara regions.

Lokosov, V., and Iu. Sinelina. Religioznaia situatsiia v Iaroslavskoi oblasti. Moscow: RITS ISPI RAN, 2004.

Matsuzato, K., and Shatilov, A. B., eds. Regiony Rossii: khronika i rukovoditeli. Vol. 3. Samarskaia oblast', Iaroslavskaia oblast'. Occasional Papers on Changes in the Slavic-Eurasian World 35. Sapporo: Slavic Research Center, Hokkaido University, 1997, 201-60.

Mitchneck, Beth. "The Changing Role of the Local Budget in Russian Cities: The Case of Yaroslavl." In Theodore H. Friedgut and Jeffrey W. Hahn, eds., Local Power and Post-Soviet Politics. Armonk, N.Y.: M. E. Sharpe, 1994, 73-95.

Ruble, Blair A. Money Sings: The Changing Politics of Urban Space in Post-Soviet Yaroslavl'. Washington, D.C.: Woodrow Wilson Center Press, 1995.

Sinelina, Iu. Iu. 'Votserkovlennost' i suevernoe povedenie zhitelei Iaroslavskoi oblasti." SI, no. 3, 2005, 96-107.

\section{R. Ingushetiia}

Marie-Fanon, Samuel. "Une opération hautement politisée: Le recensement de la population en Ingouchie." Revue d'études comparatives est-ouest 34, no. 4 (December 2003): 115-30.

\section{Irkutskaia oblast'}

Chernikov, Alexander. 'Resource-Rich Regions: Irkutsk Oblast' on the Road to the Market." CEET 10, no. 3 (September 1998): 375-90.

Schauff, Frank. "Agressiver Wahlkampf und organisatorische Schwächen: Zu den Wahlen in Irkutsk." Osteuropa 46, no. 5 (May 1996): 519-23. 


\section{Jewish Autonomous Region}

Kuchenbecher, Antje. Zionismus ohne Zion. Birobidjan: Idee und Geschichte eines jüdischen Staates im Sowjet-Fernost. Berlin: Metropol, 2000.

Weinberg, Robert. Stalin's Forgotten Zion: Birobidzhan and the Making of a Soviet Jewish Homeland. Berkeley and Los Angeles: University of California Press, 1998.

\section{R. Kabardino-Balkariia}

Akkieva, Svetlana. Kabardno-Balkarskaia Respublika: model' etnologicheskogo monitoringa. Moscow: Institut etnologii i antropologii RAN, 1998.

Akkieva,S.I., andKh.M.Dumanov,eds.Politikaipravovsfereetnogosudarstvennykh otnoshenii Kabardino-Balkarii. 2 vols. Moscow: Tsentr po izucheniiu mezhnatsional'nykh otnoshenii instituta etnologii i antropologii im. N. N. Miklukho-Maklaia, 2001.

Babich, I. L., ed. Etnopoliticheskaia situatsiia v Kabardino-Balkarii. Moscow: Tsimo, 1994.

Begidov, A. M. Kabardino-Balkariia: proshloe, nastoiashchee, budushchee. Moscow: Novyi khronograf, 2003.

Hahn, Gordon. "The Rise of Islamist Extremism in Kabardino-Balkariya." Dem 13, no. 4 (Fall 2005): 543-94.

Kokov, V. M. "Nasha strategiia—kachestvo zhizni cheloveka." Vlast', no. 11, 1997, 50-55.

\section{Kaliningradskaia oblast'}

Abramov, V. N. Kaliningradskaia oblast': sotsial'no-politicheskie igeopoliticheskie aspekty obshchestvennoi transformatsii 90-kh gg. St. Petersburg: Nestor, 1998.

- Formirovanie partiinoi sistemy Rossiiskoi Federatsii: partiinopoliticheskaia sfera Kalingradskoi oblasti. Kaliningrad: Regional'naia strategiia, 2000.

Baxendale, James, Stephen Dewar, and David Gowan, eds. The EU and Kaliningrad: The Consequences of EU Enlargement on Kaliningrad. London: Kogan Page, 2000.

Birckenbach, Hanne-Margret and Christian Wellmann, eds. The Kaliningrad Challenge: Options and Recommendations. Münster: LIT-Verlag, 2003.

Burova, N. V., and O. A. Mel'nikova. "Izuchenie tenevoi ekonomicheskoi 
deiatel'nosti na regional'nom urovne: primer Kaliningrada." Vestnik statistiki, no. 5, 2003, 24-32.

Chuikina, A. M., ed. Ekonomika Kaliningradskoi oblasti v usloviiakh evropeiskoi ekonomicheskoi integratsii. Kaliningrad: KGU, 2003.

Gareev, T., V. Zhdanov and G. Fedorov. "Novaia ekonomika Kaliningradskoi oblasti." VE, no. 2, 2005, 23-39.

Gödeke, Herwig. "Das Programm für die Sonderwirtschaftszone Kaliningrad, 1998-2005," Osteuropa 48, no. 11-12 (November-December 1998): 111016.

Holtom, Paul. "A 'Baltic Republic in the Russian Federation' or the 'Fourth Baltic Republic'? Kaliningrad's Regional Programme in the 1990s." Journal of Baltic Studies 34, no. 2 (Summer 2003), 159-79.

Joenniemi, Pertti, and Jan Prawitz, eds. Kaliningrad: The European Amber Region. Aldershot: Ashgate, 1998.

"Kaliningradskaia oblast': ekonomicheskie kollizii perekhodnogo perioda." In E. Kuznetsova, ed., Regiony igoroda Rossii: ekonomika i vneshneekonomicheskie sviazi. Moscow: IMEPI RAN, 1996, 31-43.

Karabeshkin, Leonid, and Christian Wellmann. The Russian Domestic Debate on Kaliningrad. Münster: LIT-Verlag, 2004.

Khlopetsky, A. Region sotrudnichestva. Moscow: Gnozis, 2001.

Deals with the practical application of "cooperation region" theory to Kaliningrad.

Kortunov, Sergei. "Kaliningrad kak vorota v Bol'shuiu Yevropu." Rossiia v global'noi politike 2, no. 6 (November-December 2004): 162-74.

Krickus, Richard J. The Kaliningrad Question. Lanham, Md.: Rowman \& Littlefield, 2001.

Lamand, V., and E. Vinokurov. "Formirovanie torgovoi spetsializatsii Kaliningradskoi oblasti." VE, no. 2, 2003, 53-63.

Major, Viktor. Kaliningrad/Königsberg: Auf dem schweren Weg zurück nach Europa. Münster: LIT-Verlag, 2001.

Matsuzato, K., and A. B. Shatilov, eds. Regiony Rossii: khronika i rukovoditeli. Vol. 4. Leningradskaia oblast', Kaliningradskaia oblast'. Occasional Papers on Changes in the Slavic-Eurasian World 36. Sapporo: Slavic Research Center, Hokkaido University, 1997, 115-235.

Moses, Joel C. "Political-Economic Elites and Russian Regional Elections, 19992000: Democratic Tendencies in Kaliningrad, Perm, and Volgograd." EAS 54, no. 6 (September 2002): 905-31.

_ . "The Politics of Kalingrad Oblast: A Borderland of the Russian Federation." 
Russian Review 63, no. 1 (January 2004): 107-29.

Nikzhentaitis, Alvydas. "Das Kaliningrader Gebiet im Spannungsfeld internationaler Interessen: Unter besonderer Berücksichtigung der deutsch-litauischen Beziehungen." Osteuropa 45, no. 10 (October 1995): 927-35.

Oldberg, Ingmar. "The Emergence of a Regional Identity in the Kaliningrad Oblast." Cooperation and Conflict 35, no. 3 (September 2000): 269-88.

"Problemy Kaliningradskoi oblasti." VE, no. 11, 2001, 80-127.

Symposium of four articles.

Reviakin, E. "Prioritety ekonomicheskoi politiki Rossii v Kaliningradskoi oblasti." $M E M O$, no. 12, 2002, 68-75.

Reymann, Sybille. "Das Kaliningrader Gebiet und seine Beziehungen zu ausgewählten Ostseeanrainern.” Osteuropa Wirtschaft 44, no. 2 (June 1999): 177-95.

Samson, I., and I. Eliseeva, "Novyi obraz Kaliningradskoi oblasti." VE, no. 2, 2003, 40-52.

Sezneva, Olga. "Living in the Russian Present with a German Past: Problems of Identity in the City of Kaliningrad." In David Crowley and Susanne Reid, eds., Socialist Spaces: Sites of Everyday Life in the Socialist Bloc. Oxford: Berg, 2002.

Simonian, R. "Kalingradskii eksklav: novaia rol' v usloviiakh rasshireniia ES." Vlast', no. 10, 2003, 55-60,

Smorodinskaia, Natal'ia. Kaliningradskii eksklav: perspektivy transformatsii $v$ pilotnyi region. Moscow: Institut ekonomiki RAN, 2001.

—. "Sud'ba Kaliningrada: global'noe izmerenie." Pro et Contra 8, no. 2 (Spring 2003): 137-62.

Timmermann, Heinz. "Kaliningrad: Eine Pilotregion für die Gestallung der Partnerschaft EU-Russland?" Osteuropa 51, no. 9 (September 2001): 103166.

Vetter, Reinhold. "Kaliningrad und die Osterweiterung der Europäischen Union: Kooperationsbemühungen zum Ausgleich zivilisatorischer Unterschiede." Osteuropa 50, no. 2 (February 2000): 144-60.

Vinokurov, E. "Obshchee ekonomicheskoe prostranstvo ES-Rossiia i Kaliningrad." $M E M O$, no. 11, 2003, 66-71.

Voronov, K. "Kaliningradskaia oblast' v vzaimootnosheniiakh Rossii i ES: medlennyi dreif." MEMO, no.3, 2005, 42-53.

"Die Zukunft Kaliningrads." Osteuropa, no. 2-3, February-March 2003, special issue. 


\section{R. Kalmykiia}

Brushtein Il'ia. "Ostrov Kalmykiia.” SM, no. 2, 2006, 78-96 (part 1), and no. 3, $122-38$ (part 2).

Golenkova, Z. T., et al. "Sotsial'nye problemy razvitiia Kalmykii." Monitoring obshchestvennogo mneniia, no. 3 (71), 2004, 76-84.

Guchinova, E. Postsovetskaia Elista: vlast', biznes, krasota. Ocherki sotsial'nokul'turnoi antropologii kalmykov. St. Petersburg: Aleteiia, 2003.

Guchinova, E.-B., and G. A. Komarova, eds. Kalmykiia-etnopoliticheskaia panorama: ocherki, dokumenty, materialy. 2 vols. Moscow: Institut etnologii i antropologii RAN, 1995-96.

Gushler, A. "Drug stepei stroit N'iu-Vasiuki." $A A S$, no. 1, 1999, 48-54.

Guzenkova, T. S., et al., eds. Kalmyki: pereput'e 1980-kh: problemy etnokul'turnogo razvitiia. Moscow: Institut etnologii i antropologii RAN, 1993.

Iliumzhinov, K. 'Kuda idet Kalmykiia?" Obozrevatel', no. 12, 1994, 27-34.

Katushov, K. P., and B. M. Munianova. "Kalmykiia: sotsial'no-etnicheskie shtrikhi massovogo soznaniia.” SI, no. 7, 2000, 103-05.

Kolosov, V., and V. Streletskii. "Kalmykiia-Khal'mg-Tangch: ekonomika, partii, lidery." Vlast', no. 1, 1996, 24-33.

Lidzhi-Goriaeva, S. E., and B. M. Munianova. "Politicheskii resurs vlasti v Kalmykii i obshchestvennoe mnenie." SI, no. 3, 2003, 122-24.

Magomedov, A. K. 'Korporatsiia 'Kalmykiia'—vyrazhenie ideologii kalmytskoi praviashchei elity." MEMO, no. 12, 1995, 106-13.

_. "Vlast' novoi Kalmykii: organizatsiia i predely soglasiia politicheskoi elity." Rossiia i sovremennyi mir, no. 3, 1995, 156-69.

Maksimov, K. N. "Formirovanie organov mestnogo samoupravleniia v Respublike Kalmykiia." Biznes i politika, no. 3, 1997, 15-19.

Nuskhaev, A. L. Politika gosudarstvennoi sotsiokratii kalmykii v edinoi Rossii. Elista: Kalmytskoe knizhnoe izdatel'stvo, 1996.

Turunok, S. G. "Kirsan Iliumzhinov.” Kentavr, no. 1, 1995, 35-47.

\section{Kaluzhskaia oblast'}

Kalugin, O. A. "Mekhanizmy elitoobrazovaniia $\mathrm{v}$ regione (na istoricheskom opyte formirovaniia kaluzhskikh politico-administrativnykh grupp)." Polis, no. 4, 1998, 145-51. 


\section{R. Karachaevo-Cherkessiia}

Arutiunov, S. A., et al. "Etnokul'turnaia situatsiia v Karachevao-Cherkesskoi avtonomnoi oblasti." Sovetskaia etnografiia, no. 2, 1990, 23-29.

Khalkechev, M. N. "Rozhdaemost' i reproduktivnye ustanovki molodezhi Karachaevo-Cherkesii." SI, no. 8, 2005, 62-67.

Laipanov, Kazii. "O gosudarstvennosti karachaevtsev i cherkesov." As-Alan, no. 1, 2000, 287-304.

\section{R. Kareliia}

Filatov, S. "Kareliia: pravoslavno-liuteranskoe pogranich'e," Druzhba narodov, no. 5, 2000, 130-38.

Laine, Antti, and Mikko Ylikangas, eds. Rise and Fall of Soviet Karelia: People and Power. Helsinki: Kikimora, 2002.

Morozova, T. V., S. A. Gurova, and G. B. Kozyreva. Sel'skie soobshchestva Karelii: traditsii, sovremennost', perspektivy. Petrozavodsk: Karel'skii NTS RAN, 2004.

Nilov, V. M. “Sotsial'nye izmeneniia i zdorov'e naseleniia Karelii.” SI, no. 11, 2004, 90-98.

Pliusnin, Iu. M. Pomory: naselenie poberezhii Belogo moria v gody krizisa (19952001). Novosibirsk: RITS NGU, 2003.

Puuronen, Vesa, et al., eds. Youth in a Changing Karelia: A Comparative Study of Everyday Life, Future Orientations, and Political Culture of Youth in NorthWest Russia and Eastern Finland. Aldershot: Ashgate, 2000.

"Respublika Kareliia." MZh, no. 3, 1994, 5-50.

“Respublika Kareliia.” Zhizn'natsional'nostei, no. 4-5, 1995, 15-49.

Romanov, S. L. "Mezhregional'noe sotrudnichestvo na Severe Evropy." MZh, no. 3, 1998, 32-39.

Shliamin, V. A. "Vzglyad iz Karelii na vneshneekonomicheskie problemy Severozapada." MZh, no. 7, 1996, 34-40.

_. "Zaboty rossiiskogo Severo-zapada." MZh, no. 11-12, 1996, 22-25.

\section{Kemerovskaia oblast'}

Ashwin, Sarah. “'There's No Joy Any More': The Experience of Reform in a Kuzbass Mining Settlement." EAS 47, no. 8 (December 1995): 1367-81.

Biriukov, S. V., and E. V. Mel'nichenko. "Elektoral'nyi protsess i stanovlenie regional'nykh politicheskikh rezhimov (na primere Kemerovskoi oblasti)." 
Vestnik Moskovskogo Universiteta, series 18, Sotsiologiia i politologiia, no. 1, 2002, 32-56.

Crowley, Stephen. "The Kuzbass: Liberals, Populists, and Labor." In Timothy J.

Colton and Jerry F. Hough, eds., Growing Pains: Russian Democracy and the Election of 1993. Washington, D.C.: Brookings Institution Press, 1998, 533-66.

Ferguson, Rob. "Will Democracy Strike Back? Workers and Politics in the Kuzbass." EAS 50, no. 3 (May 1998): 445-68.

\section{Khabarovskii krai}

"Khabarovskii krai: krai na kraiu Rossii." Rossiiskaia Federatsiia segodnia, no. 24, 2001, 41-57.

Levkov, S. A. "Khabarovskii krai: paradoksy munitsipal'noi reformy." Polis, no. $5,2004,40-52$.

Petersson, Bö. "A Tale of Four Cities: Studying National Self-Images among Russian Regional Politicians in Perm, St. Petersburg, Volgograd, and Khabarovsk." SPSR 23, no. 3 (1996): 251-84.

\section{R. Khakasiia}

Anaiban, Z. B. Zhenshchiny Tuvy i Khakasii v period rossiiskikh reform. Moscow: Institut vostokovedeniia, 2005.

Golubtsova, E. V., and A. M. Burovsky. "Khakasiia: ideologiia i landshafty." Vestnik Evrazii, no. 1, 1995, 32-45.

Larina, N. I., et al. "Respublika Khakasiia: portret territorii." EKO, no. 1, 1997, 91-103.

Logacheva, A. S. "Khakasiia-vospriiatie naseleniem novykh uslovii zhizni." SI, no. $9,2005,83-85$.

\section{Khanty-Mansiisk Autonomous Okrug}

Wilson, Garry N. “'Matryoshka Federalism' and the Case of the Khanty Mansiisk Autonomous Okrug." PSA 17, no. 2 (April-June 2001): 167-94.

\section{Kirovskaia oblast'}

Zorin, N., and R. Kudriavtseva. "Agrarnye reformy v Kirovskoi oblasti.” Ekonomist, no. 10, 2003, 86-94. 


\section{R. Komi}

Alexander, James. "Pluralism in the Komi Republic? Overcoming Executive Resistance." Dem 7, no. 3 (Summer 1999): 370-82.

. "Problems of Democratisation in the Komi Republic." In Cameron Ross, ed., Regional Politics in Russia. Manchester: Manchester University Press, 2002, 135-53.

Alexander, James, and Jörn Grävingholt. "Evaluating Democratic Progress inside Russia: The Komi Republic and the Republic of Bashkortostan." Dem 9, no. 4 (Winter 2002): 77-105.

Il'in, Vladimir. "Respublika Komi: natsional'nye problemy i konstitutsionnaia reforma." In Vladimir Gel'man, ed., Ocherki rossiiskoi politiki: issledovaniia i nabliudeniia, 1993-1994 gg. Moscow: Institute of Humanitarian and Political Research, 1994, 102-11.

Il'in, V.I., and N. V. Kolsenik. "Sotsial'naia mobil'nost regional'noi administrativnoi elity v perekhodnyi period." Rubezh, no. 10-11, 1997, 124-38.

Kolesnik, N. V. "Finansovaia elita rossiiskoi provintsii." Zhurnal sotsiologii $i$ sotsial'noi antropologii, no. 1, 2000, 102-30.

Kotov, O. V., et al. Sovremennye Komi. Ekaterinburg: Institut iazyka, literatury i istorii RAN, Komi nauchnyi tsentr, 1996.

Kovalev, V.A. "Respublika Komi." In V. Gel'man etal., eds. Organy gosudarstvennoi vlasti sub"ektov Rossiiskoi Federatsii. Moscow: IGPI, 1998, 83-91.

—. "Administrativnaia mobilizatsiia izbiratelei v Respublike Komi." In G. M. Liukhterkhandt-Mikhaleva and S. I. Ryzhenkov, eds., Vybory i partii v regionakh Rossii. Moscow: Letnii sad, 2000, 228-41.

—. "Respublika Komi: politiko-pravovye otnosheniia s federal'nym tsentrom i problemy stanovleniia mestnogo samoupravleniia." In G. M. Liukhterkhandt and S. I. Ryzhenkov, eds., Tsentr-regiony-mestnoe upravlenie. Moscow: IGPI/ Letnii sad, 2001, 116-35.

- "Respublika Komi: nekotorye osobennosti vzaimodeistviia obshchestva i gosudarstva v postsovetskii period.” In G. M. Mikhaleva and S. I. Ryzhenkov, eds. Grazhdane $i$ vlast': problemy i podkhody. Moscow: Letnii sad, 2001, $125-41$.

- "Postavtoritarnyi sindrom v regione (opyt respubliki Komi v kontekste putinskogo federalizma)." Polis, no. 6, 2002, 95-103.

"Respublika Komi v putine rossiiskogo federalizma (khronika respublikanskogo politicheskogo rezhima i regional'noi politiki v Rossiiskoi 
Federatsii v 1990-kh—nachale 2000-kh gg.).” In Kimitaka Matsuzato, ed., Fenomen Vladimira Putina i rossiiskie regiony: pobeda neozhidannaia ili zakonomernaia? Slaviano-evraziiskie issledovaniia, 1. Moscow: Materik, 2004, 195-266.

Kovalev, V. A., and P. P. Krotov. "Regional'naia vlast' i biznes: problemy vzaimodeistviia." SI, no. 7, 2004, 95-104.

A discussion between the two authors with particular reference to Komi.

Kovalev, V. A., and Iu. P. Shabaev. "Otsenka konfliktnogo potentsiala v Respublike Komi." Regionologiia, no. 3, 1997, 199-207.

Lazhentsov, V. "Ekonomicheskii federalizm v teorii i na praktike," Zhizn' natsional'nostei No. 4, 1996, 44-47.

Müller, Barbara. "Sprachenpolitik in der Republik Komi." Osteuropa 48, no. 6 (June 1998): 604-16.

"Respublika Komi." Rossiiskaia Federatsiia segodnia, no. 16, 2001, 30-49.

"Respublika Komi: razvitie ekonomiki i vneshneekonomicheskikh sviazei." In

Regiony i goroda Rossii: ekonomika i vneshneekonomicheskie sviazi. Moscow:

RAN, 1996, 44-52.

Respublika Komi-80 let: ocherki, posviashchennye 80-letiiu gosudarstvennosti Respubliki Komi v sostave RF. Syktyvkar: Komi knizhnoe izdatel'stvo, 2001.

Shabaev, Iu. P. Etnokul'turnoe $i$ etnopoliticheskoe razvitie narodov Komi $v$ XX veke. Moscow: Tsentr po izucheniiu mezhnatsional'nykh otnoshenii Instituta etnologii i antropologii RAN, 1998.

_. "Territorial'noe soobshchestvo i etnicheskie vozzreniia naseleniia Komi." SI, no. 11, 2004, 75-83.

Shabaev, Iu. P., and V. M. Peshkova. Russkie v Respublike Komi. Moscow: Institut etnologii i antropologii RAN, 1997.

Turovskii, R. "Respublika Komi: ekonomika, partii, lidery.” Vlast', no. 10, 1995, $56-62$.

Vybory v Respublike Komi, 1989-2000: informatsionnyi sbornik. ed. A. A. Sozykina et al. Syktyvkar: Izbiratel'naia komissiia Respubliki Komi, 2002.

\section{Komi-Permiak autonomous okrug}

Poluainov, N. A., et al., eds. Komi-Permiatskii avtonomnyi okrug na rubezhe vekov. Kudymkar: Komi-Permiatskoe knizhnoe izdatel'stvo, 2000.

Zubov, Iu. P., ed. Komi-Permiatskii okrug: vek XX. Perm': Gort, 2001. 


\section{Kostromskaia oblast'}

“Kostromakaia oblast'." Vash vybor, no. 2, 1994, 2-48.

Treivish, Andrei. "Kostroma Oblast': An Average-Russian, Average-Depressed Region." CEET 10, no. 3 (September 1998): 319-40.

Wegren, Stephen K. "Agricultural Reform in the Nonchernozem Zone: The Case of Kostroma Oblast.” PSG 33, no. 10 (December 1992): 645-85.

. "The Development of Market Relations in Agricultural Land: The Case of Kostroma Oblast.” PSG 36, no. 8 (October 1995): 496-512.

\section{Krasnodarskii krai}

Magomedov, A. "Krasnodar Krai: A 'Growth Pole' in the Transitional Economy of Russia?” CEET 10, no. 3 (September 1998): 363-74.

- "Kharakter politicheskogo sopernichestva lokal'nykh elit v Krasnodarskom krae: mobilizatsiia konstitutionnykh, ekonomicheskikh i geopoliticheskikh resursov." Konstitutsionnoe pravo: Vostochnoevropeiskoe obozrenie, no. 2, 1999, 93-99.

__. "Krasnodarskii krai v usloviiakh geopoliticheskoi i lokal'noi konkurentsii politicheskikh sil." Polis, no. 5, 1999, 141-54.

- "Modernizatsionnye vyzovy i politicheskie otvety praviashchei elity Krasnodarskogo kraia." MEMO, no. 1, 2000, 69-78.

Magomedov, A. K., and M. M. Kirichenko. 'Ot El'tsina k Putinu: Kreml' i regional'naia Rossiia (na primere Ul'ianovskoi oblasti i Krasnodarskogo kraia)." In Kimitaka Matsuzato, ed., Fenomen Vladimira Putina i rossiiskie regiony: pobeda neozhidannaia ili zakonomernaia? Slaviano-evraziiskie issledovaniia 1. Moscow: Materik, 2004, 267-311.

Osipov, A. G. Rossiiskii opyt etnicheskoi diskriminatsii: meskhetintsy v Krasnodarskom krae. Moscow: Zven'ia, 1999.

Petrov, V. N., and V. I. Okhrimenko. Obshchina turok-meskhintsevv Krasnodarskom krae: cherty sotsial'nogo portreta. Krasnodar: Elsinvet, 2005.

Prilepskii, V. V., and I. V. Samarkina. "Demokraticheskie tranzity i regional'nyi sotsium (Krasnodarskii krai).” Politiia, no. 4 (Winter), 2000, 99-112.

Rakachev, V. N. "Etnodemograficheskie izmeneniia v Krasnodarskom krae, 19891999 gg." Sotsiologicheskii zhurnal, no. 2, 2001, 49-55.

Schneider, Eberhard. "Neue Entwicklungen in Russlands Regionalpolitik: Die Gouverneurswahl in Krasnojarsk-ein Lehrstück?" Osteuropa 52, no. 12 (December 2002): 1562-72. 
Webb, John. "Krasnodar: A Case Study of the Rural Factor in Russian Politics." Journal of Contemporary History 29, no. 2 (April 1994): 229-60.

\section{Krasnoiarskii krai}

Grishaev, S. V. “Dinamika sotsial'noi struktury krasnoiarskogo kraia.” SI, no. 2, 2001, 117-20.

Ivannikova, O. V. "Vliianie situatsii v regione na vospriiatie politikov federal'nogo urovnia: Kuban'." Polis, no. 4, 2000, 145-48.

Kot, V. S. Samoupravlenie i upravlenie $v$ severnom promyshlennom raione: osobennosti i politicheskie problemy. Moscow: Globus, 2003.

Magomedov, A. "Praviashchaia elita Kubani: raznye otvety na vyzovy vremeni." Rossiia i sovremennyi mir, no. 4, 1998, 96-122.

Petrov, Nikolai V. Aleksandr Lebed'v Krasnoiarskom krae. Moscow: Moskovskii tsentr Karnegi, 1999.

Sukhovol'skii, A. V., and V. G. Sukhovol'skii. "Regional'nye vybory v Krasnoiarskom krae (1990-1998): politicheskii i strukturnyi analiz.” In G. M. Liukhterkhandt-Mikhaleva and S. I. Ryzhenkov, eds., Vybory i partii v regionakh Rossii. Moscow: Letnii sad, 2000, 242-65.

Sukhovol'skii, V. G. “A. I. Lebed' v Krasnoiarskom krae: elektoral'nye uspekhi i politicheskie porazheniia." Politiia, no. 1, 1999, 95-109.

Yorke, Andrew. "Business and Politics in Krasnoyarsk krai." EAS 55, no. 2 (March 2003): 241-62.

\section{Kurganskaia oblast'}

Kolosov, V. 'Kurganskaia oblast': ekonomika, partii, lidery," Vlast' No. 2, 1996, $79-84$.

\section{Kurskaia oblast'}

Korolev, B. N. Chereda pobed i porazhenii (Kurskaia oblast'v 1990-2000 gg.). Kursk: Uchitel', 2002.

Melvin, Neil. "Kursk: A Preserve of Communism." In Timothy J. Colton and Jerry F. Hough, eds., Growing Pains: Russian Democracy and the Election of 1993. Washington, D.C.: Brookings Institution Press, 1998, 491-532.

Nechaev, V. D. "Vertikal'noe razdelenie vlastei v sub"ekte RF na primere Kurskoi oblasti.” In G. M. Liukhterkhandt and S. I. Ryzhenkov, eds., Tsentr-regionymestnoe upravlenie. Moscow: IGPI/Letnii sad, 2001, 136-70. 
Leningradskaia oblast' (See St. Petersburg)

\section{Lipetskaia oblast'}

Matsuzato, K., and A. B. Shatilov, eds. Regiony Rossii: khronika i rukovoditeli. Vol. 1. Krasnyi poias (Tsentral'noe chernozem'e): Lipetskaia oblast', Tambovskaia oblast', Penzenskaia oblast'. Occasional Papers on Changes in the Slavic-Eurasian World 33. Sapporo: Slavic Research Center, Hokkaido University, 1997, 13-81.

\section{Magadanskaia oblast’}

Drobizheva, Leonkadia. "A Comparison of Elite Groups in Tatarstan, Sakha, Magadan, and Orenburg." PSA 15, no. 4 (October-December 1999): 387406.

Khakhovskaia, L. N. Kamchadaly Magadanskoi oblasti (istoriia, kul'tura, identifikatsiia). Magadan: SVKNII DVO RAN, 2003.

Kokorev, E. M., et al. "Ekonomika Magadanskoi oblasti v sisteme novogo regiona." Vestnik DORAN, no. 2, 1994, 3-10.

Navasardov, S. N. "Demograficheskaia situatsiia i sotsial'nye posledstviia ekonomicheskikh reform v Magadanskoi oblasti." SI, no. 7, 1994, 48-51.

Round, John. "Rescaling Russia's Geography: The Challenges of Depopulating the Northern Periphery." EAS 57, no. 5 (July 2005): 705-28.

\section{R. Mari-EI}

Galkin, I. S., ed. Problemy razvitiia mariiskogo iazyka kak gosudarstvennogo. Ioshkar-Ola: Mariiskii nauchno-issledovatel'skii institut, 2000.

Ianalov, V. G., ed. Mariiskii mir: problemy natsional'nogo, sotsial'noekonomicheskogo i kul'turnogo razvitiia mariiskogo naroda. Ioshkar-Ola: n. p., 2000.

Krainov, G. N., ed., Natsional'nye otnosheniia i gosudarstvennaia natsional'naia politika v Respublike Marii El. Ioshkar-Ola: Pravitel'stvo Respubliki Marii El, 1997.

Matsuzato, K., ed. Regiony Rossii: khronika i rukovoditeli. Vol. 8. Respublika Marii El, Chuvashskaia Respublika, Respublika Bashkortostan. SRC Occasional Papers, special issue. Sapporo: Slavic Research Center, Hokkaido University, 2003, 23-117.

Natsional 'no-regional'nye problemy gosudarstvennogo stroitel'stva: po materialam 
sotsiologicheskogo issledovaniia 1995 g. Ioshkar-Ola: Mariiskii nauchnoissledovatel'skii institut iazyka, literatury i istorii im. V. M. Vasil'eva, 1996.

Shkalina, G. E., and G. I. Koroleva-Konoplianaia. "Natsional'noe: mezhdu ideologiei i kul'turoi." Sotsial'no-politicheskii zhurnal, no. 1, 1997, 110-16.

Whitehouse, Mark. "Nationalism in a Peaceful Republic: Mari El." ASN Analysis of Current Events 7, no. 5 (January 1996): 5-6.

\section{R. Mordoviia}

Bogatova, O. A. "Etnicheskie granitsy v Mordovii: paradoks mnogourovnevoi identichnosti." SI, no. 6, 2004, 69-75.

Gruznov, P. D., ed. Ekonomicheskii potentsial regiona. Saransk: Krasnyi oktiabr', 2001.

Kisilev, A. G., and Pidde, A. L. "Mordoviia: posle parlamentskikh vyborov." Vlast', no. 3, 2000, 69-6.

- "Mordoviia: praktika gosudarstvennogo upravleniia." Politiia, no. 4, 2000, 113-21.

Mel'nikov, Iu. "Mordoviia: shtrikhi k kartine vyborov." Kommunist, no. 5, 1996, $57-59$.

Poliakov, O. E. Mordoviia mnogonatsional'naia: vzaimootnosheniia narodov, vzaimootnosheniia iazykov. Saransk : NII regionologii, 1993.

Popov, G. Ia., ed. Mezhnatsional'nye otnosheniia v Mordovskoi SSR: itogi etnosotsiologicheskogo issledovaniia. 5 vols. Saransk: NII regionologii, 1992-1994.

Regiony Rossii: khronika i rukovoditeli. Vol. 7. Respublika Tatarstan, Udmurtskaia respublika, Respublika Mordoviia. Ed. K. Matsuzato. Occasional Papers on the Elite of the Mid-Volga Ethnic Republics 3. Sapporo: Slavic Research Center, Hokkaido University, 2000, 151-266.

"Respublika Mordoviia." Rossiiskaia Federatsiia segodnia, no. 22, 2001, 25-40.

Silliaste, G. G. "Russkaia sem'ia v novoi mezhnatsional'noi situatsii." SI, no. 3, 1995, 101-09.

Sukharev, A. I., ed. Tsivilizovannoe razvitie natsii i mezhnatsional 'nykh otnoshenii. Saransk: NII regionologii, 1992.

\section{Moscow / Moskovskaia oblast'}

Arutunian, Iu. V. Moskvichi: etnosotsiologicheskoe issledovanie. Moscow: Nauka, 2005.

_. "O potentsiale mezhetnicheskoi integratsii v moskovskom megapolise." 
SI, no. 1, 2005, 27-40.

Baburin, V. L. "Politicheskaia transformatsiia sotsiumov $\mathrm{v}$ urbanizovannykh raionakh (na primere blizhnego Podmoskov'ia)." In V. Klimanov and N. Zubarevich, eds., Politika i ekonomika v regional'nom izmerenii. Moscow: IGPI/Letnii sad, 2000, 234-51.

. Moskovskii stolichnyi region na rubezhe vekov: noveishaia istoriia i puti razvitiia. Smolensk: Oikumena, 2003.

Bri, M. "Moskva." In V. Gel'man et al., eds., Organy gosudarstvennoi vlasti sub"ektov Rossiiskoi Federatsii. Moscow: IGPI, 1998, 72-78.

Busygina, Irina. "Der Platzund die Rolle Moskaus in der Rußländischen Föderation." Osteuropa 49, no. 11-12 (November-December 1999): 1144-56.

Colton, Timothy J. "The Politics of Democratization: The Moscow Election of 1990." SE 6, no. 4 (October-December 1990): 285-344.

. Moscow: Governing the Socialist Metropolis. Cambridge, Mass.: The Belknap Press of Harvard University Press, 1995.

The last chapter, "Toward a Post-Socialist Metropolis," discusses developments well into 1994.

Ioffe, Grigory, and Tatyana Nefedova. "Environs of Russian Cities: A Case Study of Moscow." EAS 50, no. 8 (December 1998): 1325-56.

Kolosov, V.A. "Moskva na politicheskoi karte Rossii i politicheskaia karta Moskvy." Izvestiia Rossiiskoi Akademii nauk: geografiia, no. 5, 1996, 75-89.

Kolosov, V. A., and O. I. Vendina. "Sotsial'naia poliarizatsiia i politicheskoe povedenie moskvichei." Sotsiologicheskii zhurnal, no. 3-4, 1996, 164-75.

__. "Politicheskie predpochteniia moskvichei v khode izbiratel'noi kampanii." Vestnik Rossiiskoi Akademii nauk 67, no. 8 (August 1997): 675-80.

Kolosov, V. A., N. A. Borodulina, and O. I. Vendina. "Iurii Luzhkov: imidzh politicheskogo lidera." Politiia, no. 3, Autumn 2001, 45-70.

Konyushko, S. V. "Ekonomicheskaia sostavliaiushchaia vlastnogo potentsiala administrativno-politicheskoi elity Moskvy.” Politiia, no. 2(29), Summer 2003, 150-63.

Kullberg, Judith. "Preserving the Radical Stronghold: The Election in Moscow." In Timothy J. Colton and Jerry F. Hough, eds., Growing Pains: Russian Democracy and the Election of 1993. Washington, D.C.: Brookings Institution Press, 1998, 311-48.

O'Loughlin, John, Vladimir Kolossov, and Olga Vendina. "The Electoral Geographies of a Polarizing City: Moscow, 1993-1996.” PSGE 38, no. 10 (December 1997): 567-600. 
Sautina, E. V. "Chto zhdut zhiteli Moskovskoi oblasti ot institutov gosudarstvennoi vlasti," SI 2000, No. 10, 47-51.

Politiia, no. 3 (26), Autumn 2002, entire issue.

A symposium of comparative articles on the two capitals covering historical issues, public opinion, the political parties, and elections.

Shaw, Denis J. B., and Cordual Gdaniec. "The Impact of Economic Restructuring in Moscow in the Early 1990s." In Michael J. Bradshaw and D. J. B. Shaw, eds., Regional Problems during Economic Transition in Russia: Case Studies. Russian Regional Research Group Working Paper Series, no. 1. Birmingham: University of Birmingham, 1996, 38-57.

Treyvish, Andrey. "The Central Economic Region and Moscow Oblast." In

Michael J. Bradshaw and D. J. B. Shaw, eds., Regional Problems during Economic Transition in Russia: Case Studies. Russian Regional Research Group Working Paper Series, no. 1. Birmingham: University of Birmingham, 1996, 3-36.

Vendina, O. I. “Moskva —obraz goroda, ne pokhozhii na portret." Politiia, no. 3, Autumn 2001, 71-93.

\section{Murmanskaia oblast'}

Dellenbrant, J. A., and O. Andreev. "Russian Politics in Transition: Political Parties and Organizations in Russia and the Murmansk Region." Scandinavian Political Studies 17, no. 2 (June 1994): 109-42.

Pliusnin, Iu. M. Pomory: naselenie poberezhii Belogo moria v gody krizisa (19952001). Novosibirsk: RITS NGU, 2003.

\section{Nizhegorodskaia oblast' (Nizhnii Novgorod)}

Borisov, Sergei V. "Aktual'nyi politicheskii rezhim v Nizhegorodskoi oblasti: stanovlenie v 1990-e gody." Polis, no. 1, 1999, 98-115.

— Novgorod: VVAGS, 1996.

Borisov, S. V., A. V. Dakhin, and A. S. Makarychev. "Bez pobeditelia: vybory mera Nizhnego Novgoroda." Polis, no. 6, 2002, 83-94.

Dakhin, A. "Strukturnye izmeneniia administrativnoi i finansovo-ekonomicheskoi elity regiona(1998-1999gg.)."Konstitutsionnoepravo: vostochnoevropeiskoe obozrenie, no. 1, 2000, 188-92.

_. "Transformatsiia regional'nykh elit na primere Nizhegorodskoi oblasti." Polis, no. 4, 2003, 108-19. 
Evans, Alfred B. "Civil Society and Political Authority in the Semenov District." Dem 5, no. 2 (Spring 1997): 197-221.

Gel'man, V. Ia. “'Soobshchestvo elit' i predely demokratizatsii: Nizhegorodskaia oblast'." Polis, no. 1, 1999, 79-97.

Gould-Davies, Nigel. "Nizhnii Novgorod: The Dual Structure of Political Space." In Timothy J. Colton and Jerry F. Hough, eds., Growing Pains: Russian Democracy and the Election of 1993. Washington, D.C.: Brookings Institution Press, 1998, 431-62.

Il'in, I. V. "Ekonomicheskoe moshennichestvo v Nizhegorodskoi oblasti." SI, no. 12, 1999, 105-07.

"Nizhegorodskaia oblast': region krupnym planom." Rossiiskaia Federatsiia segodnia, no. 2, 2000, 37-52.

"Nizhnii Novgorod: A Russian Success Story?" Ed. Camilla Seth. Harriman Review 8, no. 1 (Spring 1995), entire issue.

Penezhko, P. "Konversiia po-nizhnegorodski." Novyi mir, no. 3, 1993, 142-58.

Petrov, Nikolai. "Nizhegorodskaia oblast': ekonomika, partii, lidery." Vlast', no. 3, 1996, 41-46.

Regiony Rossii: khronika i rukovoditeli. Vol. 6. Nizhegorodskaia oblast', Ul 'ianovskaia oblast'. Ed. K. Matsuzato and A. B. Shatilov. Occasional Papers on Regional/Subregional Politics in Post-Communist Countries 1. Sapporo: Slavic Research Center, Hokkaido University, 1999, 11-163.

Simonov, I. V. "Nizhegorodskii region: religioznyi portret.” SI, no. 12, 1999, 118 23.

Umland, Andreas. “'Nur für die Demokratie!' Beobachtungen zu den Wahlen in der russischen Provinz.” Osteuropa 46, no. 11 (November 1996): 1108-16.

Vybory v Zakonodatel'noe sobranie Nizhegorodskoi oblasti 2002 goda: problema sotsial'ngo dialoga. Nizhnii Novgorod: NISTS, 2003.

\section{The North}

Agranat, Grigorii. "Sever: zalozhnik i zhertva.” SM, no. 1, 1998, 57-65.

Artiukov, A. V. "Sotsial'naia situatsiia na rossiiskom Severe.” SI, no. 4, 1999, 2937.

_. "Semeinaia politika na rossiiskom Severe: effektivnost' i rezervy." SI, no. 4, 2001, 80-85.

Bogoiavlenskii, D. D. "Vymiraiut li narody Severa?” SI, no. 8, 2005, 55-61.

Donskoi, F. S. "Integratsionnye protsessy v zhizni severian.” SI, no. 5, 2005, 96100. 
Finkler, Harald W. "Health Care in the Russian and Canadian North: A Comparative Perspective." PSG 36, no. 4 (April 1995): 238-45.

Fondahl, Gail A. "The Status of Indigenous Peoples in the Russian North." PSG 36, no. 4 (April 1995), 215-24.

Golubchikov, S. N., and S. V. Erokhin. Rossiiskii Sever na perelome epokh. Moscow: Pas'va, 2003.

Kotliakov, V., and G. Agranat. "Ekonomika 'pereletnykh ptits'? Sever: novaia rol', novye podkhody." SM, no. 15, 1992, 73-82.

Lynn, N. J., and P. Fryer, "National-Territorial Change in the Republics of the Russian North." Political Geography 17, no. 5 (June 1998): 567-88.

Pivneva, E. A., and D. A. Funk, eds. Narody Severa i Sibiri v postsovetskikh transformatsiiakh. Moscow: Nauka, 2005.

Polezer, Greg. "Devolution, Constitutional Development, and the Russian North." PSG 36, no. 4 (April 1995): 204-14.

Sever kak ob" ekt kompleksnykh regional'nykh issledovanii. Syktyvkar: KNTS UrO RAN ISEPS, 2005.

Sintsov, A. G. Sever v sisteme geopoliticheskikh koordinat sovremennoi Rossii. Moscow: Gorodets, 2004.

Vinokurova, A. G., et al. Zhenshchina Severa: poisk novoi sotsial'noi identichnosti. Novosibirsk: Nauka, 2004.

Volgin, N. A., and Iu. P. Alekseev. Rossiiskii sever: problemy sotsial'nogo razvitiia. Moscow: Dashkov, 2004.

\section{Northern Caucacus}

Bedzhanov, M. B. Rossiia i Severnyi Kavkaz: mezhnatsional'nye otnosheniia na poroge XXI veka. Maikop: "Adygeia," 2002.

Belozerov, V. S. Etnicheskaia karta Severnogo Kavkaza. Moscow: OGI, 2005.

Bugai, N. F., et al., eds. Severnyi Kavkaz: natsional'nye otnosheniia: istoriografiia, problemy. Maikop: Adygeiskii nauchno-issledovatel'skii institut ekonomiki, iazyka, literatury i istorii, 1992.

—. Severnyi Kavkaz: vybor puti natsional'nogo razvitiia. Maikop: Izdatel'stvo "Meoty", 1994.

Bugai, N. F., and A. M. Gonov. Severenyi Kavkaz: novye orientiry natsional'noi politiki (90-e gody XX veka). Moscow: Novyi khronograf, 2004.

Chaguchiev, M. Ch., and M. M. Sokolov. Regiony. Ekonomika. Upravlenie. Moscow: Iuniti-Dana, 2001.

The main emphasis is upon the Northern Caucasus. 
Denisova, G. S., and V. P. Ulanov. Russkie na Severnom Kavkaze: analiz transformatsii sotsiokul'turnogo statusa. Rostov-on-Don: Rostovskii gosudarstvennyi pedogicheskii institut, 2003.

Dobaev, I. "Noveishie tendentsii v razvitii islamskogo dvizheniia na Severnom Kavkaze." MEMO, no. 12, 2005, 86-93.

Kobakhidze,E.I. "Integratsionnyeidisintegratsionnye protsessy v mezhetnicheskom vzaimodeistvii na Severnom Kavkaze." SI, no. 2, 2005, 66-74.

Kureev, Kh. S. K novoi paradigme rossiiskoi natsional'noi politiki na Severnom Kavkaze. Moscow: Akademicheskii proekt, 2005.

Riazantsev, S. V. “Demograficheskaia situatsiia na Severnom Kavkaze.” SI, no. 1, 2002, 77-86.

- Sovremennyi demograficheskii i migratsionnyi portret Severnogo Kavkaza. Stavropol': Servisshkola, 2003.

— na Severnom Kavkaze.” SI, no. 7, 2005, 31-42.

“Severo-Kavkazskii ekonomicheskii raion." Federalizm, no. 4, 1997, 155-84.

Tishkov, V. A., and S. V. Cheshko. Severnyi Kazkaz: etnopoliticheskie $i$ etnokul turnye protsessy $v X X v$. Moscow: Institut etnologii i antropologii im. N. N. Miklukho-Maklaia RAN, 1996.

Zadvornov, I. A. "Severnyi Kavkaz: etnopoliticheskie i religioznye osobennosti sotsiokul'turnoi identichnosti." SI, no. 10, 2000, 52-57.

\section{The Northwest}

Duka, A. V., ed. Regional'nye elity Severo-Zapada Rossii: politicheskie $i$ ekonomicheskie orientatsii. St. Petersburg: Aleteiia, 2001.

Gadlo, A. V., et al. Etnografiia Severo-Zapada Rossii: iuzhnye okresnosti Peterburga-Priladozh'e-Tsentral'nye raiony Pskovshchiny. St. Petersburg: Izdatel'stvo Sankt-Peterburgskogo gosudarsvennogo universiteta, 2004.

Hønneland, Geir, and Helge Blakkisrud, eds. Centre-Periphery Relations in Russia: The Case of the Northwestern Regions. Aldershot: Ashgate, 2001.

\section{Novgorodskaia oblast'}

Dinello, Natalia. "Can Novgorod's Greatness Rub Off on Putin?” PPC 49, no. 5 (September-October 2002): 20-30.

Petro, Nicolai. "The Novgorod Region: A Russian Success Story.” PSA 15, no. 3 (July-September 1999): 235-61.

—. "Regional Democratisation in Russia: Some Lessons from Novgorod." 
In Cameron Ross, ed., Regional Politics in Russia. Manchester: Manchester University Press, 2002, 120-34.

. Crafting Democracy: How Novgorod Has Coped with Rapid Social Change. Ithaca, N.Y.: Cornell University Press, 2004.

Ruble, Blair A., and Nancy Popson. "The Westernization of a Russian Province: The Case of Novgorod." PSGE 39, no. 8 (October 1998): 433-47.

Ryzhenkov, S. and G. Liukhterkhandt-Mikhaleva, eds. Politika i kul 'tura v rossiiskoi provintsii: Novgorodskaia, Voronezhskaia, Saratovskaia, Sverdlovskaia oblasti. Moscow: Letnii sad, 2001.

Zimine, Dmitri A., and Michael J. Bradshaw. "Regional Adaptation to Economic Crisis in Russia: The Case of Novgorod Oblast.” PSGE 40, no. 5 (May 1999): 335-53.

\section{Novosibirskaia oblast’}

Barchunova, Tatyana V. "The Gender Dimension of Social Capital in Russia: The Novosibirsk Case.” In Judyth L. Twigg and Kate Schecter, eds., Social Capital and Social Cohesion in Post-Soviet Russia. Armonk, N.Y.: Sharpe, 2003, 132-51.

Borodulina, N. "Novosibirskaia oblast': ekonomika, partii, lidery." Vlast', no. 9, 1995, 34-39.

Harris, Jonathan. "The Municipal Legislature in Novosibirsk, 1992-95." Dem 5, no. 2 (Spring 1997): 264-80.

Seliverstov, Vyacheslav. "The West Siberian Economic Region, Novosibirsk Oblast and Novosibirsk." In Michael J. Bradshaw and D. J. B. Shaw, eds., Regional Problems during Economic Transition in Russia: Case Studies. Russian Regional Research Group Working Paper Series, no. 1. Birmingham: University of Birmingham, 1996, 90-117.

\section{Omskaia oblast'}

Le Huérou, Anne. "Elites in Omsk." PSA 15, no. 4 (October-December 1999): $362-86$.

Melvin, Neil J. "The Consolidation of a New Regional Élite: The Case of Omsk, 1987-1995." EAS 50, no. 4 (June 1998): 619-50.

Young, John F. "Institutions, Elites, and Local Politics in Russia: The Case of Omsk." In Theodore H. Friedgut and Jeffrey W. Hahn, eds., Local Power and Post-Soviet Politics. Armonk, N.Y.: M. E. Sharpe, 1994, 138-61. 


\section{Orenburgskaia oblast'}

Raguzin, V.N.,E.M.Vinogradova, and V.V.Amelin, "Sostoianiemezhnatsional'nykh otnoshenii $\mathrm{v}$ otsenkakh i predstavleniiakh naseleniia prigranichnykh $\mathrm{s}$ Kazakhstanom raionov Orenburgskoi oblasti." In E. M. Kozhokin, ed., Novaia Evraziia: Rossiia i strany blizhnego zarubezh'ia. Sbornik statei, no. 8. Moscow: Rossiiskii institut strategicheskikh issledovanii, 1998, 23-61.

Osetiia (See R. Severnaia Osetiia-Alaniia)

\section{Penzenskaia oblast'}

Kutyrcheva, N. A. "'Ostaetsia verit' na slovo Chubaisu': itogi privatizatsii v Penzenskoi oblasti, 1992-1996." Guberniia, no. 2, 1996, 157-60.

Matsuzato, K., and Shatilov, A. B., eds. Regiony Rossii: khronika i rukovoditeli.

Vol. 1. Krasnyi poias (Tsentral'noe chernozem'e): Lipetskaia oblast', Tambovskaia oblast', Penzenskaia oblast'. Occasional Papers on Changes in the Slavic-Eurasian World 33. Sapporo: Slavic Research Center, Hokkaido University, 1997, 160-314.

\section{Permskaia oblast'}

Gershanok, Gennady A. "Cats and Mice: The Presidential Campaign in the Russian Heartland." Dem 4, no. 3 (Summer 1996): 349-57.

Leibovich, O. L., and N. V. Shushkova. "Promyshlennye rabochie na Ural'skom zavode." SI, no. 6, 2005, 70-76.

Moses, Joel C. "Political-Economic Elites and Russian Regional Elections, 19992000: Democratic Tendencies in Kaliningrad, Perm, and Volgograd." EAS 54, no. 6 (September 2002): 905-31.

Neganov, S. V. "Permskaia oblast': politicheskii portret regiona i razvitie politicheskoi nauki." Polis, no. 5, 2005, 41-47.

Pallot, Judith, and Dominique Moran. "Surviving the Margins in Post-Soviet Russia: Forestry Villages in Northern Perm Oblast." PSGE 41, no. 5 (JulyAugust 2001): 341-64.

Panov, P. V., and K. A. Punina. "Konflikt i 'poriadok' v regional'nom parlamente (na primere zakonodatel'nogo sobraniia Permskoi oblasti)." Polis, no. 6, 2003, 125-34.

Petersson, Bö. "ATale of Four Cities: Studying National Self-Images among Russian Regional Politicians in Perm, St. Petersburg, Volgograd, and Khabarovsk." 
SPSR 23, no. 3 (1996): 251-84.

. "Russian Self-Images in Perm-Findings from a Pilot Study." In Klas-

Göran Karlsson, Bö Petersson, and Barbara Törnquist-Plewa, eds., Collective

Identities in an Era of Transformations. Lund, Sweden: Lund University Press, 1998, 37-73.

Politicheskii al'manakh Prikam 'ia. Perm': Perm' State University, 2001.

Povarnitsyn, Boris. "Perm Oblast: Autonomies to Choose From." Dem 9, no. 2 (Spring 2001): 243-58.

Umland, Andreas. "'Nur für die Demokratie!' Beobachtungen zu den Wahlen in der russischen Provinz.” Osteuropa 46, no. 11 (November 1996): 1108-16.

\section{Primorskii krai}

Alexseev, Mikhail A., and Tamara Troyakova. "A Mirage of the 'Amur California': Regional Identity and Economic Incentives for Political Separatism in Primorsky Kray.” In Mikhail A. Alexseev, ed., Center-Periphery Conflict in Post-Soviet Russia: A Federation Imperiled. New York: St. Martin's, 1999, 205-47.

Burns, Katherine G. "Primor'e: Local Politics and a Coalition for Reform." In

Timothy J. Colton and Jerry F. Hough, eds., Growing Pains: Russian Democracy and the Election of 1993. Washington, D.C.: Brookings Institution Press, 1998, 567-98.

Busygina, Irina. "Primor'e: sovremennaia situatsiia i perspektivy razvitiia." $S M$, no. 9, 1995, 83-91.

Filicheva, T. P. "Spatial Structure of Consumer Services in Primorskiy Kray, Soviet Far East." SG 31, no. 1 (January 1990): 237-56.

Kirkow, Peter. "Regionale Politik und wirtschaftliche Ausdifferenzierung: eine Fallstudie über Rußlands fernöstlichen Primorskij Kraj." Osteuropa 43, no. 8 (August 1993): 754-70.

- "Regional Warlordism in Russia: The Case of Primorskii Krai." EAS 47, no. 6 (September 1995): 923-47. "Transition in Russia's Principal Coastal Gateways." PSGE 38, no. 5 (May 1997): 296-314.

Kirkow, Peter, and Phil Hanson. "The Potential for Autonomous Regional Development in Russia: The Case of Primorskiy Kray." PSG 35, no. 2 (February 1994): 63-88.

Koniakina, A. P., and N. V. Shinkovskaia. "Parametry evoliutsii politicheskogo rezhima v Primor'e." Polis, no. 2, 2003, 143-49. 
Koshchienko, A. V. "Primorskii krai: ekonomika, partii, lidery.” Vlast', no. 7, 1996, $28-35$.

Minagawa, Shugo. "Regionalism” in a Transitional Period: The Case of Primorskii Krai. Occasional Papers on Changes in the Slavic-Eurasian World 11. Sapporo: Slavic Research Center, Hokkaido University, 1996.

_. "Political Clientelism in Primorskii Krai in the Transitional Period." SPSR 25, no. 2 (1998): 125-48.

Panfilova, O. A. “Tsennostnye orientatsii naselenia Primor'ia.” SI, no. 10, 2004, 117-19.

"Perspektivy Primorskogo kraia $\mathrm{v}$ usloviiakh perekhoda $\mathrm{v}$ rynku $\mathrm{v}$ svete geostrategicheskikh i ekonomicheskikh interesov Rossii." Vestnik DORAN, no. 5-6, 1994, 42-52.

"Perspektivy razvitiia Primorskogo kraia v kontekste geostrategicheskikh i ekonomicheskikh interesov Rossii." PDV, no. 1, 1995, 3-29.

Politicheskaia elita Primorskogo kraia. Occasional Papers on Changes in the Slavic-Eurasian World 4. Sapporo: Slavic Research Center, Hokkaido University, 1995.

Schwanitz, Simone. "Die Wahlen in der Fernostregion Primorje." Osteuropa 46, no. 5 (May 1996): 524-29.

Sozinov, V. A. Regulirovanie ekonomicheskogo razvitiia sub"ekta federatsii: metodologiia, organizatsiia, kontseptsiia. Vladivostok: Vladivostokskii university ekonomiki i servisa, 2004.

Troyakova, Tamara. "Regional Policy in the Russian Far East and the Rise of Localism in Primorye." Journal of East Asian Affairs 9 (Fall 1995): 428-61.

_. "Primorskie 'igry'." Rossiia i ATR, no. 3, 1997, 121-30. . “A Primorsky Republic: Myth or Reality?” CEET 10, no. 3 (September 1998): 391-404.

Turetskii, V. S. "Sostoianie i razvitie ekonomiki Primorskogo kraia." Vestnik DORAN, no. 5-6, 1994, 53-59.

\section{Pskovskaia oblast'}

Alexseev, Mikhail, and Vladimir Vagin. "Russian Regions in Expanding Europe: The Pskov Connection." EAS 51, no. 1 (January 1999): 43-64.

- "Fortress Russia or Gateway to Europe? The Pskov Connection." In Mikhail A. Alexseev, ed., Center-Periphery Conflict in Post-Soviet Russia: A Federation Imperiled. New York: St. Martin's, 1999, 167-204.

Kalistratova, G. E., and G. K. Batalova. "Pskovskaia oblast' v usloviiakh 
prigranich'ia." Voprosy statistiki, no. 5, 2003, 64-69.

Makarychev, Andrey. "Pskov at the Crossroads of Russia's Trans-Border Relations with Estonia and Latvia: Between Provinciality and Marginality." EAS 57, no. 3 (May 2005): 481-500.

Manakov, A. G., and T. M. Ivanova. "Politicheskie subkul'tury Pskovskoi oblasti." SI, no. 8, 2000, 48-53.

Patrushev, V. D., T. M. Karakhanova, and A. L. Teminskii. "Zhizn' gorozhanina desiat' let spustia: panel'noe obsledovanie pskovitian v 1986 i 1995 godakh." Sotsiologi-cheskii zhurnal, no. 1-2, 1996, 161-68.

"Pskovskaia oblast'." Vash vybor, no. 6, 1993, 4-48.

Slider, Darrell, "Pskov Under the LDPR: Elections and Dysfunctional Federalism in One Region." EAS 51, no. 5 (July 1999): 755-67.

Zhuravlev, A. N. "Pskovskaia oblast': ekonomika, partii, lidery." Vlast', no. 4, 1996, 46-51.

\section{Riazanskaia oblast'}

Avdovin, V. S. "Riazanskaia oblast'." In V. Gel'man et al., eds., Organy gosudarstvennoi vlasti sub" ektov Rossiiskoi Federatsii. Moscow: IGPI, 1998, 92-102.

—. "Politicheskaia transformatsiia i ekonomika v Riazanskoi oblasti." In V. Klimanov and N. Zubarevich, eds., Politika i ekonomika v regional'nom izmerenii. Moscow: IGPI/Letnii sad, 2000, 206-27.

. "Vliianie elektoral'nykh institutov i praktik na razvitie regional'noi partiinoi sistemy (Riazanskaia oblast').” In G. M. Liukhterkhandt-Mikhaleva and S. I. Ryzhenkov, eds., Vybory i partii v regionakh Rossii. Moscow: Letnii sad, 2000, 196-213.

- "Vzaimodeistvie trekh urovnei vlasti v Riazanskoi oblasti." In G. M. Liukhterkhandt and S. I. Ryzhenkov, eds., Tsentr-regiony-mestnoe upravlenie. Moscow: IGPI/Letnii sad, 2001, 171-90.

—. 'Riazanskaia oblast': ot 'tsentralizma El'tsina' k 'tsentralizmu Putina' cherez 'antitsentralistskuiu deviatsiiu."” In Kimitaka Matsuzato, ed., Fenomen Vladimira Putina i rossiiskie regiony: pobeda neozhidannaia ili zakonomernaia? Slaviano-evraziiskie issledovaniia 1. Moscow: Materik, 2004, 14-83.

Chizhikova, L. N. “K etnokul'turnoi istorii Riazanskogo kraia.” Etnograficheskoe obozrenie, no. 3, 1996, 79-91.

Regiony Rossii: khronika i rukovoditeli. Vol. 5. Riazanskaia, Vladimirskaia, $i$ 
Tul'skaia oblasti. Ed. K. Matsuzato and A. B. Shatilov. Occasional Papers on Changes in the Slavic-Eurasian World 63. Sapporo: Slavic Research Center, Hokkaido University, 1998, 15-121.

\section{Rostovskaia oblast'}

Evteev, V. A., E. T. Rubinskaia, and G. P. Solodkov. Regional'naia ekonomicheskaia deiatel'nost'. Rostovskaia oblast'vo vneshneekonomicheskikh sviazakh: sostoianie, problemy, tendentsii razvitiia. Rostov-on-Don: Rostizdat, 2003.

Girenko, Iu. A. "Vybory v provintsial'nom izmerenii (na primere Rostovskoi oblasti)." Politiia, no. 2, 1999, 61-74.

Kolosov, V. A., and A. D. Krindach. "Rossiia i byvshie soiuznye respubliki: problemy novogo pogranich'ia (na primere Rostovskoi oblasti).” Polis, no. 4, 1994, 37-48.

Matsuzato, K., and A. B. Shatilov, eds. Regiony Rossii: khronika i rukovoditeli. Vol. 2. Rostovskaia oblast', Saratovskaia oblast'. Occasional Papers on Changes in the Slavic-Eurasian World 34. Sapporo: Slavic Research Center, Hokkaido University, 1997, 9-82.

Ponedelkov, A. V. Politicheskaia elita: genezis i problemy ee stanovleniia v Rossii. Rostov-on-Don: Izdatel'stvo SKNTs VSh, 1995.

Particular attention is paid to elite formation in Rostov region.

Zinchenko, G. "Regional'naia elita na gosudarstvennoi sluzhbe." Vlast', no. 11, 1997, 56-61.

\section{R. Sakha (Iakutiia)}

Balzer, Marjorie Mandelstam, and Uliana Alekseevna Vinokurova. "Nationalism, Interethnic Relations, and Federalism: The Case of the Sakha Republic (Yakutia)." EAS 48, no. 1 (January 1996): 101-20.

Fondahl, Gail, Olga Lazebnik, and Greg Poelzer. "Aboriginal Territorial Rights and the Sovereignty of the Sakha Republic." PSGE 41, no. 6 (September 2000): 401-17.

Gavril'eva, T. N., and N. V. Bochkarev. "Finansovye potoki vnebiudzhetnykh fondov Respubliki Sakha (Iakutiia)." Ekonomika i organizatsiia promyshlennogo proizvodstva, no. 10, 2000, 118-29.

Gorokhova, E. Z. "Metasotsial'naia struktura naseleniia Respubliki Sakha (Iakutiia) v etnicheskom inter'ere." SI, no. 7, 2000, 98-103.

"Iakutiia: suverenitet u poliusa kholoda." $R F$, no. 3, 1995, 16-32.

Ivanov, V. N., ed. Natsional'naia politika v regione: po materialam Respubliki 
Sakha (Iakutiia). Iakutsk: Iakutskii nauchnyi tsentr SO RAN, 1993.

- Respublika Sakha (Iakutiia) na rubezhe XX-XXI vekov: ukreplenie gosudarstvennosti. Novosibirsk: Nauka, 1997.

_- Etnosotsial'noe razvitie Respubliki Sakha (Iakutiia): potentsial, tendentsii, perspektivy. Novosibirsk: Nauka, 2000.

— AN RS(IA), 2000.

Kempton, Daniel R. "The Republic of Sakha (Yakutia): The Evolution of CentrePeriphery Relations in the Russian Federation.” EAS 48, no. 4 (June 1996): 587-613.

Jordan, Bella Bychkova, and Terry G. Jordan-Bychkov. Siberian Village: Land and Life in the Sakha Republic. Minneapolis: University of Minnesota Press, 2001.

Marples, David R. "Environment and Health Problems in the Sakha Republic." PSGE 40, no. 1 (January 1999): 62-77.

Mostakhova, T. S. 'Smertnost' i prodolzhitel'nost' zhizni v Respublike Sakha (Iakutiia)." SI, no. 3, 1999, 97-102.

Miliukov, O. "Iakutiia v poiske.” Rossiia, no. 4, 1997, 40-56.

Pakhomov, A. A. "Osobennosti transformatsii sem'i i gosudarstvennoi semeinoi politiki: na primere Respubliki Sakha (Iakutiia).” SI, no. 12, 2005, 101-08.

"Respublika pod Severnoi Zvezdoi." RF, no. 23, 1996, 25-40.

Sasaki, Shiro. "Segmentary Hierarchy of Identity: The Case of Yakuts and Evens in Northern Yakutia." In Koichi Inoue and Tomohiko Uyama, eds., Quest for Models of Coexistence: National and Ethnic Dimensions of Changes in the Slavic Eurasian World. Sapporo: Slavic Research Center, Hokkaido University, 1998, 317-37.

Tarasov, Iu. S. "Praviashchaia elita Iakutii: shtrikhi k portretu." Polis, no. 2, 1993, 171-73.

Tichotsky, John. Russia's Diamond Colony: The Republic of Sakha. Amsterdam: Harwood Academic, 2000.

Tomsky, I. E. Voprosy stanovleniia gosudarstvennosti Respubliki Sakha (Iakutiia). Iakutsk: Iakutskii gosudarstvennyi universitet, 2000.

Vinokurova, T. Z. "Etnicheskie aspekty demograficheskikh problem v Respublike Sakha (Iakutiia).” SI, no. 6, 1999, 77-80.

\section{Sakhalinskaia oblast'}

Elizar'ev, V. N. Mezhdunarodnye i vneshneekonomicheskie sviazi sub"ekta 
Rossiiskoi Federatsii (na primere Sakhalinskoi oblasti). Iuzhno-Sakhalinsk: Sakhalinskaia oblastnaia tipografiia, 2001.

Grant, Bruce. In the Soviet House of Culture: A Century of Perestroikas. Princeton, N.J.: Princeton University Press, 1995.

An ethnographic study of the Nikhvi; there is some discussion of postcommunist developments.

Merzlikin, N. V., et al. Regional'noe izmerenie politicheskogo protsessa (sotsiologicheskii analiz sostoianiia $i$ dinamiki razvitiia sotsial'nopoliticheskoi situatsii na Sakhaline). Moscow: ISPI RAN, 1999.

Sagers, Matthew J. "Prospects for Oil and Gas Development in Russia's Sakhalin Oblast." PSG 36, no. 5 (May 1995): 274-90.

Zimine, Dmitri, and Michael Bradshaw. "Local Politics, Economic Structure, and Performance: The Case of Sakhalin.” EGE 44, no. 4 (June 2003): 287-304.

\section{Samarskaia oblast’}

Alaksheev, S. Iu., and I. N. Tartakovskaia. "Ideologicheskie stereotipy izbiratelei v Samare." Sotsiologicheskii zhurnal, no. 1-2, 1996, 182-90.

Aleksandrov, A. A. "Samarskaia oblast': politicheskie protsessy, 1997-2000 gg."

In Kimitaka Matsuzato, ed., Fenomen Vladimira Putina i rossiiskie regiony: pobeda neozhidannaia ili zakonomernaia? Slaviano-evraziiskie issledovaniia 1. Moscow: Materik, 2004, 141-94.

Ekonomika Samarskoi oblasti na rubezhe vekov. Samara: SGEA, 2000.

Hanson, Philip. "Samara: A Preliminary Profile of a Russian Region and Its Adaptation to the Market." EAS 49, no. 3 (May 1997): 407-27.

Konitzer-Smirnov, Andrew. "Breaching the Soviet Social Contract: Post-Soviet Social Policy Development in Ulyanovsk and Samara Oblasts." In Judyth L.

Twigg and Kate Schecter, eds., Social Capital and Social Cohesion in PostSoviet Russia. Armonk, N.Y.: M. E. Sharpe, 2003, 189-216.

Kupriianycheva, E. B. "Osobennosti politicheskoi elity Samarskoi oblasti." Polis, no. $3,1999,115-18$.

Kuznetsov, V. A., and E. Iu. Meleshkina. "Elektorat provintsial'noi Rossii (po materialam Samarskoi oblasti).” Polis, no. 3, 1999, 105-14.

Lapina, N. Iu., and A. E. Chirikova. Regiony-lidery: ekonomika i politicheskaya dinamika. Moscow: Institut sotsiologii RAN, 2002.

Focuses on Iaroslavl' and Samara regions.

Lapshova, E. M. 'Samarskaia oblast': 'Den' deistvii' 27 marta [1997 goda] i ego sotsial'no-politicheskii kontekst.” In G. M. Mikhaleva and S. I. Ryzhenkov, 
eds., Grazhdane i vlast': problemy i podkhody. Moscow: Letnii sad, 2001, 96-119.

Luchterhandt, Galina. "Politics in the Russian Province: Revda and Kinel'." EAS 49, no. 1 (January 1997): 59-87.

Manaenkov, I., and G. Marchenko. "Samarskaia oblast': peregruppirovka politicheskikh sil nananune parlamentskikh vyborov." Vlast', no. 5, 1999, $20-22$.

Matsuzato, Kimitaka. "The Split and Reconfiguration of Ex-Communist Party Factions in the Russian Oblasts: Chelyabinsk, Samara, Ulyanovsk, Tambov, and Tver (1991-95)." Dem 5, no. 1 (Winter 1997): 53-88.

Matsuzato, Kimitka, and A. B. Shatilov, eds. Regiony Rossii: khronika i rukovoditeli.

Vol. 3. Samarskaia oblast', Iaroslavskaia oblast'. Occasional Papers on Changes in the Slavic-Eurasian World 35. Sapporo: Slavic Research Center, Hokkaido University, 1997, 15-197.

Romanov, N. V. "Negosudarstvennye organizatsii Samarskoi oblasti." In G. M. Mikhaleva and S. I. Ryzhenkov, eds., Grazhdane i vlast': problemy i podkhody, Moscow: Letnii sad, 2001, 70-87.

Romanov, Pavel, and Irina Tartakovskaya. "Samara Oblast': A Governor and his Guberniya." CEET 10, no. 3 (September 1998): 341-61.

Romanov, P. V. "Negosudarstvennye organizatsii v Samarskoi oblasti." Sotsiologicheskii zhurnal, no. 2, 2001, 56-62.

"Samarskoi oblasti-150 let." Rossiiskaia Federatsiia segodnia, no. 22, 2001, 41-50.

Tarusina, I. G. "Dinamika politicheskikh ustanovok regional'nykh elit Rossii (na primere Samarskoi oblasti)." Polis, no. 1, 2002, 133-40.

"U nas v gostiakh—sotsiologi Samary." SI, no. 7, 2001, 38-79.

Sequence of seven articles on social aspects of Samara region.

Vorontsova, A. B., and V. B. Zvonovskii. "Administrativnyi resurs kak fenomen rossiiskogo izbiratel'nogo protsessa." Polis, no. 6, 2003, 114-24.

Zhabin, A. P., et al., eds. Ekonomika Samarskoi oblasti na rubezhe vekov. Samara: SGAE, 2000.

\section{Saratovskaia oblast’}

Dines, V., and A. Durnov. "Opyt regulirovaniia mezhetnicheskikh otnoshenii v Saratovskoi oblasti." Vlast', no. 3, 2000, 77-81.

Dines, V., and A. Nikolaev. "Opyt stanovleniia regional'nogo parlamenta." Vlast', no. $12,2004,57-63$. 
Dines, V., and A. Novikov. "Regiony idut na vybory: Saratovskaia oblast'." Vlast', no. $11,1999,29-32$.

Dines, V. A., et al. "Problemy ukrepleniia regional'noi bezopasnosti." Vlast', no. 3, 2001, 55-61.

- "KPRF v politicheskoi zhizni Saratovskoi oblasti." Vlast', no. 2, 2003, $35-39$.

Durnov, Aleksandr. "Opyt realizatsii Saratovskogo zakona 'O zemle.'” Vlast', no. $1,2003,3-8$.

Fomin, O. N., R. E. Pashian, and V. A. Rusanov. Desiatiletie reform v zerkale obshchestvennogo mneniia: Saratovskaia oblast'v 1992-2002 godakh.

Saratov: Povolzhskaia akademiia gosudarstvennoi sluzhby, 2004.

Gerasimova, V. V., ed. Rezervy ekonomicheskogo rosta v regione. Saratov: Povolzhskaia akademiia gosudarstvennoi sluzhby, 2004.

Golub, Iu., V. Dines, and D. Konnichev. "Saratovskaia oblast': konsolidatsiia vlasti." Vlast', no. 5, 1998, 37-45.

Kamshilov, P. "Itogi i perspektivy razvitiia Saratovskoi oblasti." Vlast', no. 1, 2000, 52-57.

Linder, Rainer. "Rußlands Regionen zwischen Autoritarismus und Transformation: Wirtschaft, Politik und Eliten im Gebiet Saratov." Osteuropa 50, no. 4 (April 2000): 410-25.

Matsuzato, K., and A. B. Shatilov, eds. Regiony Rossii: khronika i rukovoditeli. Vol. 2. Rostovskaia oblast', Saratovskaia oblast'. Occasional Papers on Changes in the Slavic-Eurasian World 34. Sapporo: Slavic Research Center, Hokkaido University, 1997, 83-331.

Moses, Joel C. "Saratov and Volgograd, 1990-1992: A Tale of Two Russian Provinces." In Theodore H. Friedgut and Jeffrey W. Hahn, eds., Local Power and Post-Soviet Politics. Armonk, N.Y.: M. E. Sharpe, 1994, 96-137.

Ragimova, O. A. “Zdorov'e mladshikh shkol'nikov Saratova.” SI, no. 11, 2003, $69-72$.

Ryzhenkov, S. Saratovskaia oblast': politika i politiki (1986-1996). Moscow: IGPI, 1996.

Ryzhenkov, S., and G. Liukhterkhandt-Mikhaleva, eds. Politika i kul 'tura v rossiiskoi provintsii: Novgorodskaia, Voronezhskaia, Saratovskaia, Sverdlovskaia oblasti. Moscow: Letnii sad, 2001.

Smyth, Regina. "Political Ambition, Elite Competition, and Electoral Success in Saratov Oblast." In Timothy J. Colton and Jerry F. Hough, eds., Growing Pains: Russian Democracy and the Election of 1993. Washington, D.C.: 
Brookings Institution Press, 1998, 463-90.

Sovremennaia regional'naia promyshlennaia politika: problemy formirovaniia $i$ mekhanizmy realizatsii. Saratov: PAGS, 2004.

Stykow, Petra. "Elite Transformation in the Saratov Region." In Vladimir

Shlapentokh et al., eds., The New Elite in Post-Communist Eastern Europe.

College Station: Texas A\&M University Press, 201-22.

Šutov, Andrej. "Das Modell eines pragmatischen Politikers für die russischen

Regionen: D. F. Ajackov und die Gouverneurswahlen in Saratov." Osteuropa 47, no. 6 (June 1997): 557-68.

Tarusina, I. G. "Dinamika politicheskikh ustanovok regional'noi elity Rossii (na primere Saratovskoi oblasti).” Polis, no. 1, 2002, 133-40.

\section{R. Severnaia Osetiia-Alaniia (Northern Ossetia)}

Archegova, L. "Demograficheskaia situatsiia: sovremennost' i perspektivy." Dar'ial, no. 1, 2000, 178-91.

Dzutsev, Kh. "Narod i vlast."” Vlast', no. 6, 2003, 53-61.

Fokin, V. A. "Severnaia Osetiia i Ingushetiia: problemy i vozmozhnye resheniia." Kentavr, no. 3, 1995, 82-95.

Gostieva, L. K., et al., eds. Severnaia Osetiia: etnopoliticheskie protsessy 19901994 gg.: ocherki, dokumenty, khronika. Moscow: Tsentr po izucheniiu mezhnatsional'nykh otnoshenii, 1995.

Jandieva, Mar'iam. "Der ethnoterritoriale Konflikt in Prigorodnyj-Bezirk Nordossetiens." Osteuropa 52, no. 11 (November 2002): 1473-90.

Kritsky, E. V. "Vospriiatie konflikta kak indikator mezhetnicheskoi napriazhennosti: na primere Severnoi Osetii." SI, no. 9, 1996, 116-21.

Skakunov, E. K. "Sotsiokul'turnyi analiz osetino-ingushetskogo konflikta." SI, no. 7, 1997, 124-30.

\section{Siberia}

Balzer, Marjorie Mandelstam. "Dilemmas of Federalism in Siberia." In Mikhail A. Alexseev, ed., Center-Periphery Conflict in Post-Soviet Russia: A Federation Imperiled. New York: St. Martin's, 1999, 131-67.

. The Tenacity of Ethnicity: A Siberian Saga in Global Perspective. Princeton,

N.J.: Princeton University Press, 1999.

Boronoev, A. O., ed. Sibir': problemy sibirskoi identichnosti. St. Petersburg: Asterion, 2003.

_. Problemy sibirskoi mental'nosti. St. Petersburg: Asterion, 2004. 
Fondahl, Gail A. "Contested Terrain: Changing Boundaries and Identities in Southeastern Siberia." PSGE 37, no. 1 (January 1996): 3-15.

Funk, D. A., et al., eds. Praktika postsovetskikh adaptatsii narodov Sibiri. Moscow: Nauka, 2005.

Gokhberg, M. "Sibirskii ekonomicheskiiokrug(Vostochno-Sibirskiiekonomicheskii okrug)." Ekonomist, no. 1, 2001, 66-75.

Golovnev, A. V., and G. Osherenko. Siberian Survival: The Nenets and Their Story. Ithaca, N.Y.: Cornell University Press, 2002.

Hughes, James. "Regionalism in Russia: The Rise and Fall of Siberian Agreement." EAS 46, no. 7 (1994): 1133-62.

Kalugina, Z. I. Sotsial'naia mnogolikost'Sibiri v period obshchestvennykh peremen. Novosibirsk: IEiOPP SO RAN, 2003.

"Panel on Siberia: Economic and Territorial Issues." SG 32, no. 6 (June 1991): 363-432.

Popkov, Iu. V., V. G. Kostiug, and V. N. Tuguzhekova. Etnosy Sibiri v usloviiakh sovremennykh reform (sotsiologicheskaia ekspertiza). Novosibirsk: Nonparel', 2003.

Region: ekonomika i sotsiologiia. Novosibirsk: Russian Academy of Sciences,

Siberian Section, 1993-.

Published since 1963; under this title since 1993. Quarterly.

Scharff, Roland. "Demographische Wende in Siberien." Osteuropa 45, no. 3 (March 1995): 267-75.

"Sibir': ee mesto v rossiiskikh i mirovykh delakh." MZh, no. 4, 1993, 6-160.

Vitebsky, Piers. Reindeer People: Living with Animals and Spirits in Siberia.

London: HarperCollins, 2005.

Based on anthropological work among the Eveny.

See also: Western Siberia.

\section{Smolenskaia oblast'}

Evdokimov, M. Iu. "Problemy ekonomiko-politicheskoi transformatsii rossiiskogo pogranich'ia (na primere Smolenskoi oblasti)." In V. Klimanov and N. Zubarevich, eds., Politika i ekonomika v regional'nom izmerenii. Moscow: IGPI/Letnii sad, 2000, 228-33.

Lallemand, Jean-Charles. "Politics for the Few: Elites in Bryansk and Smolensk." PSA 15, no. 4 (October-December 1999): 312-35. 


\section{The South}

Ignatov, V. G., and V. I. Butov. Iuzhnaya Rossiia i ee regiony: sovremennoe sostoianie i problemy razvitiia. Moscow: MarT, 2006.

Kolosov, V.A., and A. D. Krindach. "Tendentsii postsovetskogo razvitiya massovogo soznaniya i politicheskaia kul'tura Iuga Rossii." Polis, no. 6, 1994, 120-33.

Particular reference is made to Rostov, Krasnodar, and Stavropol.

\section{Southern Federal District}

Agaponov, Aleksandr. “Otvetstvennost' regional'noi politicheskoi vlasti: analiz i tekhnologiia (na primere Iuzhnogo federal'nogo okruga)." Vlast', no. 6, 2004, $28-37$.

\section{Stavropol'skii krai}

Chikhichin, V. V. "Politiko-geograficheskie obrazy sub"ektov RF: faktory formirovaniia (na primere Stavropol'skogo kraia)." Polis, no. 2, 2005, 6471.

Kolosov, V. A., T. A. Galkina, and A. D. Krindach. “Territorial'naia identichnost' i mezhetnicheskieotnosheniia(na primere vostochnykhraionov Stavropol'skogo kraiia)." Polis, no. 2, 2001, 61-77.

Lazareva, G. I., and O. P. Rozhkov. Regional'naia promyshlenno-investitsionnaia politika i biudzhet Stavropol'skogo kraia. Stavropol': SevKavGTI, 2005.

Levitan, A. B. Ekonomika Khabarskogo kraia: problemy i perspektivy razvitiia. Vladivostok: Dal'nauka, 2004.

Matskovich, T. N. Problemy sotsial'no-ekonomicheskogo razvitiia regiona. Stavropol': Agrus, 2005.

Novikova, O. S., I. O. Babkin, and A. Iu. Khots. "Mnenie regional'noi elity." SI, no. 9, 2001, 37-41.

Popova, E. A. "Problemnye izmereniia elektoral'noi politiki v Rossii: gubernatorskie vybory v sravnitel'noi perspective." Polis, no. 3, 2001, 47-62.

\section{St. Petersburg / Leningradskaia oblast'}

Achkasova, V., and A. Duka. "Konflikty i kompromissy v strukturakh regional'noi politicheskoi elity: tipologiia protivoborstva (Sankt-Peterburg v period transformatsii sistemy)." Strategiia, no. 9, 1997, 42-51.

_. "Regional'naia politicheskaia vlast': elitnye konflikty i vozmozhnosti soglashenii." In Dzh. Azrael et al., eds., Evoliutsiia vzaimootnoshenii tsentra $i$ 
regionov Rossii: ot konflikta k poisku soglasiia. Moscow: Kompleks-Progress, 1997, 191-206.

Andrews, Jo, and Alexandra Vacroux. "Political Change in Leningrad: The Elections of 1990." In Theodore H. Friedgut and Jeffrey W. Hahn, eds. Local Power and Post-Soviet Politics. Armonk, N.Y.: M. E. Sharpe, 1994, 43-72.

Artemov, G. P., et al. "Elektoral'nye ob"edineniia Rossii: opyt provedeniia exitpoll v Sankt-Peterburge." Polis, no. 2, 2000, 54-67.

Bater, James H., and John R. Staples. "Planning for Change in Central St. Petersburg." PSGE 41, no. 2 (March 2000): 77-97.

Brudny, Yitzhak M. "St. Petersburg: The Election in the Democratic Metropolis."

In Timothy J. Colton and Jerry F. Hough, eds., Growing Pains: Russian Democracy and the Election of 1993. Washington, D.C.: Brookings Institution Press, 1998, 349-96.

Campbell, Adrian. "Local Government Policymaking and Management in Russia: The Case of St. Petersburg.” Policy Studies Journal 21, no. 1 (Spring 1993): $133-41$.

Darinskii, A. V. Nevskii krai: Sankt-Peterburg i Leningradskaia oblast'. Priroda. Naselenie. Khoziaistvo. Regiony. St. Petersburg: Glagol, 2000.

Drabkina, T. M. “Zakonodatel'nyi (predstavitel'nyi) organ vlasti Leningrada-Sankt Peterburga: elektoral'naia istoriia." In G. Liukhterkhandt-Mikhaleva and S. Ryzhenkov, eds., Vybory $i$ partii v regionakh Rossii, Moscow: Letnii sad, 2000, 214-27.

Duka, Alexandr. "Institutsionalizatsiia politiko-administrativnoi elity v SanktPeterburge." Politiia, no. 2 (29), Summer 2003, 126-49. - "Reforms and Orientations of Regional Elites: The Case of St. Petersburg. In Anton Steen and Vladimir Gel'man, eds., Elites and Democratic Development in Russia. London: Routledge, 2003, 148-67.

Gel'man, Vladimir, and Mary McAuley. "The Politics of City Government: Leningrad/St. Petersburg, 1990-1992." In Theodore H. Friedgut and Jeffrey W. Hahn, eds., Local Power and Post-Soviet Politics. Armonk, N.Y: M. E. Sharpe, 1994, 15-42.

Golofast, B. V., et al. "Elita Peterburga glazami naseleniia.” Mir Rossii, no. 2, 1995, 90-105.

Golosov, Grigorii, and Vadim Goncharov. "High Stakes, Low Chances: The Failure of Party Politics in St. Petersburg." In Cameron Ross, ed., Regional Politics in Russia. Manchester: Manchester University Press, 2002, 77-94.

Hahn, Gordon. "Managed Democracy? Building Stealth Authoritarianism in St. 
Petersburg," Dem 12, no. 2 (Spring 2004): 195-231.

Hahn, Jeffrey W. "St. Petersburg and the Decline of Local Self-Government in Post-Soviet Russia." PSA 20, no. 2 (April-June 2004): 107-31.

Kihlgren, Allesandro. "Economic Policy in Post-Soviet St. Petersburg." EGE 44, no. 5 (July-August 2003): 368-83.

Kornev, N. P. “Zhilishchnaia stratifikatsiia v tsentre Sankt-Peterburga.” SI, no. 6, 2005, 77-85.

Kozlovsky, V. V., ed. Sankt-Peterburg v zerkale sotsiologii. St. Petersburg: Sotsiologicheskoe obshchestvo im. M. M. Kovalevskogo, 2003.

Kugel, Samuil, ed. Sotsial'nye i politicheskie orientatsatsii Sankt-Peterburgskoi elity. St. Petersburg: Izdatel'stvo Sankt-Peterburgskogo universiteta ekonomiki i finansov, 1998.

Leikind, O., and D. Severiukhin, eds. Negosudarstvennye organizatsii SanktPeterburga: spravochnik. St. Petersburg: Notabene, 1997.

Matsuzato, K., and A. B. Shatilov, eds. Regiony Rossii: khronika i rukovoditeli. Vol.

4. Leningradskaia oblast', Kaliningradskaia oblast'. Occasional Papers on Changes in the Slavic-Eurasian World 36. Sapporo: Slavic Research Center, Hokkaido University, 1997, 13-112.

Orttung, Robert W. From Leningrad to St. Petersburg: Democratisation in a Russian City. Basingstoke: Macmillan, 1995.

Petersson, Bö. "A Tale of Four Cities: Studying National Self-Images among Russian Regional Politicians in Perm, St. Petersburg, Volgograd, and Khabarovsk." SPSR 23, no. 3 (1996): 251-84.

Rabzhaeva, M. V., and V. E. Semenkov. "Kakaia identichnost' u zhitelei SanktPeterburga?" SI, no. 3, 2003, 82-89.

"Region krupnym planom: Leningradskaia oblast'." $R F$, no. 13, 1997, 25-40.

"Russkii gorod na pereput'e: Sankt-Peterburg." Mir Rossii, no. 2, 1995, 64-201.

Trautmann, Ljuba. "St. Petersburg wählte demokratisch." Osteuropa 46, no. 5 (May 1996): 474-82.

_. "Führungswechsel an der Newa: Bürgermeister und Präsidentswahlen in St. Petersburg." Osteuropa 46, no. 11 (November 1996): 1124-35.

Vinnikov, Alexander. "The End of Soviet Power in St. Petersburg: An Insider's View." EAS 46, no. 7 (1994): 1215-30.

Vishnevsky, B. L. "Peterburgskie vybory: turnir provokatorov." Polis, no. 2, 1999, 98-109. $105-22$. 
"Vozrozhdenie Rossii kak morskoi derzhavy nachnetsya s Leningradskoi oblasti." Rossiia, no. 5, 1997, 48-63.

Wehner, Markus. "St. Petersburg —Winter 1998: Der Mord an Galina Starovojtova und die Wahlen zum Stadtparlament.” Osteuropa 49, no. 3 (March 1999): 231-40.

\section{Sverdlovskaia oblast'}

Baranova, S. V. "Polozhenie vynuzhdennykh migrantov v Sverdlovskoi oblasti." SI, no. 2, 2005, 139-41.

Berzin, B. Iu., and V. T. Maklakov. "Vybory gubernatora v regione." SI, no. 5, 1996, 56-64.

Easter, Gerald M. "Redefining Centre-Regional Relations in the Russian Federation: Sverdlovsk Oblast'.” EAS 49, no. 4 (June 1997): 617-35.

Ekonomicheskaia entsiklopediia regionov Rossii: Sverdlovskaia oblast'. Ed. A. I. Tatakin. Moscow: Ekonomika, 2003.

The first of a projected 95 -volume series. Of these, 89 will deal with individual subjects of the Federation, 5 will consider cross-regional issues, and there will be a reference volume.

Ettner, Hagen. "Föderalismus: To Be or Not To Be? Das Gebiet Sverdlovsk im Föderationsgefüge Russlands." Osteuropa 55, no. 2 (February 2005): 58-74.

Gel'man, Vladimir, and Grigorii V. Golosov. "Politicheskie partii v Sverdlovskoi oblasti: regional'nye praktiki v sravnitel'noi perspective." MEMO, no. 5, 1998, 133-44.

—. "Regional Party System Formation in Russia: The Deviant Case of Sverdlovsk Oblast." In John Löwenhardt, ed., Party Politics in PostCommunist Russia. London: Frank Cass, 1998, 31-53.

Hübner, Peter, Galina Luchterhandt, and Eberhard Schneider. "Als Wahlbeobachter in Jekaterinburg und Perwouralsk." Osteuropa 46, no. 5 (May 1996): 50718.

Kukolev, I. V. "Provintsial'nyi aspekt politiko-ekonomicheskikh elit." Vlast', no. 4, 1997, 42-47.

Luchterhandt, Galina. "Politics in the Russian Province: Revda and Kinel'." EAS 49, no. 1 (January 1997): 59-87.

Moser, Robert G. "Sverdlovsk: Mixed Results in a Hotbed of Regional Autonomy." In Timothy J. Colton and Jerry F. Hough, eds., Growing Pains: Russian Democracy and the Election of 1993. Washington, D.C.: Brookings Institution Press, 1998, 397-430. 
Nelson, Lynn D., and Irina Y. Kuzes. "Interest Representation in Sverdlovsk and the Ascendancy of Regional Corporatism.” Dem 5, no. 2 (Spring 1997): 222-36. . "Elites and Institutions in Russian Economic Transformation: The Case of Sverdlovsk." In David Lane, ed., The Legacy of State Socialism and the Future of Transformation. Lanham, Md.: Rowman Littlefield, 2002, 87-105. Ryzhenkov, S., and G. Liukhterkhandt-Mikhaleva, eds. Politika i kul 'tura v rossiiskoi provintsii: Novgorodskaia, Voronezhskaia, Saratovskaia, Sverdlovskaia oblasti. Moscow: Letnii sad, 2001.

Skul'movskaia, L. G. Region kak sub"ekt funktsionirovaniia i razvitiia kul'tury. Ekaterinburg: Izdatel'stvo Uralskogo universiteta, 2005.

Startsev, Yaroslav. "Gubernatorial Politics in Sverdlovsk Oblast'." PSA 15, no. 4 (October-December 1999): 336-61.

Sutherland, Douglas, and Kirill Novosellski. "The Urals Economic Region, Sverdlovsk Oblast, and Ekaterinburg." In Michael J. Bradshaw and D. J. B. Shaw, eds., Regional Problems during Economic Transition in Russia: Case Studies. Russian Regional Research Group Working Paper Series, no. 1. Birmingham: University of Birmingham, 1996, 58-89.

\section{Tambovskaia oblast’}

Matsuzato, Kimitaka. "The Split and Reconfiguration of Ex-Communist Party Factions in the Russian Oblasts: Chelyabinsk, Samara, Ulyanovsk, Tambov, and Tver (1991-95)." Dem 5, no. 1 (Winter 1997): 53-88.

Matsuzato, K., and A. B. Shatilov, eds. Regiony Rossii: khronika i rukovoditeli. Vol. 1. Krasnyi poias (Tsentral'noe chernozem'e): Lipetskaia oblast', Tambovskaia oblast', Penzenskaia oblast'. Occasional Papers on Changes in the Slavic-Eurasian World 33. Sapporo: Slavic Research Center, Hokkaido University, 1997, 85-157.

Sel'tser, D. G. "Ot A. I. Riabova do O. I. Betina: O traditsionnoi paradigme 'kommunisty-demokraty', klanovosti i fenomene Vladimira Putina (Tambovskaia oblast', 1995-2000 gg.).” In Kimitaka Matsuzato, ed., Fenomen Vladimira Putina i rossiiskie regiony: pobeda neozhidannaia ili zakonomernaia? Slaviano-evraziiskie issledovaniia 1. Moscow: Materik, 2004, 84-140.

“Tambov na karte federal'noi." Rossiiskaia Federatsiia segodnia, no. 22, 2000, 47-66.

Vlast', politika $i$ vybory v regionakh: voprosy istorii, zakonodatel'stva i praktiki. Sbornik statei. Tambov: Tambovskaia oblastnaia izbiratel'naia komissiia, 
2002.

Devotes particular attention to the elections to the Tambov Duma in 2001.

\section{R. Tatarstan}

Arslanova, A. A., et al., eds. Aktual'nye problemy istorii gosudarstvennosti tatarskogo naroda. Kazan': Matbugat iorty, 2000.

Bondarenko, E. A. "Respublika Tatarstan: natsional'nye otnosheniiia." SI, no. 11, 1999, 68-72.

Bukharaev, Ravil. The Model of Tatarstan under Mintimer Shaimiev. London: RoutledgeCurzon, 1999.

- Prezident Mintimir Shaimiev i model' Tatarstana. St. Petersburg: Blits, 2000.

_. "Model' Tatarstana: politika kak tvorchestvo." Druzhba narodov, no. 5, 2001, 169-89.

Daucé, Françoise. "La religion dans les mouvements identitaires post-soviétiques: L'exemple du Tatarstan." Revue d'études comparatives est-ouest 34, no. 4 (December 2003): 59-76.

Derluguian, Georgi M. "Ethnofederalism and Ethnonationalism in the Separatist Politics of Chechnya and Tatarstan: Sources or Resources?" International Journal of Public Administration 22, no. 9-10 (1999): 1387-428.

Farukhshin [sic], Midkhat. "Tatarstan: Syndrome of Authoritarianism.” In Cameron Ross, ed., Regional Politics in Russia. Manchester: Manchester University Press, 2002, 193-206.

Farukshin, M. Kh. "Politicheskaia elita $\mathrm{v}$ Tatarstane: vyzovy vremeni i trudnosti adaptatsii." Polis, no. 6, 1994, 67-79.

. "The Ruling Elite of Tatarstan: Contemporary Challenges and Problems of Adjustment." In Vladimir Shlapentokh et al., eds., The New Elite in PostCommunist Eastern Europe. College Station: Texas A\&M University Press, 1999, 223-40.

_. "Avtoritarnaia situatsiia v regional'nom prelomenii: Tatarstan." Politiia, no. 4 (14), Winter 1999, 122-32.

Farukshin, M. Kh., and N. M. Mukhamiarov. "Mezhetnicheskie otnosheniia v Respublike Tatarstan: usloviia i perspektivy stabil'nosti.” Regionologiia, no. 6, 1995, 45-57.

Farukshin, M. Kh., and V.V. Mikhailov, eds. Chto khotel by znat'izbiratel'Tatarstana o vyborakh (no ne znaet gde ego sprosit'). Kazan': GranDan, 2002.

A collection of critical papers on the state of democracy in Tatarstan; a concluding chapter 
offers comparisons with Komi, and an appendix includes the results of the most recent federal elections in Tatarstan and of the election of presidential election in the republic in 2001 .

Filippova, E. V., ed. Tatarstan: osnovy politicheskogo ustroistva $i$ kratkaia kharakteristika ekonomiki (spravochnik). Moscow: Fond razvitiia parlamentarizma v Rossii, 1996.

Frank, A. Islamic Historiography and "Bulghar" Identity among the Tatars and Bashkirs of Russia. Leiden: Brill, 1998.

Gabdrakhmanova, G. F. 'Rol' migratsii v preobrazovanii etnicheskoi struktury Tatarstana." SI, no. 6, 2004, 62-68.

Giuliano, Elise. "Who Determines the Self in the Politics of Self-Determination? Identity and Preference Formation in Tatarstan's Nationalist Mobilization." Comparative Politics 32, no. 3 (April 2000): 295-316.

Golubko, M. N. "Opyt i uroki soverenizatsii (na materialakh Bashkortostana i Tatarstana)." Otechestvennaia istoriia, no. 2, 1995, 17-52.

Gorenburg, Dmitry. "Not with One Voice: An Explanation of Intragroup Variation in Nationalist Sentiment." World Politics 53, no. 1 (October 2000): 115-42.

Graney, Katherine E. "Education Reform in Tatarstan and Bashkortostan: Sovereignty Projects in Post-Soviet Russia.” EAS 51, no. 4 (June 1999): 61132.

."Ten Years of Sovereignty in Tatarstan: End of the Beginning or Beginning of the End?" PPC 48, no. 5 (September-October 2001): 32-41.

Ishakov, D. M., ed. Tatarskaia natsiia: istorii i sovremennost'. Kazan': Magarif, 2002.

Ivanov, V. V., et al. "Chelnochnyi biznes v Rossii.” SI, no. 11, 1998, 40-44.

Jentzsch, Corinna, and Manja Nickel. "Die Qual der Dumawahl: Wahlbeobachtung in Tatarstan 2003." Osteuropa 54, no. 1 (January 2004): 8-16.

Jones Luong, Pauline. "Tatarstan: Elite Bargaining and Ethnic Separatism." In Timothy J. Colton and Jerry F. Hough, eds., Growing Pains: Russian Democracy and the Election of 1993. Washington, D.C.: Brookings Institution Press, 1998, 637-68.

Kaplan, Cynthia S. "International Negotiations and Plural Societies: The Cases of

Estonia and Tatarstan." International Negotiation 2, no. 1 (1997): 43-78.

Khabenskaia, E. O. Tatary o Tatarstanom. Moscow: Natalis, 2002.

Deals with models of ethnic identity among Tatar intellectuals in Moscow, Kazan', and Saratov.

Khakim, Rafael'. Sumerki imperii: kvoprosu natsii i gosudarstva. Kazan': Tatarskoe 
knizhnoe izdatel'stvo, 1993.

Kondrashov, Sergei. Nationalism and the Drive for Sovereignty in Tatarstan, 198892. New York: St. Martin's, 2000.

Lewis, D. C. "Ethnicity and Religion in Tatarstan and the Volga-Ural Region." Central Asian Survey 16, no. 2 (June 1997): 215-36.

Löwenhardt, John. "The 1996 Presidential Elections in Tatarstan.” JCSTP13, no. 1 (March 1997): 132-44.

Löwenhardt, John, and Ruben Verheul. "The Village Votes: The December 1999 Elections in Tatarstan's Pestretsy District." JCSTP 16, no. 3 (September 2000): 113-22.

Makhmud, A. "Nezavisimoe gosudarstvo Tatarstan." Nezavisimaia otchizna, no. 1, 1996, 3-75.

McCann, Leo. "Globalization and Post-Socialist Development: The Tatarstan Variety of Capitalism." PCE 16, no. 3 (September 2004): 349-62.

. Economic Development in Tatarstan: Global Markets and a Russian

Region. London: RoutledgeCurzon, 2005.

Mikhailov, Valentin. "Tatarstan. Jahre der Souveränität: Eine kurze Bilanz." Osteuropa 49, no. 4 (April 1999): 366-86.

Mirsiiapov, I. I. Natsional'naia ideologiia $i$ natsional'nye vzaimootnosheniia $v$ Respublike Tatarstan. Moscow: Ves' mir, 2004.

Moukhariamov, Nail Midkhatovich. "The Tatarstan Model:A Situational Dynamic."

In Peter J. Stavrakis, et al., eds. Beyond the Monolith: The Emergence of Regionalism in Post-Soviet Russia. Washington, D.C.: Woodrow Wilson Center Press, 1997, 213-32.

Mukhametshin, Rafik. "Post-Soviet Tatarstan: Democratic Strains in the Ideological Evolution of the Tatar National Movement." In Yaacov Ro'i, ed., Democracy and Pluralism in Muslim Eurasia. London: Cass, 2004, 287-306.

Mukhariamov, N. M., and L. M. Mukhariamova. "Tatarstan v usloviiakh retsentralizatsii po-putinski.” In Kimitaka Matsuzato, ed., Fenomen Vladimira Putina i rossiiskie regiony: pobeda neozhidannaia ili zakonomernaia? Slaviano-evraziiskie issledovaniia 1. Moscow: Materik, 2004, 315-66.

Mustafin, M. R., and R. G. Khuzeev. Vse o Tatarstane (ekonomiko-geograficheskii spravochnik). 2d ed. Kazan': Tatarskoe Knizhnoe Izdatel'stvo, 1994.

Reference work (160 pp.) with sections on population and the economy and short profiles of the cities, towns, and rural districts (raiony) of the republic.

Noack, Christian. "Tatarstan — ein Modell für die föderale Erneuerung Rußlands?" Osteuropa 46, no. 2 (February 1996): 134-49. 
."Islam und Nationalismus an der Mittleren Wolga — das Beispiel Tatarstan." Osteuropa 48, no. 5 (May 1998): 485-99.

Osobaia zona: vybory $v$ Tatarstane. Ed. V. V. Mikhailov et al. Ul'ianovsk: Srednevolzhskii nauchnyi tsentr, 2000.

A collection of articles by journalists, deputies, and scholars on the electoral process in contemporary Tatarstan, with special emphasis upon its manipulation by the authorities.

Regiony Rossii: khronika i rukovoditeli. Vol. 7. Respublika Tatarstan, Udmurtskaia respublika, Respublika Mordoviia. Ed. K. Matsuzato. Occasional Papers on the Elite of the Mid-Volga Ethnic Republics 3. Sapporo: Slavic Research Center, Hokkaido University, 2000, 15-150.

"Respublika na Volge i Kame-Tatarstan." MZh, no. 1, 1995, 5-109.

"Respublika Tatarstan." Rossiiskaia Federatsiia segodnia, 2001, 3-97, special issue.

Rorlich, Azode-Ayse. "History, Collective Memory, and Identity: The Tatars of Sovereign Tatarstan." CPCS 32, no. 4 (December 1999): 379-96.

Sagitova, L. V. Etnichnost'v sovremennom Tatarstane: vosproizvodstvo etnichnosti $v$ tatarstanskom obshchestve na rubezhe 1980-1990-kh gg.: po materialam respublikanskoi pressy i etnosotsiologicheskikh issledovanii. Kazan': Tatpoligraf, 1998.

Saifutdinov, M. "Vybory Prezidenta v Tatarstane: imidzh kandidatov v presse." Vlast', no. 1, 2002, 31-37.

Sharafutdinova, Gulnaz. "Paradiplomacy in the Russian Regions: Tatarstan's Search for Statehood." EAS 55, no. 4 (June 2003): 613-29.

Shatrova, L. A. "Gendernye stereotypy na rynke truda Tatarstana." SI, no. 3, 2003, 124-26.

Slocum, John W. "A Sovereign State Within Russia? The External Relations of the Republic of Tatarstan." Global Society 13, no. 1 (January 1999): 49-75.

"Sotsiologicheskii potentsial Tatarstana." SI, no. 11, 1998, 3-133.

A symposium of sociological articles.

Sultanov, F. M. Islam i tatarskoe natsional'noe dvizhenie v rossiiskom i mirovom musulmanskom kontekste: istoriia i sovremennost'. Kazan': Shkola, 1999.

Suverennyi Tatarstan. Sovereign Tatarstan. Moscow: INSAN, 1997.

An official publication incorporating the texts of selected items of legislation, some in English translation.

Tagirov, E. R. Tatarstan: natsional'no-gosudarstvennye interesy (politicheskoe esse). Kazan': Izdatel'stvo Kazanskogo finansovo-ekonomicheskogo instituta, 1996. 
Tagirov, I. R. Istoriia natsional'noi gosudarstvennosti tatarskogo naroda $i$ Tatarstana. Kazan': Tatarskoe knizhnoe izdatel'stvo, 2000.

"Twelve Agreements Between Tatarstan and the Russian Federation." Journal of South Asian and Middle Eastern Studies 18, no. 1 (1994): 68-95.

Valeev, V. T. Sibirskie Tatary. Kazan': Kazanskoe knizhnoe izdatel'stvo, 1993.

Walker, Edward W. "The Dog That Didn't Bark: Tatarstan and Asymmetrical Federalism in Russia." Harriman Review 9, no. 4 (Winter 1996): 1-35.

Zaikina, G. A., and E. V. Foteeva. "Mezhnatsional'nyi brak v massovom soznanii." Vestnik Rossiiskoi Akademii nauk 66, no. 4 (April 1996): 296-304.

Zakiev, M. Z., ed. Iazykovaia politika v Respublike Tatarstan, 80-90-e gody: dokumenty i materialy. Kazan': Magarif, 1999.

Zhodzkaeva, E. A., and E. A. Shumilova. "Vozrozhdenie religii i etnicheskaia identichnost' tatarskoi molodezhi v Respublike Tatarstan.” SI, no. 3, 2003, 106-08.

\section{Tiumenskaia oblast'}

Alekseeva, T. A., et al. "Problemy territorial'noi reformy v Rossii (na primere vzaimootnoshenii Tiumenskoi oblasti s Khanty-Mansiiskim i IamaloNenetskim avtonomnymi okrugami)." Politiia, no. 2 (33), Summer 2004, 78-105.

Glatter, Pete. "Continuity and Change in the Tyumen' Regional Elite, 1991-2001." EAS 55, no. 3 (May 2003): 401-35.

Golenkova, Z. T., et al. “Dinamika sotsial'no-strukturnykh protsessov v Tiumen'skoi oblasti." Monitoring obshchestvennogo mneniia, no. 3, July-September 2005, $101-11$.

Gubin, A. V. "Sostoianie zdorov'ia naseleniia Tiumenskoi oblasti.” SI, no. 5, 1999, 93-95.

Kolchin, S. V. "Problemy i perspektivy razvitiia ekonomiki Tiumenskoi oblasti." $M E M O$, no. 6, 1995, 102-13.

Osherenko, Gail. "Indigenous Political and Property Rights and Economic/ Environmental Reform in Northwest Siberia.” PSG 36, no. 4 (April 1995): 225-37.

—. "Property Rights and Transformation in Russia: Institutional Change in the Far North." EAS 47, no. 7 (November 1995): 1077-108.

Permiakova, O. A. "Tiumen' v situatsii vyborov." SI, no. 10, 2000, 43-47.

. "Tiumenskaia oblast': vremia vybora ili vremya vyborov." Vlast', no. 4, 2001, 46-53. 
Sedova, N. N. "Sotsial'nye problemy razvitiia Tiumenskoi oblasti." Monitoring obshchestvennogo mneniia, no. 1 (73), January-March 2005, 111-25.

Sosin, Iu. "Tiumenskii krai-obshchii dom: polemicheskie zametki." SM, no. 11, 1996, 95-104.

“Tiumenskaia oblast'." Zhizn' natsional'nostei, no. 6, 1995, 3-94.

Zabolotnaia, G. M. "Regional'nyi elektorat partii mezhdu vyborami.” SI, no. 9, 2003, 73-78.

\section{Tomskaia oblast'}

Tarusina, Inessa. "Elite Transformation and Regime Change: The Case of Tomsk Oblast." In Anton Steen and Vladimir Gel'man, eds., Elites and Democratic Development in Russia. London: Routledge, 2003, 168-86.

\section{Tul'skaya oblast'}

Regiony Rossii: khronika i rukovoditeli. Vol. 5. Riazanskaia, Vladimirskaia, $i$ Tul'skaia oblasti. Ed. K. Matsuzato and A. B. Shatilov. Occasional Papers on Changes in the Slavic-Eurasian World 63. Sapporo: Slavic Research Center, Hokkaido University, 1998, 219-75.

\section{Tverskaia oblast'}

Matsuzato, Kimitaka. "The Split and Reconfiguration of Ex-Communist Party Factions in the Russian Oblasts: Chelyabinsk, Samara, Ulyanovsk, Tambov, and Tver (1991-95)." Dem 5, no. 1 (Winter 1997): 53-88.

Ovchinnikov, B. V. "Tverskaia oblast'," In V. Gel'man, et al., eds., Organy gosudarstvennoi vlasti sub"ektov Rossiiskoi Federatsii. Moscow: IGPI, 1998, 103-15.

Pavlov, Iu. A., and Iu. Ia. Mikhailov. "Problemy adaptatsii byvshikh voennosluzhashchikh v Tverskom regione.” SI, no. 10, 2001, 85-87.

\section{R. Tyva}

Anaiban, Z. B. Mezhnatsional'nye otnosheniia v Tuve v90-e gody. Moscow: Institut etnografii i antropologii RAN, 1999.

- Zhenshchiny Tuvy i Khakasii v period rossiiskikh reform. Moscow: Institut vostokovedeniia, 2005.

Anaiban, Z. V., M. N. Guboglo, and M. S. Kozlov. Formirovanie etnopoliticheskoi situatsii. Moscow: Tsentr po izucheniiu mezhnatsional'nykh otnoshenii IEA 
RAN, 1999.

Balakina, G. F. "Sovremennaia Tuva: sotsiokul'turnyi aspekt razvitiia.” SI, no. 10, 1994, 159-61.

_. "Tuvinskie realii perekhoda k rynku." SI, no. 6, 1998, 77-81.

Dargyn-Ool, Chimiza. "Problemy i perspektivy modernizatsii v Tuve." $S M$, no. 12, 2005, 48-63.

Moskalenko, N. P. Etnopoliticheskaia istoriia Tuvy v XX veke. Moscow: Nauka, 2004.

Penter, Tanja. "Die Republik Tywa (Tuwa): Nationale und Kulturelle Wiedergeburt einer ehemaligen Sowjetkolonie." Osteuropa 47, no. 7 (July 1997): 666-83.

Sedova, N. N. "Sotsial'nye problemy Tyvinskoi oblasti." Monitoring obshchestvennogo mneniia, no. 1, January-March 2005, 111-25.

“Tuva: respublika v samom tsentre Azii." Zhizn'natsional'nostei, no. 1, 1995, 928.

\section{Udmurtskaia Respublika}

Egorov, I. V. "Udmurtskaia Respublika." In V. Gel'man, et al., eds., Organy gosudarstvennoi vlasti sub" ektov Rossiiskoi Federatsii. Moscow: IGPI, 1998, 79-82.

Guboglo,M.N., and S.K. Smirnova.FenomenUdmurtii:paradoksyetnopoliticheskoi transformatsii na iskhode XX veka. Moscow: TsIMO RAN, 2001.

Kandinskaia, S. V. "Udmurty ob etnicheskoi identichnosti (opyt pilotazhnogo issledovaniia)." SI, no. 5, 2005, 100-05.

Kokorin, M. "Prioritet men'shinstva." $R F$, no. 14, 1997, 57-59.

Kulikov, K. I. Udmurtiia-sub"ekt Rossii: problemy ekonomiki, politiki, natsional'nykh otnoshenii, 1990-e gody. Izhevsk: Udmurtskii institut istorii, iazyka i literatury UrO RAN, 1999.

Regiony Rossii: khronika i rukovoditeli. Vol. 7. Respublika Tatarstan, Udmurtskaia respublika, Respublika Mordoviia. Ed. K. Matsuzato. Occasional Papers on the Elite of the Mid-Volga Ethnic Republics 3.) Sapporo: Slavic Research Center, Hokkaido University, 2000, 267-468.

Shkliaev, G. K. Mezhetnicheskie otnosheniia v Udmurtii: opyt istorikopsikhologicheskogo analiza. Izhevsk: Rossiiskaia akademiia nauk, Uralskoe otdelenie, Udmurtskii institut istorii, iazyka i literatury, 1998.

“Udmurtiia: region krupnym planom." $R F$, no. 9, 1996, 25-40. 


\section{Ul'ianovskaia oblast'}

Bikmetov, R. M. “Izbiratel'nyi protsess, vlast' i oppozitsiia v Ul'ianovskoi oblasti." Polis, no. 3, 1999, 119-30.

Evers, Frank. "Reformen und Soziales in der rußländischen Provinz am Beispiel von Uljanowsk." Osteuropa 44, no. 3 (March 1994): 256-66.

Hutcheson, Derek S. "Campaigning in the Russian Regions: The Case of Ul'yanovsk." JCSTP 17, no. 2 (June 2001): 70-93.

Konitzer-Smirnov, Andrew. "Breaching the Soviet Social Contract: Post-Soviet Social Policy Development in Ulyanovsk and Samara Oblasts." In Judyth L. Twigg and Kate Schecter, eds., Social Capital and Social Cohesion in PostSoviet Russia. Armonk, N.Y.: Sharpe, 2003, 189-216

Magomedov, A. K., and M. M. Kirichenko. "Ot El'tsina k Putinu: kreml' i regional'naia Rossiia (na primere Ul'ianovskoi oblasti i Krasnodarskogo kraia).” In Kimitaka Matsuzato, ed., Fenomen Vladimira Putina i rossiiskie regiony: pobeda neozhidannaia ili zakonomernaia? Slaviano-evraziiskie issledovaniia 1. Moscow: Materik, 2004, 267-311.

Matsuzato, Kimitaka. "The Split and Reconfiguration of Ex-Communist Party Factions in the Russian Oblasts: Chelyabinsk, Samara, Ulyanovsk, Tambov, and Tver (1991-95).” Dem 5, no. 1 (Winter 1997): 53-88.

Omel'chenko, Elena, and Hilary Pilkington. "Stabilization or Stagnation? A Regional Perspective." In Peter Lentini, ed., Elections and Political Order in Russia. Budapest: Central European University Press, 1995, 143-66.

Regiony Rossii: khronika i rukovoditeli. Vol. 6. Nizhegorodskaia oblast', Ul'ianovskaia oblast'. Ed. K. Matsuzato and A. B. Shatilov. Occasional Papers on Regional/Subregional Politics in Post-Communist Countries 1. Sapporo: Slavic Research Center, Hokkaido University, 1999, 165-291.

“Ul'ianovskaia oblast'." $R F$, no. 9, 1997, 25-40.

\section{Ural}

Kirillov, A. D. Ural: ot El'tsina do El tsina: khronika politicheskogo razvitiia, 1990-1997 gg. Ekaterinburg: Izdatel'stvo Ural'skogo universiteta, 1997.

Kirillov, A. D., N. N. Popov, and B. A. Kirillov. Zakonodateli Urala: predstaviteli naroda i gosudarstva. Ekaterinburg: Ural'skii rabochii, 2000.

Luchterhandt, Galina. Parteien in der russischen Provinz: Politische Entwicklung in den Gebieten des Ural under der Wolgaregion. Bremen: Edition Temmen, 1998. 
Patsula, A. Sotsiologiia politicheskogo marafona: dinamika deiatel'nosti politicheskikh partii i obshchestvennykh ob"edinenii regiona $v$ predvybornyi period 1997-1999 godov. Cheliabinsk: Okolitsa, 1999.

__ Ekologicheskaia politika v Ural'skom regione: sotsial'no-psikhologicheskii klimat na territoriiakh Ural'skogo regiona, podvergshikhsia radiatsionnomu vozdeistviiu. Cheliabinsk: Izdatel'stvo Tat'iany Lur'e, 2004.

Tatarkin, A. "Sotsial'no-ekonomicheskie vozmozhnosti razvitiia reform v Ural'skom regione," VE, no. 2, 1995, 123-28.

_. Uralskii region: posledstviia ekonomicheskogo reformirovaniia. Ekaterinburg: Uro RAN, 1996.

_. Ural na rubezhe vekov: problemy i prognozy sotsial'no-ekonomicheskogo razvitiia. Moscow: Ekonomika, 1999.

\section{Vladimirskaia oblast'}

Regiony Rossii: khronika i rukovoditeli. Vol. 5. Riazanskaia, Vladimirskaia, $i$ Tul'skaia oblasti. Ed. K. Matsuzato and A. B. Shatilov. Occasional Papers on Changes in the Slavic-Eurasian World 63. Sapporo: Slavic Research Center, Hokkaido University, 1998, 123-218.

"Vladimirskaia zemlia: nadezhnyi region dlia delovogo sotrudnichestva." Vneshniaia torgovlia, no. 4, 2001, 2-52.

\section{Volga}

Barzilov, S. I., and S. Iu. Naumov. Rossiiskaia provintsiia kak politicheskii fenomen. Saratov: Povolzhskaia akademiia gosudarstvennoi sluzhby, 2004.

Ekonomicheskii potentsial regiona. Saransk: Krasnyi oktiabr', 2001.

Considers the economic potential of the Volga region, including questions of economic strategy and the performance of individual enterprises.

Lewis, D. C. "Ethnicity and Religion in Tatarstan and the Volga-Ural Region." Central Asian Survey 16, no. 2 (June 1997): 215-36.

Linik, L. N. 'Izbiratel'naia sistema respubliki v sostave Rossiiskoi Federatsii (na primere respublik Povolzhskogo regiona).” Pravovedenie, no. 1, 2003, 3949.

Luchterhandt, Galina. Parteien in der russischen Provinz: Politische Entwicklung in den Gebieten des Ural under der Wolgaregion. Bremen: Edition Temmen, 1998.

Magomedov, A. G. Misteriia regionalizma. Regional'nye praviashchie elity i regional'nye ideologii $\mathrm{v}$ sovremennoi Rossii: modeli politicheskogo 
vossozdaniia “snizu” (sratnitel'nyi analiz na primere respublik i oblastei Povol'zhia). Moscow: MONF, 2000.

Mkrtchian, N. V. "Migratsiia i region (na primere Privolzhskogo federal'nogo okruga)." Mir Rossii, no. 2, 2004, 24-42.

"Povolzhskii ekonomicheskii raion." Federalizm, no. 3, 1997, 161-86.

\section{Volgogradskaia oblast'}

“Bednyi kormilets Federatsii: Volgogradskaia oblast'.” Rossiia, no. 6, 1997, 4458.

Ekonomicheskaya entsiklopediia regionov Rossii: Volgogradskaia oblast'. Moscow: Ekonomika, 2005.

Gel'man, V. Ia. "Demokratizatsiia, strukturnyi pliuralizm i neustoichivyi bitsentrizm: Volgogradskaia oblast'." Polis, no. 2, 2000, 111-32.

Krüger, Sandra, Hans-Henning Schröder, and Heinz Timmermann. "Wie in Wolgograd gewählt wurde." Osteuropa 46, no. 5 (May 1996): 493-506.

Moses, Joel C. "Saratov and Volgograd, 1990-1992: A Tale of Two Russian Provinces." In Theodore H. Friedgut and Jeffrey W. Hahn, eds. Local Power and Post-Soviet Politics. Armonk, N.Y.: M. E. Sharpe, 1994, 96-137.

. "Political-Economic Elites and Russian Regional Elections, 1999-2000:

Democratic Tendencies in Kaliningrad, Perm, and Volgograd." EAS 54, no. 6 (September 2002): 905-31.

Petersson, Bö. "A Tale of Four Cities: Studying National Self-Images among Russian Regional Politicians in Perm, St. Petersburg, Volgograd, and Khabarovsk." SPSR 23, no. 3 (1996): 251-84.

Schauff, Frank. "Ungeahnte Dynamik der Regionen: wahlbeobachtung in Wolgograd." Osteuropa 46, no. 11 (November 1996): 1117-23.

\section{Vologodskaia oblast’}

Butenschön, Marianna, and Timm Beichelt. "“Frei gewählt, aber unfair gekämpft':

Wahlbeobachtung in Wologda.” Osteuropa 46, no. 5 (May 1996): 483-86.

Efremov, K. E., and N. N. Ovcharuk. "Reiting Vologodskoi oblasti v SeveroZapadnom federal'nom ukruge." Voprosy statistiki, no. 5, 2003, 51-63.

\section{Voronezhskaia oblast'}

Ryzhenkov, S., and G. Liukhterkhandt-Mikhaleva, eds. Politika i kul 'tura v rossiiskoi provintsii: Novgorodskaia, Voronezhskaia, Saratovskaia, Sverdlovskaia 
oblasti. Moscow: Letnii sad, 2001.

Turovskii, R. F. "Voronezhskaia oblast': ekonomika, partii, lidery." Vlast', no. 11, 1995, 62-68.

Wollmann, Hellmut. "Wahlbeobachtung in Woronesh.” Osteuropa 46, no. 5 (May 1996): 487-92.

\section{Western Siberia}

Golosov, Grigorii. "New Russian Political Parties and the Transition to Democracy: The Case of Western Siberia." Government and Opposition 30, no. 1 (Winter 1995): 110-19.

. "Russian Political Parties and the 'Bosses': Evidence from the 1994 Provincial Elections in Western Siberia." Party Politics 3, no. 1 (January 1997): 5-21.

Osipov, O. V. and V. I. Kozodoi. Politicheskii spektr: formirovanie mnogopartiinosti v Zapadnoi Sibiri (1986-1996 gg.). Novosibirsk: Sibir'-Forum, 2003.

\section{Periodicals}

$N G$-Regiony. Monthly supplement to the newspaper Nezavisimaia gazeta since October 1997.

Rossiia - tsentr i regiony. Moscow, irregular, since 1997.

Issued by the Institute of Socio-Political Research of the Russian Academy of Sciences; vol. 15 appeared in 2005.

Rossiiskaia Federatsiia. Moscow, monthly.

Many relevant contributions, but intended for a general readership; only a selection has been included in this bibliography.

Russian Regional Report, Institute for EastWest Studies, 700 Broadway, New York, NY 10003, USA. Regions@,iews.org; http://www.iews.org/rrrabout. nsf/pages/rrr+page.

Available in email and printed versions, $R R R$ provides a steady stream of information and analysis from and on the regions.

\section{Reference}

Bradshaw, M. J., and J. A. Palacin. An Atlas of the Economic Performance of Russia's Regions. Russian Regional Research Group Working Paper Series, no. 2. University of Birmingham: School of Geography and Environmental 
Sciences and Centre for Russian and East European Studies, 1996.

Ekonomicheskoe polozhenie regionov Rossiiskoi Federatsii. Moscow: Goskomstat Rossii, 1994.

Provides region-level official data for 1980, 1985, 1990, and 1993.

Orttung, Robert W., ed. The Republics and Regions of the Russian Federation: A Guide to Politics, Policies, and Leaders. Armonk, N.Y.: M. E. Sharpe, 2000. Includes basic political, economic, and demographic data and covers government structure and electoral history up to the federal reorganization of summer 2000. Each entry includes a biographical sketch of the local president, governor, or prime minister, and an overview of local political trends and business conditions.

Osnovnye pokazateli sotsial'no-ekonomicheskogo polozheniia federal'nykh okrugov.

A statistical serial dealing with the federal districts, published by the State Statistical Committee.

Petrov, Nikolai, ed. Regiony Rossii v . . . godu: ezhegodnoe prilozhenie $k$ "Politicheskomu al'manakhu Rossii." Moscow: Gendal'f, since 1999.

A volume for 1998 appeared in 1999, and for 1999 in 2001.

Politicheskii al'manakh Rossii 1995. Ed. M. Makfol [McFaul] and N. Petrov. Moscow: Moskovskii tsentr Karnegi, 1995.

Politicheskii al'manakh Rossii 1997. 3 vols. Ed. M. Makfol [McFaul] and N. Petrov. Moscow: Moskovskii tsentr Karnegi and Washington, D.C.: Carnegie Endowment for International Peace, 1998. Also available on CD-ROM.

Continued by an annual supplement: see Petrov, Regiony Rossii, above.

Regiony Rossii: informatsionno-statisticheskii sbornik. Moscow: Goskomstat Rossii, 1997-.

Official statistical source, covering regions individually and by social and economic characteristics. Most series begin in 1985. Annual; also available on CD-ROM. Fullest available source of official data by subject of the federation. From 2002, published in two parallel volumes: Regiony Rossii: osnovnye kharakteristiki sub"ektov Rossiiskoi Federatsii, and Regiony Rossii: sotsial'no-politicheskie pokazateli. From 2004, published as three parallel volumes: Regiony Rossii: osnovnye kharakteristiki sub" ektov Rossiiskoi Federatsii (an overview volume), Regiony Rossii: sotsial'no-ekonomicheskie pokazateli (region by region coverage), and Regiony Rossii: sotsial'no-ekonomicheskie kharaketeristiki gorodov (similar coverage of urban areas).

Regiony Rossi v 2000-2001 gg. Tsifrovaia versiia kul'turnoi deiatel'nosti. Ed. A. A. Ushkarev. St. Petersburg: Aleteia, 2005.

Ronin, Vladimir. Regiony Rossii. Antwerp: Benerus, 1996.

Encyclopedic in character; the descriptive material is arranged by "large regions." 
Rossiiskie regiony nakanune vyborov-95. Ed. M. N. Afanas'ev et al. Moscow: Iuridicheskaia literatura, 1995.

For each federal subject this reference book contains (too often incorrect) statistics on territory, population, economy, electorate, election results 1991-1993, the names of representatives in the Federation Council and Duma and of regional leaders just before the December 1995 elections.

Rossiiskie regiony posle vyborov-96. Ed. G. V. Bylov et al. Moscow: Iuridicheskaia literatura, 1997.

Similar in scope to the previous title, but recording the position subsequent to the 1996 presidential election; both were produced under the auspices of the presidential administration.

Sravnitel'nye pokazateli ekonomicheskogo polozheniia regionov Rossiiskoi Federatsii. Moscow: Goskomstat Rossii, 1995.

Includes official region-level data for 1980, 1985, 1990, and 1994.

The Territories of the Russian Federation. 4th ed. London: Europa Publications, 2006.

Includes an economic overview by Philip Hanson and Michael J. Bradshaw, a chronology, and a statistical section, followed by entries for each of the subjects of the federation covering history, economic conditions, and a directory of local officials. The first edition appeared in 1999, a second edition in 2001, and a third in 2003.

Vybory glav ispolnitel'noi vlasti sub"ektov Rossiiskoi Federatsii, 1995-1997: elektoral'naia statistika. Moscow: Ves' mir, 1997.

Published by the Central Electoral Commission. Detailed coverage of elections to regional executives, with some comparative analysis.

Vybory $v$ zakonodatel'nye (predstavitel'nye) organy gosudarstvennoi vlasti sub"ektov Rossiiskoi Federatsii, 1995-1997. Moscow: Ves' mir, 1998.

Published by the Central Electoral Commission. Detailed coverage of elections to regional legislatures, with some comparative analysis.

Vybory v organy gosudarstvennoi vlasti sub"ektov Rossiiskoi Federatsii, 19972000. elektoral'naia statistika. 2 vols. Moscow: Ves' mir, 2001.

Published by the Central Electoral Commission; updates regional election results.

\section{Internet Sites}

The quality and availability of internet sites that deal with the Russian regions has been constantly changing, although some consolidation has taken place. Among these, www.regions.ru has developed into the most professional and comprehensive site, in cyrillic with a parallel site in transliterated Russian. The regions themselves 
maintain important websites, typically in the form www.nameoftheregion.ru. A very long list of Russian regional and local sites may be found at http://weblist. $\mathrm{ru} /$ english/Regional/Russia/.

On current developments, the Russian Political Weekly of Radio Free Europe/ Radio Liberty at www.rferl.org contains regular news items on and from the regions. See also the Russian Regional Report at www.isn.ethz.ch/pubs/ph/details. cfm?id=13831, issued since 1999. A Universal Database of Regional Russian Newspapers, maintained by EastView, incorporates more than eighty titles.

It may often be most sensible to approach regional internet sites through a portal maintained by a large research-oriented institution. See for instance the comprehensive listing at SOSIG's Eurostudies: Russian Federation page: http:// sosig.ac.uk/roads/subject-listing/EuroStudies-cat/ru/alphalist.html. Others include Hokkaido University's Slavic Research Center at: src-h.slav.hokudai.ac.jp/indexe.html; the Russian studies guide maintained by the Norwegian Institute of International Affairs, Oslo, at: www.nupi.no/English/Research/Russian_studies/; the "world wide web virtual library for Russian and East European studies" maintained at the University of Pittsburgh at: www.ucis.pitt.edu/reesweb/; the Guide to Slavonic Internet Resources maintained by the British Library, London, at: www.bl.uk/collections/easteuropean/slavonicinternet.html; the Directory of Internet Resources on Central and Eastern Europe and Russia maintained by the School of Slavonic and East European Studies, London, at: www.ssees.ac.uk/ dirctory.htm; and Portals to the World: Russia, which is a subject guide to internet resources maintained by the Library of Congress in Washington, D.C., at: www. loc.gov/rr/international/european/russia/ru.html. A guide to Russian regional internet internet sites is available at www.slavophilia.com/pages/Country_Focus/ Russia/Regional/, and a Russian Regional Database is maintained at the Centre for the Study of Public Policy, University of Aberdeen, Scotland, at: www.abdn. ac.uk/cspp/catalog11_0.shtml. 
Center for Russian \& East European Studies

University Center for International Studies

University of Pittsburgh

4400 W. W. Posvar Hall

320 S. Bouquet Street

Pittsburgh, Pennsylvania 15260

(412) 648-8716

www.ucis.pitt.edu/crees/cbpaper.html.

Ronald Linden, Bob Donnorummo, William Chase, Co-Editors Eileen O’Malley, Managing Editor

Vera Dorosh, Editorial Assistant 